\title{
Seabuckthorn Berries as a Novel Source of Prebiotic in Yogurt Model
}

\author{
by
}

Christina Khoury, B.Sc.

A thesis submitted to the Faculty of Graduate and Postdoctoral Affairs in partial fulfillment of the requirements for the degree of

Master of Science

in

Chemistry

(Specialization in Food Science and Nutrition)

Carleton University

Ottawa, Ontario

(C) 2012

Christina Khoury 
Library and Archives

Canada

Published Heritage

Branch

395 Wellington Street

Ottawa ON K1A ON4

Canada
Bibliothèque et

Archives Canada

Direction du

Patrimoine de l'édition

395 , rue Wellington

Ottawa ON K1A ON4

Canada
Your file Votre référence

ISBN: 978-0-494-94314-4

Our file Notre référence

ISBN: 978-0-494-94314-4
NOTICE:

The author has granted a nonexclusive license allowing Library and Archives Canada to reproduce, publish, archive, preserve, conserve, communicate to the public by telecommunication or on the Internet, loan, distrbute and sell theses worldwide, for commercial or noncommercial purposes, in microform, paper, electronic and/or any other formats.

The author retains copyright ownership and moral rights in this thesis. Neither the thesis nor substantial extracts from it may be printed or otherwise reproduced without the author's permission.
AVIS:

L'auteur a accordé une licence non exclusive permettant à la Bibliothèque et Archives Canada de reproduire, publier, archiver, sauvegarder, conserver, transmettre au public par télécommunication ou par l'Internet, prêter, distribuer et vendre des thèses partout dans le monde, à des fins commerciales ou autres, sur support microforme, papier, électronique et/ou autres formats.

L'auteur conserve la propriété du droit d'auteur et des droits moraux qui protege cette thèse. $\mathrm{Ni}$ la thèse ni des extraits substantiels de celle-ci ne doivent être imprimés ou autrement reproduits sans son autorisation.
In compliance with the Canadian Privacy Act some supporting forms may have been removed from this thesis.

While these forms may be included in the document page count, their removal does not represent any loss of content from the thesis.
Conformément à la loi canadienne sur la protection de la vie privée, quelques formulaires secondaires ont été enlevés de cette thèse.

Bien que ces formulaires aient inclus dans la pagination, il n'y aura aucun contenu manquant. 


\section{Acknowledgements}

First and foremost I'd like to thank my supervisor and mentor, Dr. Farah Hosseinian. I was a timid fourth year student when I walked into your office and you saw something in me that, at the time, I didn't know I had. Our talks about the future and research sparked me early on and inspired me to put my whole mind and heart, sweat, and blood into my work. The answer to your final question is: I got it done.

A special thank you to Dr. Bob Burk, Marilyn Stock, and Chantelle Gravelle for your guidance and assistance to obtain the prestigious Queen Elizabeth II award. Your open door policy to the graduate students was always appreciated.

I'd like to thank all the ladies and very few gentlemen in the Food Science and Nutrition lab for their great energy and camaraderie and a special thank you to the FSN leaders: Dr. Avis, Dr. Tsompo, and Dr. Bezaire for their teachings and guidance throughout my graduate studies.

To my extended family: Aynur, Rania, Julia, Ibrahim, Susanna, Mehri and Hannah for all the technical and non-technical support. I could not have asked for better team members.

A special recognition to my family for supporting me through my two undergrads and finally my Master's schooling. I wouldn't be where I am without you.

To my very patient husband, Raja Khoury, thank you for your endless support in my times of anxiety and moodiness. LHMK. 


\section{Thesis Abstract}

Functional foods are defined as foods that have demonstrated physiological benefits and can reduce the risk of chronic disease beyond basic nutritional functions, including maintenance of gut health (Cencic \& Chingwaru, 2010). Yogurt fortified with probiotics and fruit is considered a functional food, because it is believed to reduce the risk of chronic gut disease. Due to the demand, nationally and internationally, new combinations of fruits such as seabuckthorn and yogurt have the potential to be exploited in the food industry.

The first objective of this study was to determine if seabuckthorn (S) berries could serve as a prebiotic in yogurt, in addition to the antioxidant activity. After, 7 days of cold storage all seabuckthorn yogurt treatments showed significantly higher microbial counts compared to those of the control $(\mathrm{P} \leq 0.05)$ and following 21 days of cold storage, yogurt samples containing $2 \%$ seabuckthorn and probiotic Lactobacillus acidophilus had the highest microbial count $(\mathrm{P} \leq 0.05)$. Water-extractable crude materials $(\mathrm{CM})$ and waterextractable polysaccharides (WEP) of seabuckthorn exhibited strong antioxidant activity with an ORAC value of $138.95 \pm 0.99 \mu \mathrm{mol} \mathrm{TE} / 100 \mathrm{~g}$ and $29.22 \pm 3.08 \mu \mathrm{mol} \mathrm{TE} / 100 \mathrm{~g}$ respectively.

After determining total count of microorganisms the second objective was to determine the effects of seabuckthorn whole fruit (S) and water extractablepolysaccharide materials (SP) on different probiotic bacteria in yogurt using selective media. It was found that after 21 days of cold storage, $\mathrm{S}$ and SP both had higher viable bacteria counts of probiotics L. acidophilus and Bifidobacterium lactis, in comparison to 
the controls $(\mathrm{P} \leq 0.05)$. Results of this study suggest seabuckthorn may serve as a new prebiotic source for functional foods and nutraceutical applications.

The third objective was to determine if Electronic-nose (e-nose) has the potential as a novel tool for differentiating flavours of different yogurts. E-nose results indicated that flavoured yogurt could indeed be separated suggesting that the technique could be applied in areas of food industry for food monitoring, shelf life, and differentiation. The abstract for each chapter describes the thesis objectives in more detail. 


\section{Table of Contents}

Acknowledgements...................................................................................................................................ii

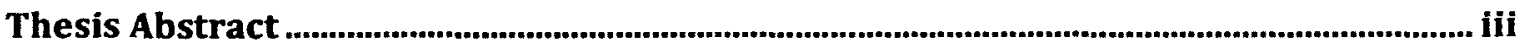

List of Figures ....................................................................................................................................... vii

List of Tables................................................................................................................................................... viii

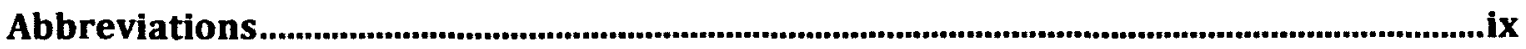

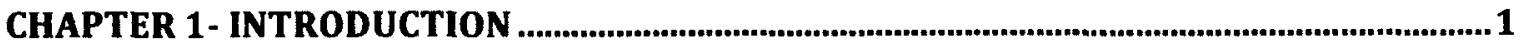

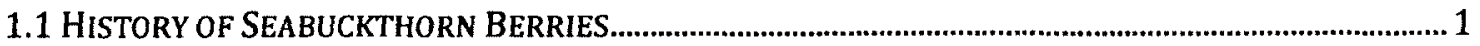

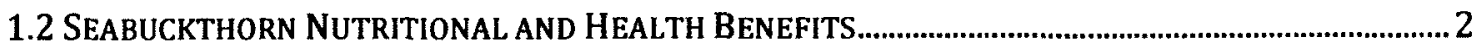

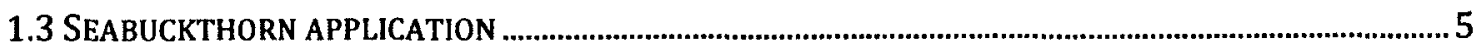

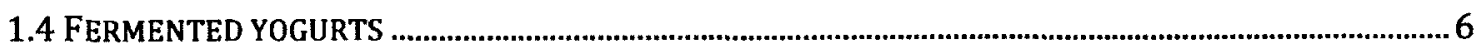

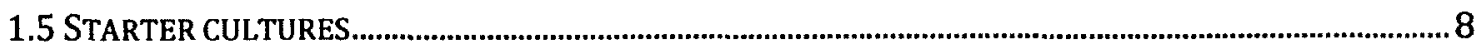

1.6 PROBIOTICS

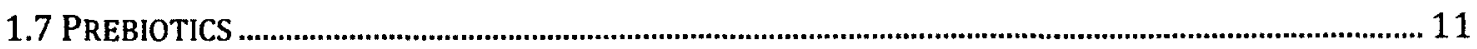

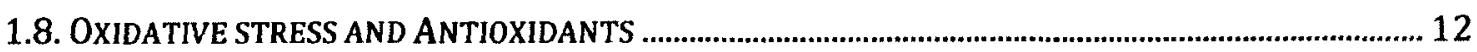

1.8.1 Oxygen radical absorbance capacity assay (ORAC) ............................................................... 14

1.8.2 Scavenging of 1,1-diphenyl-2-picrylhydrazyl (DPPH) ................................................... 14

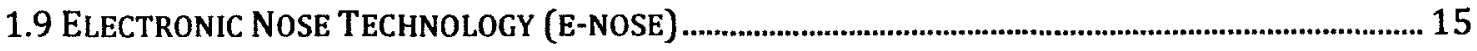

CHAPTER 2- SEABUCKTHORN IS A SUPER-BERRY WITH DUAL FUNCTIONALITY AS A

PREBIOTIC WITH ANTIOXIDANT ACTIVITY........................................................................... 16

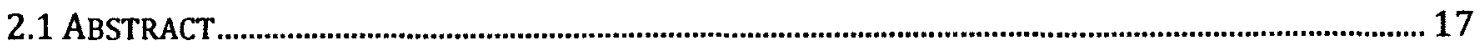

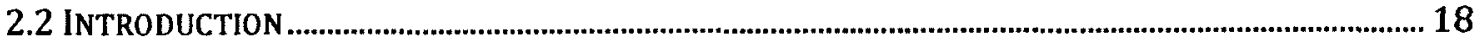

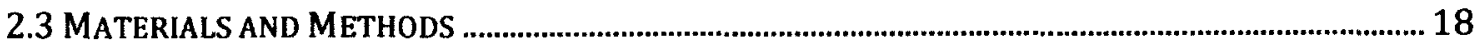

2.3.1 Seabuckthorn fruit preparation ............................................................................................... 18

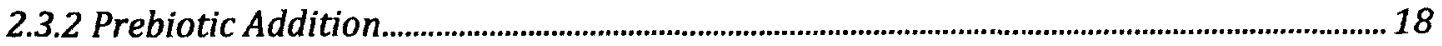

2.3.3 Microbial Analyses ............................................................................................................................. 19

2.3.4 Extraction of water extractable materials ...............................................................................21

2.3.5 Oxygen Radical Absorbance Capacity (ORAC) assay ...........................................................22

2.3.6 DPPH • scavenging activity assay .................................................................................................... 23

2.3.7 Statistical Analyses ...................................................................................................................................24

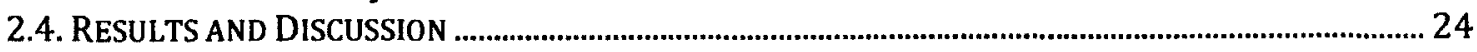

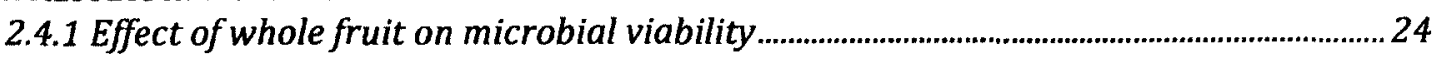

2.4.2 Effect of whole fruit on $\mathrm{pH}$ and Titratable Activity (TTA) ..................................................28

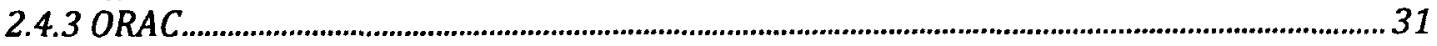

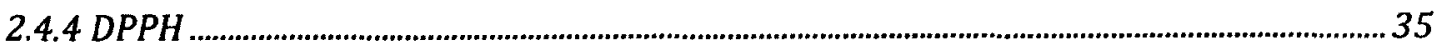

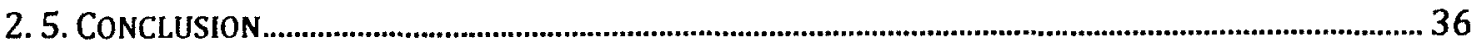

CHAPTER 3- POTENTIAL OF WATER EXTRACTABLE MATERIALS FROM
SEABUCKTHORN AS A PREBIOTIC IN YOGURT.......................................................... 38

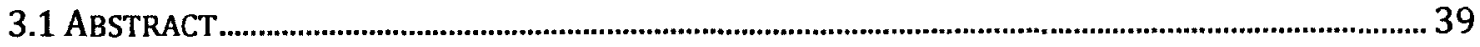

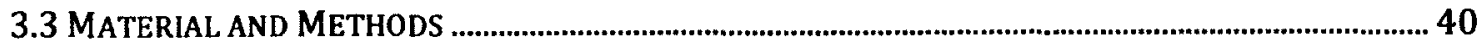

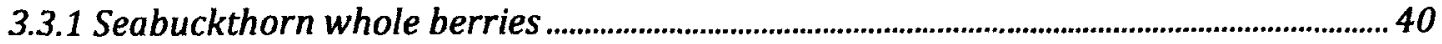

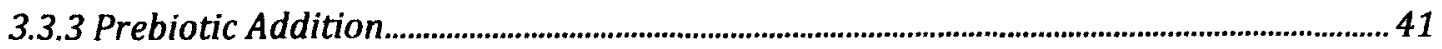

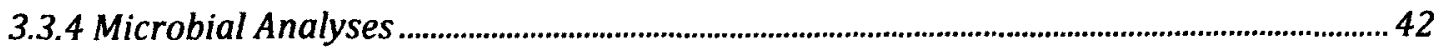

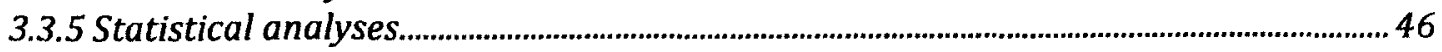

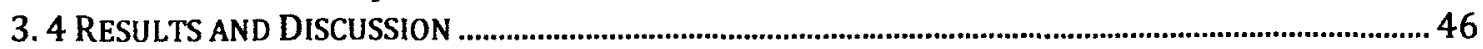

3.4.1 PH AND TTA 
3.4.2 Viable Microbial Enumeration........................................................................................................51

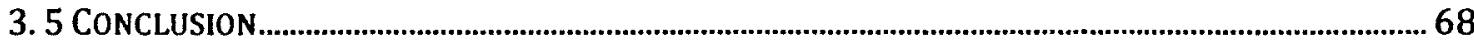

CHAPTER 4- E-NOSE AS A NOVEL TECHNIQUE TO "SNIFF-OUT" OUT LACTIC ACID

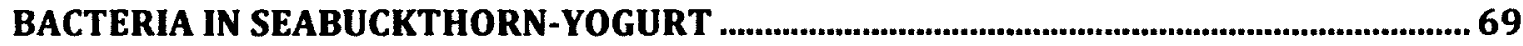

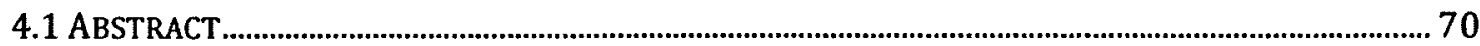

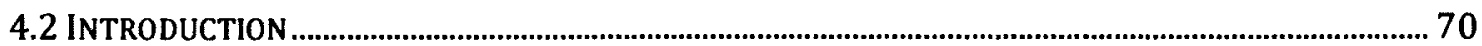

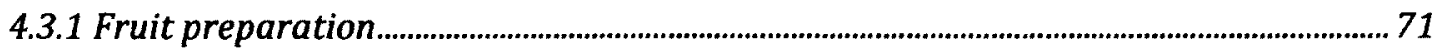

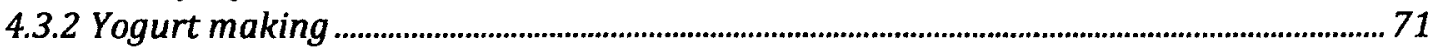

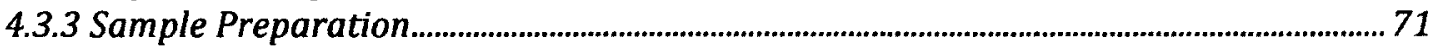

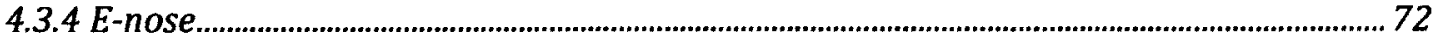

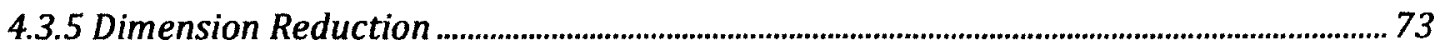

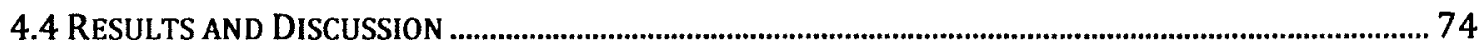

4.5 CONCLUSIONS

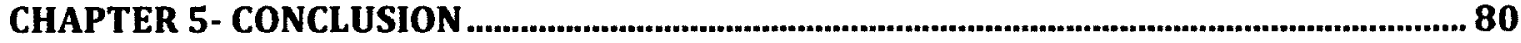

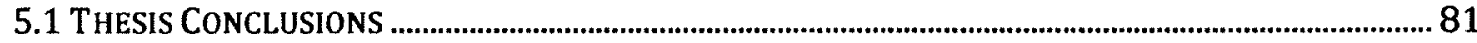




\section{List of Figures}

Figure 1- 1: Most abundant carotenoid found in seabuckthorn: $\beta$-carotene.................. 2

Figure 1- 2: Phenolic acid that is also found in seabuckthorn................................. 13

Figure 2- 1: Enumeration of viable lactic acid bacteria in yogurts without seabuckthorn (S) $(\mathrm{Y}, \mathrm{Y}+1, \mathrm{Y}+2$, and $\mathrm{Y}+1+2)$ and with $(\mathrm{YS}, \mathrm{YS}+1, \mathrm{YS}+2$, and $\mathrm{YS}+1+2)$ whole fruit within a day

Figure 2- 2: Standard curve of concentration $(\mu \mathrm{M})$ versus antioxidant activity $(\mu \mathrm{mol})$ for Trolox standard.

Figure 2- 3: Mean net area under the curve associated with various concentrations of crude water extractable (CM) materials from seabuckthorn.

Figure 2- 4: ORAC values of water-extractable crude materials (CM) and polysaccharide materials (WEP) of seabuckthorn with a $1: 1$ dilution

Figure 2- 5: DPPH free radical antioxidant scavenging activity of seabuckthorn waterextractable crude materials (CM) and water-extractable polysaccharides (WEP) ... 36

Figure 3- 1: Resultant yogurt products with varying concentrations of seabuckthorn polysaccharides.

Figure 3-2: $S$. thermophilus counts in yogurt with S, SP, and without seabuckthorn samples on day $1,7,14,21$, and 28 respectively

Figure 3- 3: Enumeration of $L$. bulgaricus in yogurt with seabuckthorn fruit (S), seabuckthorn polysaccharide (SP), and without extracts during shelf-life $(1,7,14$, 21 , and 28 respectively).

Figure 3- 4: A) Enumeration of L. acidophilus in yogurts with seabuckthorn fruit (S), seabuckthorn polysaccharide (SP), and without extract during shelf-life $(1,7,14,21$, and 28 respectively), B) enumeration of B. lactis in yogurts with S, SP, and without extract during shelf-life $(1,7,14,21$, and 28 respectively) 66

Figure 4- 1: Bar-graph representation of raw e-nose sensor responses for yogurt samples plain yogurt $(\mathrm{Y})$, seabuckthorn yogurt (SB), and raspberry yogurt (R).................76

Figure 4- 2: PCA representation of e-nose responses of samples that were grouped into $\mathrm{Y}, \mathrm{SB}$, and $\mathrm{R}$

Figure 4- 3: Discrimination index percentage (DI\%) representing the distance between two groups. 


\section{List of Tables}

Table 1- 1: Fatty acid content of seabuckthorn berry pulp and seed oil .......................... 4

Table 1- 2: Broad classification of fermented milks.................................................... 7

Table 2- 1: Experimental design evaluating seabuckthorn (S) fruit on probiotic viability

Table 2- 2: Total microbial counts using two-way ANOVA showing the effect of days on all yogurt treatments 28

Table 2- 3: $\mathrm{pH}$ during shelf life of yogurts without $(\mathrm{Y}, \mathrm{Y}+1, \mathrm{Y}+2$, and $\mathrm{Y}+1+2)$ and with $\mathrm{S}(\mathrm{YS}, \mathrm{YS}+1, \mathrm{YS}+2$, and $\mathrm{YS}+1+2)$ 30

Table 2- 4: Total titratable acidity (TTA) of yogurts without seabuckthorn (S) (Y, Y+1, $\mathrm{Y}+2$, and $\mathrm{Y}+1+2)$ and with $(\mathrm{YS}, \mathrm{YS}+1, \mathrm{YS}+2$, and $\mathrm{YS}+1+2)$ whole fruit

Table 3- 1: Experimental design evaluating the effect of seabuckthorn whole fruit (S) and seabucthorn polysaccharide (SP) additon on probiotic viability in yogurt.

Table 3- 2: $\mathrm{pH}$ values in yogurts without $(\mathrm{Y}, \mathrm{Y}+1, \mathrm{Y}+2$, and $\mathrm{Y}+1+2)$, with ( $\mathrm{YS}, \mathrm{YS}+1$, $Y S+2$, and $Y S+1+2)$ seabuckthorn whole fruit, and seabuckthorn polysaccharides (YSP, YSP+1, YSP+2, and YSP+1+2).

Table 3- 3: Total titratable acidity (TTA) in yogurts without $(\mathrm{Y}, \mathrm{Y}+1, \mathrm{Y}+2$, and $\mathrm{Y}+1+2)$, with (YS, YS+1, YS +2 , and $Y S+1+2$ ) seabuckthorn whole fruit, and seabuckthorn polysaccharides (YSP, YSP+1, YSP+2, and YSP+1+2) ......................................51

Table 3- 4: Two-way ANOVA analysis showing the effect of days on $S$. thermophilus counts in yogurt treatments.

Table 3- 5: Two-way ANOVA analysis showing the effect of days on L. bulgaricus counts in yogurt treatments.

Table 3- 6: Two-way ANOVA showing the effect of days on yogurt treatments containing $L$. acidophilus.

Table 3- 7: Two-way ANOVA showing the effect of days on yogurt treatments containing $B$. lactis.

Table 4- 1: Experimental design: plain yogurt $(\mathrm{Y})$, seabuckthorn (SB), and Raspberry (R)

Table 4- 2: FOX 3000 sensors in the electronic nose 75 


\section{Abbreviations}

AAPH- 2,2'-Azobis(2-amidinopropane) dihydrochloride

AUC-Area under the curve

CM- Water-extractable crude materials

DPPH- 2,2-diphenyl-1 - picrylhydrazyl

E-nose- Electronic nose

FOS- Fructo-oligosaccharides

GOS- Galacto-oligosaccharides

IBD- Inflammatory bowel disease

LDL- Lipoprotein

L. bulgaricus- Lactobacillus delbrueckii ssp. bulgaricus

MOS- Metal oxide sensors

NDO- Non-digestible oligosaccharides

ORAC- Oxygen radical absorbance capacity

ROS- Reactive oxygen species

S. thermophilus-Streptococcus salivarius ssp. thermophilus

S or SB-Seabuckthorn

SP-Seabuckthorn polysaccharides, which are also water-extractable polysaccharides (WEP)

Trolox-6-Hydroxy-2, 5, 7, 8-tetramethylchroman-2-carboxylic acid

TE- Trolox equivalent

VOC- Volatile organic compounds

WEP- Water-extractable polysaccharides 


\section{Chapter 1- Introduction}

\subsection{History of Seabuckthorn Berries}

Seabuckthorn (Hippophae rhamnoides L.) is a thorny, deciduous shrub that is native to European and Asian countries (Kumar, Kumar, Chaurasia, \& Singh, 2011). The plant is unisexual, where female and male plants differ in their characteristics (Kumar, et al., 2011). The meaning of Hippophae is shinning horse, which came from its traditional use as fodder for horses centuries ago (Kumar, et al., 2011). Seabuckthorn was used to feed horses so that they would gain weight rapidly and produce a shiny coat.

Originally, these plants grew in the harsh conditions of the Himalayan Mountains at high altitudes of $2500-4300 \mathrm{~m}$, but can now be found all over the world (Beveridge, $\mathrm{Li}$, Oomah, \& Smith, 1999; Negi, Chauhan, Sadia, Rohinishree, \& Ramteke, 2005).

Seabuckthorn has over a thousand-year history as a source for treating many ailments thus has been deemed a "wonder plant" in many Asian countries (Kumar, et al., 2011). Almost all parts of the berry were used to treat a variety of conditions for example in Middle Asia, the leaves are used to treat skin disorders and rheumatoid arthritis (Kumar, et al., 2011). The extracts from the leaves and branches of the plant were used medicinally for colitis and enterocolitis in Mongolia, while ancient Tibetan and Chinese medicinal literature document seabuckthorn use for fever, hepatic disease, inflammation, tumors, and metabolic disorders (Kumar, et al., 2011). In addition, oil from the seed and fruit have been used in Russia to treat eczema, psoriasis, burns, frostbite, and chronic dermatoses (Kumar, et al., 2011). 
The historic use of this ancient plant suggests that the berry and parts of the plant is a powerhouse of nutrients. However, more studies must be commenced to explore the plants application to treat human ailments.

\subsection{Seabuckthorn Nutritional and Health Benefits}

There are vast nutritional ingredients that exist within seabuckthorn indicating that the plant holds great potential as a functional food to benefit human health.

Seabuckthorn berries weigh anywhere from $270-480 \mathrm{mg}$ and typically contain approximately $73-85 \%$ moisture (Beveridge, et al., 1999). All parts of the plant are considered to be sources of a number of bioactive substances (Upadhyay, Kumar, \& Gupta, 2010). The fruit is rich in carbohydrates, proteins, organic acids, amino acids, and vitamins (Kumar, et al., 2011; Zeb, 2004b). The bioactives in the fruit include, vitamin C, vitamin E, flavonoids, and carotenoids (Figure 1-1), while the seed and pulp oils contain fat-soluble vitamins, plant sterols, and essential fatty acids (Uruakpa \& Utioh, 2012).

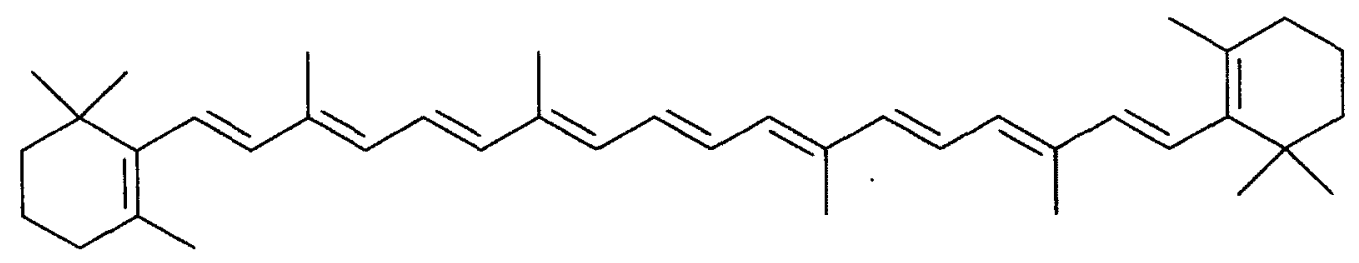

Structure of $\beta$-Carotene

Figure 1- 1: Most abundant carotenoid found in seabuckthorn: $\beta$-carotene (Sies \& Stahl, 1995).

Fatty acid content differs between the seed oil and the flesh parts of the fruit (Table 11). For instance, the seed oil is composed of linoleic, $\alpha$ - linoleic, oleic, palmitic, stearic, and vaccinic acids (Kumar, et al., 2011). However, oil in the flesh parts of the fruit contains high levels of palmitoleic $(\Omega 7)$, palimitic, and oleic acid. A trade mark 
characteristic that this plant possesses is that it is the only seed oil of a fruit that naturally contains a 1:1 ratio of linolenic $(\Omega 3)$ to linoleic acid $(\Omega 6)($ Kumar, et al., 2011). This characteristic is important, because essential fatty acids function to transport fat-soluble vitamins such as Vitamin A, D, E, and $\mathrm{K}$. Omega-3 has been associated with positive effects on neurological disorders, bone health, and is an important part of a balanced diet (Kumar, et al., 2011).

Tocopherols and tocotrienols are also abundant in the fruit $(203 \mathrm{mg} / 100 \mathrm{~g}$ fruit wt.) and are known as Vitamin E (Kumar, et al., 2011; Uruakpa, et al., 2012). In particular $\alpha$ tocopherol is the most abundant, in the fruit, accounting for 76 to $89 \%$ of the berry and possesses the highest antioxidant activity (Kumar, et al., 2011). The antioxidant capability of vitamin $\mathrm{E}$ makes seabuckthorn useful as a nutraceutical to eliminate free radicals in the human body (Kumar, et al., 2011; Negi, et al., 2005).

Seabuckthorn is also rich in vitamin C ( $360 \mathrm{mg} / 100 \mathrm{~g}$ fruit wt.), which is among the highest in the plant kingdom and has been documented as higher than strawberry, raspberry, and blackberry (Uruakpa, et al., 2012). Carotenoids are also free radical scavengers and $\beta$-carotene is a vitamin A precursor, which is the type of carotenoid found in the pulp oil (249 $\mathrm{mg} / 100 \mathrm{~g}$ ) (Uruakpa, et al., 2012). Studies have shown that individuals with high $\beta$-carotene intake may significantly reduce their risks of lung cancer (Kumar, et al., 2011). 
Table 1- 1: Fatty acid content of seabuckthorn berry pulp and seed oil (Uruakpa, et al., 2012); ND= No data

\begin{tabular}{ccc}
\hline Fatty acids & Seed oil & Pulp oil \\
\hline Linoleic & $34 \% ; 18: 2 n-6$ & ND \\
$\alpha$-Linoleic & $25 \% ; 18: 3 n-3$ & ND \\
Oleic & $19 \% ; 18: 1 n-9$ & $26 \% ; 18: 1 n-9$ \\
Palmitic & ND & $33 \% ; 16: 0$ \\
Palmitoleic & ND & $25 \% ; 16: 1 n-7$ \\
\hline
\end{tabular}

The leaves of seabuckthorn have received food industry attention, because of its reported antitumor, antiviral, and antioxidant properties due to the rich polyphenolic compounds (Uruakpa, et al., 2012). Hydrolysable tannins, flavonols, flavones, proanthocyanidins, and various phenolic acids are responsible for the many biological properties and antioxidant activities of the plant. The prominent flavonoid compounds responsible for the antioxidant activities of the berries and leaves are quercetin, kaempherol, and isorhamnetin (Uruakpa, et al., 2012).

Total phenolic acid content of the berry pulp is approximately $1068 \mathrm{mg} / \mathrm{kg} ; 5741$ $\mathrm{mg} / \mathrm{kg}$ for the seed kernel; and $4988 \mathrm{mg} / \mathrm{kg}$ for leaves, making seabuckthorn a rich source of phenolics (Uruakpa, et al., 2012). Phenolic acids are responsible for health benefits associated with anticarcinogenic, antioxidant, and antitumor properties (Koca \& Karadeniz, 2009).

Seabuckthorn also contains 1 to $2 \%$ of sterols in the seed oil and 2 to $3 \%$ in the fruit oil and sitosterol is the most abundant found in the berry, however isofucosterol, campsterol, stigmastanol, citrostadienol, avenasterol, and cycloartenol can also be found (Kumar, et al., 2011). Sitosterol in particular is attributed to reducing low-density 
lipoprotein (LDL) cholesterol levels, which is also considered another health benefit of consuming the berry (Uruakpa, et al., 2012).

Seabuckthorn berry is unique, because of the combined nutritional importance of the fatty acids and sterols, and the high antioxidative capacity of its vitamins and carotenoids making this berry a power fruit.

\subsection{Seabuckthorn application}

In European and Asian countries seabuckthorn has been exploited for the use in pharmaceutical, cosmetic, and food industries (Beveridge, et al., 1999; Kumar, et al., 2011). The essential nutrients and bioactives that compose this berry make this fruit a successful candidate for industry.

The polyphenols in the seabuckthorn leaves have made this plant the target for tea extracts, tea powder, and animal feed (Uruakpa, et al., 2012). The seabuckthorn root system has also caught the attention of many Prairie farmers, because of its soil conservation and land reclamation abilities. The root system of the plant possesses nodules containing Frankia sp., which are responsible for nitrogen fixation and soil fertilization, however the mechanisms have yet to be discovered (T. S. Li \& Schroeder, 1996).

The seabuckthorn oil has a protective capacity as it is believed that the tocopherols and carotenoids can reduce the UV-B formation of toxic products (Kumar, et al., 2011). Therefore, this property has been utilized by industry to produce skin products with the addition of the oil as a natural sunscreen.

The palmitoleic acid (omega-7) in the pulp oil is among the highest in any plant to date adding to the uniqueness of this berry (Kumar, et al., 2011). Omega-7 has received 
the attention of the cosmetic industries and celebrities world wide, because of the antiaging properties of the fatty acid and has been incorporated in face and body creams. All adipose tissues contain omega-7, which has been found to combat wrinkles, but also has been mentioned in the literature to help combat oxidative stress in rats (Zheng, Long, Liu, Zhang, \& Yang, 2012). Palmitoleic acid is also found in high quantities in the adipose tissues of the liver. In the literature, hyperglycemia and hypertriglyceridemia was improved with palmitoleic acid by increasing insulin sensitivity, by suppressing proinflammatory gene expressions and improving hepatic lipid metabolism in diabetic mice (Z. H. Yang, Miyahara, \& Hatanaka, 2011).

Seabuckthorn food products have also been circulated in Canada where there is a Food Development Centre in Manitoba, creating foods infused with the fruit (Uruakpa, et al., 2012). The pleasant aroma, colour, and tart fruity flavor have made it popular in beverages, jam, wine, and purees. Due to the high amount of fiber, vitamin $\mathrm{C}$, and iron the seabuckthorn pulp has been used in the formulation of nutritional snack bars (Uruakpa, et al., 2012). Also, the protein content in the berry has made it a candidate for sports energy drinks in China.

Seabuckthorn is gaining ground in the industry of cosmetics, pharmaceuticals, and food in North America, because of the nutritional value and sensory appeal of the fruit.

\subsection{Fermented yogurts}

Fermented foods have existed for many centuries with over 3500 traditional fermented foods worldwide (Khurana \& Kanawjia, 2007). Before the use of refrigerators fermented foods were used to preserve nutrients. Fermented milks are defined as "products to which other food substances may be added or not, obtained by $\mathrm{pH}$ decrease 
in milk or reconstituted milk, to which other lactic products may be added or not by lactic fermentation, through the action of specific microorganisms" (Khurana, et al., 2007).

The consumption of fermented milks is generally increasing worldwide and many different kinds exist depending on geographical location as seen in Table 1-2 (Khurana, et al., 2007).

Table 1- 2: Broad classification of fermented milks. Adapted from (Khurana, et al., 2007).

\begin{tabular}{|c|c|c|}
\hline Name & Country of Origin & Microflora \\
\hline Acidophilus Milk & Australia & L. acidophilus \\
\hline Yoghurt (Bio-ghurt) & Middle Asia, Balkans & $\begin{array}{l}\text { S. salivarius ssp. thermophilus, } L \text {. } \\
\text { delbreukii ssp. bulgaricus, } \\
\text { Micrococcus and other lactic } \\
\text { acid, cocci, yeasts, molds }\end{array}$ \\
\hline Kefir & Caucasus & $\begin{array}{l}\text { L. lactis ssp. lactis, Leuconostoc } \\
\text { spp. L. delbreukii ssp. caucasiucu, } \\
\text { Saccharomyces kefir, } \\
\text { Torula kefir, micrococci, spore } \\
\text { forming bacilli }\end{array}$ \\
\hline Dahi (dadhi) & India, Persia & $\begin{array}{l}\text { L. lactis ssp. lactis, } S \text {. salivarius } \\
\text { ssp. thermophilus, L. delbreukii }\end{array}$ \\
\hline Cultured Butter Milk & $\begin{array}{l}\text { Scandinavian and European } \\
\text { countries }\end{array}$ & $\begin{array}{l}\text { L. lactis ssp. lactis, L. lactis ssp. } \\
\text { diacetylactis, } \\
\text { Lueconostocdextranicum ssp } \\
\text { citrovorum }\end{array}$ \\
\hline Leben, Labneh & Lebanon, Arab Countries & $\begin{array}{c}\text { L. lactis ssp. lactis, } S \text {. salivarius } \\
\text { ssp. thermophilus, L. delbreukii } \\
\text { ssp. bulgaricus, } \\
\text { L. plantarum, lactose fermenting } \\
\text { yeasts }\end{array}$ \\
\hline
\end{tabular}

Dairy products have become a channel for added nutrition and the innovation of new drinks and yogurts. Cultured dairy products are the medium of choice to generate an array of products that fit into the current consumer demand for health driven foods 
(Khurana, et al., 2007). Currently, the demand for probiotics, prebiotics, and synbiotics addition to fermented milks have increased and are predicted to grow even more, because of added nutrition in a single serving (Khurana, et al., 2007).

Other ingredients designed to enhance customer appeal are being added into fermented milks, such as essential minerals and vitamins, dietary fibers, $\omega$-3-fatty acids, isoflavones, phytosterols and phytostanols, and gamma-amino butyric acid (GABA) (Khurana, et al., 2007). Recently, there has been a trend to add fruit juices and pulps to cultured milk products (Khurana, et al., 2007). Fruit pulp, juice, and puree additions have created a wide variety of sensory choices in flavour, texture, and colour in fermented milks appealing to the consumer.

Food industry is welcoming new flavours and textures of fermented dairy, due to the demand from consumers. Therefore, seabuckthorn may be a prime candidate as a new additive to yogurt, as it is packed with essential fatty acids and other nutrients the combinations of which have not been found in other plant species.

\subsection{Starter cultures}

Streptococcus salivarius ssp. thermophilus (S. thermophilus) and Lactobacillus delbrueckii ssp. bulgaricus (L. bulgaricus) are starter cultures mainly used for yogurt production (Ranadheera, Baines, \& Adams, 2010). They are considered to be yogurt starter cultures and not probiotics, because they are not expected to survive and grow in an individual's intestinal tract (Ranadheera, et al., 2010).

The production of fermented milks requires bacterial starter cultures to carry out the fermentation process. Two of the most important factors in determining the overall quality of the yogurt are both the type and the character of the starter organisms 
(Ranadheera, et al., 2010). In commercially sold yogurt, acidification, aroma, flavour, stability and texture are all important (Beshkova, Simova, Frengova, Simov, \& Dimitrov, 2003). Once starter cultures are added to milk they stimulate each other through acid development, by fermenting lactose, in order to successfully produce yogurt (Ranadheera, et al., 2010).

\subsection{Probiotics}

Probiotics are defined as "viable, defined microorganisms in sufficient numbers, which alter the microflora in a compartment of the host and by that exert beneficial health effects in this host" (Scholz-Ahrens, et al., 2007). The incorporation of probiotics in fermented dairy foods has developed into the most successful functional foods.

There are many strains of probiotic bacteria, however only a few are marketed in food industry. Lactobacilli and bifidobacteria are probably the most studied and they have been proven to be safe in foods (Saxelin, Tynkkynen, Mattila-Sandholm, \& de Vos, 2005).

The intestinal tract is colonized by a vast variety of microbes that show functional variation and recently $16 \mathrm{~S}$ ribosomal RNA testing has distinguished $\sim 20 \%$ and $\sim 50 \%$ of the microbes to be Gram-positive bacteria with low and high GC content respectively (Saxelin, et al., 2005). This finding suggests that the identity of these microbes could be probiotics, because most of them are Gram-positive and lactobacilli has a low GC content and bifidobacteria has a high GC content (Saxelin, et al., 2005).

Probiotic therapy has been investigated for effectiveness in a range of gastrointestinal diseases and disorders and has documented beneficial effects on health in human studies. It has been well supported that probiotics help to relieve the symptoms of 
acute diarrhoea from rotavirus and other non-identified agents (Saxelin, et al., 2005). Individuals undergoing antibiotic treatment have been recommended to take probiotics to balance the gastro-intestinal functions in both children and adults (Saxelin, et al., 2005). Interestingly, probiotics have been shown to suppress the growth and inflammation in the stomach from Helicobacter pylori, which is the main cause of gastric ulcers and risk factor for gastric cancer (Kailasapathy \& Chin, 2000; Saxelin, et al., 2005). They have also been found to activate precursors responsible for the formation of pro-inflammatory cytokines and chemokines in the immune response system (Kailasapathy, et al., 2000; Saxelin, et al., 2005).

The modes of action of probiotics are multifactorial and may possess several different mechanisms. For example, the probiotic strains that inhibit pathogenic bacteria do so by repairing mucosal damage in the intestine mucosal wall, thereby making it less permeable to bacteria (Kailasapathy, et al., 2000; Saxelin, et al., 2005). Probiotics may also produce short chain fatty acids that reduce the $\mathrm{pH}$ of the lumen, therefore inhibit certain pathogens (Gibson, Probert, Loo, Rastall, \& Roberfroid, 2004; Kailasapathy, Harmstorf, \& Phillips, 2008; Saxelin, et al., 2005).

The growth of probiotics is still under investigation, as some researchers believe growth occurs during the manufacturing stages of cultured foods, while growth may occur after ingestion in the intestinal tract (Gibson, et al., 2004; Lourens-Hattingh \& Viljoen, 2001; Saxelin, et al., 2005). 


\subsection{Prebiotics}

Prebiotics "are nondigestible food ingredients that beneficially affect the host by selectively stimulating the growth and/or activity of probiotics in the gastrointestinal tract and thereby exert a health-promoting effect" (Scholz-Ahrens, et al., 2007).

The most studied prebiotics are inulin, fructo-oligosaccharides (FOS), galactooligosaccharides (GOS), while other common prebiotics include soya-oligosaccharides, xylo-oligosaccharides, pyrodextrins, isomalto-oligosaccharides and lactulose (ScholzAhrens, et al., 2007). Prebiotics are also referred to as colonic foods that encourage the growth of favourable bacteria as they promote the growth and activities of probiotics (Ranadheera, et al., 2010).

Inulin, FOS, lactulose, and GOS have been shown to reduce the activity of microbial enzymes involved in the production of toxins and carcinogens as well as their metabolites in faeces (Burns \& Rowland, 2000). Studies illustrate prebiotics might have the potential to reduce colorectal cancer or even alter its progression, however the mechanism of action is still unclear (Burns, et al., 2000). However, some researchers believe the mechanism may involve changes in bacterial numbers and activity in the gut, expression of mucosal genes, and stimulation of the immune system (Tuohy, Probert, Smejkal, \& Gibson, 2003). Prebiotics have also been shown to help decrease the effects of Inflammatory Bowel Disease (IBD), by increasing the production of butyrate, which promotes mucosal cell proliferation and accelerates the healing process in the colon (Tuohy, et al., 2003). Prebiotics have been shown to stimulate the absorption of iron and minerals such as calcium, magnesium, and zinc (Scholz-Ahrens, et al., 2007). 
There is no daily-recommended dose of prebiotics, however $4 \mathrm{~g} /$ day of inulin or FOS is believed by researchers to be beneficial and show an increase in gut bifidobacteria (Tuohy, et al., 2003).

\subsection{Oxidative stress and Antioxidants}

Increased oxygen levels in the human body may promote a higher rate of free radicals and reactive oxygen species (ROS) (Zheng, et al., 2012). ROS can be superoxide anions, hydroxyl radicals, and hydrogen peroxide (Gliwa, Gunenc, Ames, Willmore, \& Hosseinian, 2011; Varshneya, Kant, \& Mehta, 2012). An increase in oxygen levels consequently contributes to an increase in aerobic metabolism primarily occurring in mitochondria (Gliwa, et al., 2011; Zheng, et al., 2012). An increase in free radicals may affect numerous pathways including an increase in lipid peroxidation and impairment of the enzymatic and non-enzymatic antioxidant defense systems in target tissues (Zheng, et al., 2012). In addition, damage to proteins nucleic acids, and membrane lipids in the cells can be caused through oxidation (Gliwa, et al., 2011). An inadequate antioxidant defense system or accumulation of ROS leads to oxidative stress and diseases such as cancer, coronary heart disease, obesity, and aging (Gliwa, et al., 2011; Varshneya, et al., 2012).

The human body can protect against oxidative injury, by enzymatic and nonenzymatic antioxidants and by ingesting antioxidants from our daily diet to eliminate free radicals (Varshneya, et al., 2012; Zheng, et al., 2012). Many plants possess antioxidant abilities and show their activities by a number of mechanisms, a few of which include prevention of chain initiation, decomposition of peroxides, and radical scavenging ability (Varshneya, et al., 2012). 
Nutritionally derived antioxidants are vitamins $\mathrm{E}$ and $\mathrm{C}, \boldsymbol{\beta}$-carotene, flavonoids, and polyphenols, which can be found in plants, vegetables, and fruits (Zheng, et al., 2012). Researchers believe the antioxidant activity may be attributed to their phenolic compounds, which act as free radical terminators (Figure 1-2) (Zheng, et al., 2012). In particular flavonoids, which are a group of polyphenols, can scavenge free radicals, donate hydrogen atoms or electrons, or chelate metal cations (Balasundram, Sundram, \& Samman, 2006).<smiles>O=C(O)c1cc(O)c(O)c(O)c1</smiles>

Structure of Gallic acid

Figure 1- 2: Phenolic acid that is also found in seabuckthorn (Balasundram, et al., 2006).

Free radical formation and removal can be balanced by introducing ROS scavenging materials through ingesting foods rich in antioxidant properties such as plants, vegetables, and fruits as they are safer than antioxidants that are produced synthetically (Varshneya, et al., 2012). Every compound has their own characteristic level of antioxidant abilities; therefore methods have been developed to measure antioxidant activity: 


\subsubsection{Oxygen radical absorbance capacity assay (ORAC)}

ORAC assay is widely accepted as a tool to measure antioxidant activity of various compounds in the field of scientific research as well as in nutraceutical and food industries.

To measure antioxidant activity the free radical, substrate, and antioxidant reaction must be considered, as the kinetics does not produce a fixed linear equation (Huang, Ou, Hampsch-Woodill, Flanagan, \& Prior, 2002). Accurate measurements of antioxidant capacity must take into account the inhibition degree and time where ORAC combines both of these factors into a single value (Huang, et al., 2002).

To produce a value for antioxidant activity an oxidation reaction is created, in vitro, using 2,2'-Azobis (2-amidinopropane) dihydrochloride (AAPH) as the free radical generator, Trolox as the antioxidant and standard, a sample to react with the free radical, a control, and fluorescein working solution as the probe. The reaction is allowed to reach completion where changes in fluorescence intensity reflect antioxidant capacity.

ORAC values are determined using the area under the curve (Net AUC), from the curves generated by fluorescence decay, and from the Trolox standard curve. ORAC values are then expressed as Trolox equivalents.

\subsubsection{Scavenging of 1,1-diphenyl-2-picrylhydrazyl (DPPH)}

DPPH is a stable free radical that is used to determine antioxidant activity of potential extracts. DPPH is a deep purple compound, attributed to its unpaired electrons that are mixed with an antioxidant extract and buffer, which is then measured frequently 
for a one-hour duration. An antioxidant extract would be able to donate an electron to $\mathrm{DPPH}$, resulting in the quenching of the radical and a colour change from purple to yellow. Using a spectrophotometer, absorbances of the samples and controls are measured and \% $\mathrm{DPPH}$ - scavenging activity is calculated using the following equation:

$$
\left(1-\left[\frac{A_{\text {sample }}}{A_{\text {control } t=0}}\right]\right) \times 100
$$

The ability of an antioxidant to create the non-radical form of DPPH is then recorded (Varshneya, et al., 2012).

\subsection{Electronic Nose Technology (e-nose)}

Electronic nose machinery (e-nose) is used to analyze complex odors in the "headspace" of foods and drinks and very soon in diagnostics of medical ailments. The headspace is composed of a mixture of volatile compounds that are produced by the product. E-nose has metal oxide sensors or conducting polymer resistive gas sensors that are used to analyze the headspace of a sample (Gardner, Shin, \& Hines, 2000).

Simply, samples are placed in vials or petri dishes and introduced directly to the machine where individual sensors collectively generate a digital reading of the aromas detected in the headspace.

This artificial olfactory machine has many advantages one of which is that it does not require sample preparation that is for example needed for GC-MS and GC-FID (Gardner, et al., 2000). In addition, e-nose uses many types of sensors, resulting in a wider range of capabilities and applications. Multiple compounds and aromas may be detected in a single reading, therefore producing collective data output and graphical analysis from the sensors (Ampuero \& Bosset, 2003; Gardner, et al., 2000). 
Chapter 2- Seabuckthorn is a Super-Berry with Dual Functionality as a Prebiotic with Antioxidant Activity 


\subsection{Abstract}

The first objective of the study was to determine if seabuckthorn (S) berries exhibit potential prebiotic activity in yogurt. Whole crushed seabuckthorn $(2 \%)$ was added to pasteurized whole milk (homogenized $3.25 \%$ ) simultaneously with controls without fruit. Batches were prepared in triplicates and inoculated with starter cultures including: Streptococcus salivarius subsp. thermophilus and Lactobacillus delbrueckii subsp. bulgaricus subsequently divided into four groups according to probiotic addition. A microbial analysis was used to observe the effect of the fruit on the growth of two probiotic strains: Lactobacillus acidophilus and Bifidobacterium lactis. Microbial counts were conducted on days $1,7,14,21$ and 28 of cold storage $\left(4^{\circ} \mathrm{C}\right)$ as well as post acidification $(\mathrm{pH})$ readings and titratable acidity (TTA). After, 7 days of cold storage all seabuckthorn yogurt treatments showed significantly higher microbial counts compared to those of the control $(P \leq 0.05)$ and following 21 days of cold storage, yogurt samples containing $2 \%$ seabuckthorn and probiotic $L$. acidophilus had the highest microbial count. TTA and pH results showed similar trends to those found from microbial analyses. Water-extractable crude materials (CM) and water-extractable polysaccharides (WEP) of seabuckthorn exhibited strong antioxidant activity with an ORAC value of $138.95 \pm 0.99$ $\mu \mathrm{mol}$ Trolox Equivalent (TE) $/ 100 \mathrm{~g}$ and $29.22 \pm 3.08 \mu \mathrm{mol} \mathrm{TE} / 100 \mathrm{~g}$ respectively. This study suggests that seabuckthorn may contain bioactive polysaccharides that can be used as a valuable source of prebiotics in fermented dairy products and antioxidant for functional food applications. 


\subsection{Introduction}

Seabuckthorn berries contain non-digestible oligosaccharides (NDO), which have the ability to enhance the activity of health promoting bacteria found in the human digestive system and decrease the activity of health damaging bacteria, which is indicative of prebiotic properties (Roberfroid, 2007). Seabuckthorn has not been previously analyzed as a prebiotic candidate in yogurt, suggesting that preliminary research requires discovery of seabuckthorn's effect on the total count of bacteria in yogurt. Thus, the following study focuses on the addition of seabuckthorn berries to yogurt and its effect on microbial count, $\mathrm{pH}$, and titratable acidity. In the second portion of this study, the antioxidant activity of water extractable materials from seabuckthorn is measured using two methods: Oxygen Radical Absorbance Capacity (ORAC) and DPPH method.

\subsection{Materials and Methods}

\subsubsection{Seabuckthorn fruit preparation}

Seabuckthorn berries were obtained from Horticulture Research Center (Laval University, Quebec) and frozen as the whole fruit upon arrival at $-20^{\circ} \mathrm{C}$. For analyses, the fruit was defrosted at $4^{\circ} \mathrm{C}$ for twenty-four hours and were then homogenized in a food processor. The homogenized berries were added to twelve of the twenty-four test tubes that would contain pasteurized homogenized milk.

\subsubsection{Prebiotic Addition}

It was determined that $2 \%(1 \mathrm{~g} / 50 \mathrm{~mL})$ of homogenized seabuckthorn fruit was to be added to treatments, which was determined using methods adapted from Agil and 
Hosseinian (2012). The concentration was chosen, because it was the highest amount that could be added without resulting in synersis. Extract was added to $50 \mathrm{~mL}$ pasteurized milk and incubated at $42^{\circ} \mathrm{C}$ until completion of fermentation, approximately pH 5.0.

\subsubsection{Microbial Analyses}

The effect of prebiotics on probiotic activity was determined, following the methods of (Espírito Santo, Silva, Soares, Anjos, Gioielli, \& Oliveira, 2010).

\subsubsection{Propagation of Microbial Cultures}

The starter cultures used to prepare the yogurt were Lactobacillus delbrueckii subsp. bulgaricus (B-548; USDA) and Streptococcus salivarius subsp. thermophilus (14485; ATCC). Lyophilized probiotics used in the experimental were Lactobacillus acidophilus (B-4495; USDA) and Bifidobacterium lactis (41405; USDA). Each of the strains were grown in $10 \mathrm{~mL}$ sterile aliquots of MRS (de Man Rogosa Sharpe) liquid media and incubated at $37^{\circ} \mathrm{C}$ for 48 hours. The activated cultures were used after three successive rinsings with sterilized distilled water for the preparation of the mother cultures to make yogurt. The cultures were diluted with sterilized milk and were counted using a hemocytometer $\left(121^{\circ} \mathrm{C}\right.$ for $15 \mathrm{~min}$. in an autoclave) to obtain a concentration of approximately $8 \log$ cell $/ \mathrm{mL}$. Once the dilutions were made, the treatments of yogurt were inoculated with $0.5 \mathrm{~mL}$ of each yogurt starter culture and $1.0 \mathrm{~mL}$ of each required probiotic(s) as seen in Table 2-1.

\subsubsection{Milk Preparation}

Pasteurized whole milk (homogenized 3.25\%) was purchased from a local grocery store. The milk was treated at $85^{\circ} \mathrm{C}$ for 15 minutes on a hot plate and then 
cooled to $42{ }^{\circ} \mathrm{C}$ in a water bath. Once cooled, $50 \mathrm{~mL}$ of the whole milk was added to each of the twenty-four test tubes. After the test tubes were inoculated with the appropriate starter cultures, probiotics and seabuckthorn berry concentration, all were incubated at $42{ }^{\circ} \mathrm{C}$ until yogurts reached approximately $\mathrm{pH} 5.0$.

Table 2- 1: Experimental design evaluating seabuckthorn (S) fruit on probiotic viability. Abbreviations: without $S(-)$; with $S(+)$; standard yogurt containing starter cultures S. thermophilus + L. bulgaricus (Y); probiotic L. acidophilus (Pro1); probiotic B. lactis (Pro2).

\begin{tabular}{lcc}
\hline Microorganisms & $\begin{array}{c}\text { Seabuckthorn } \\
\text { Fruit }\end{array}$ & $\begin{array}{c}\text { Sample } \\
\text { coding }\end{array}$ \\
\hline $\begin{array}{l}\text { Y: Streptococcus salivarius } \\
\text { subsp.thermophilus + Lactobacillus } \\
\text { delbrueckii subsp.bulgaricus } \\
\text { Y + Lactobacillus acidophilus (Pro1) }\end{array}$ & - & $\mathrm{Y}$ \\
$\mathrm{Y}+$ Bifidobacterium lactis (Pro2) & - & $\mathrm{Y}+1$ \\
$\mathrm{Y}+$ Prol\&2 & - & $\mathrm{Y}+2$ \\
YS & - & $\mathrm{Y}+1+2$ \\
YS + Lactobacillus acidophilus (Pro1) & + & $\mathrm{YS}$ \\
YS + Bifidobacterium lactis (Pro2) & + & $\mathrm{YS}+1$ \\
YS + Pro 1 \& 2 & + & $\mathrm{YS}+2$ \\
\end{tabular}

\subsubsection{Experimental Design}

Eight different yogurt treatments were prepared in triplicates; four treatments contained seabuckthorn homogenate and similarly four treatments that did not contain the fruit, as the controls. The probiotics were added to the designated tubes as seen in Table 2-1. Once the tubes were inoculated, the initial $\mathrm{pH}$ was taken with a Denver Instrument UB-5 Ultrabasic $\mathrm{pH}$ meter. The test tubes were placed in an incubator at $42^{\circ} \mathrm{C}$ for 
fermentation. Fermentation was terminated once $\mathrm{pH}$ reached approximately $\mathrm{pH} 5.0$. Once fermented, the yogurts were stored at $4{ }^{\circ} \mathrm{C}$.

\subsubsection{4 pH and Titratable Acidity}

Post-acidification was determined on days $1,7,14,21$, and 28 using a Denver Instruments UB-5 Ultrabasic $\mathrm{pH}$ meter. Total titratable acidity (TTA, mg lactic acid/g yogurt) was determined by titrating a mixture of $1 \mathrm{~mL}$ yogurt sample and $9 \mathrm{~mL}$ sterile distilled water (1:9) with $0.1 \mathrm{~N} \mathrm{NaOH}$ using a $0.1 \%$ Phenolphetalein colour indicator.

\subsubsection{Extraction of water extractable materials}

\subsubsection{Water extractable materials-crude materials (CM)}

Extraction of $\mathrm{CM}$ from seabuckthorn was executed by dissolving $5 \mathrm{~g}$ in $50 \mathrm{~mL}$ distilled water in a quartz tube belonging to CEM STAR System 2 microwave digestion system (CEM Corporation, Matthews, NC, USA). Extraction was set to $90^{\circ} \mathrm{C}$ for 30 minutes, where the extract was let to cool at room temperature. The cooled mixture was then centrifuged at $4000 \mathrm{rpm}$ for 20 minutes at room temperature $\left(23{ }^{\circ} \mathrm{C}\right)$. Some of the supernatant was collected and stored at $-20^{\circ} \mathrm{C}$ until further analysis, while some extract was run through further purification. Please see section 2.3.4.1 for extraction of waterextractable polysaccharides.

\subsubsection{Water-extractable polysaccharides (WEP)}

Extraction of WEPs was performed by first, following the methods of $\mathrm{CM}$ of seabuckthorn whole fruit. Following, initial crude extractions, $20 \mu \mathrm{l}$ of $\alpha$-amylase solution and $20 \mu \mathrm{l}$ proteases from Bacillus lichenformisis (Type XII-A) was administered in order to eliminate proteins and starch molecules. The mixture was stirred overnight at 
$37^{\circ} \mathrm{C}$, followed by centrifugation for 20 minutes at $4000 \mathrm{rpm}$ at room temperature $\left(23^{\circ} \mathrm{C}\right)$. The precipitate of the mixture was discarded and the supernatant solution was poured into $30 \mathrm{~mL}$ dialysis tubes, which restricted molecular weights of less then 3,500 $\mathrm{Da}$ (Spectra/Porß Dialysis Membrane wet in $0.1 \%$ Sodium azide). The tubes were placed in double deionized water for 48 hours with water changes every 4 hours. The WEP solution was then stored at $-20^{\circ} \mathrm{C}$ until further analysis.

\subsubsection{Oxygen Radical Absorbance Capacity (ORAC) assay}

The antioxidant activity of seabuckthorn CM and WEP materials was measured using an ORAC assay according to Agil and Hosseinian (2012). The instrument for analysis was the $\mathrm{FLx} 800^{\mathrm{TM}}$ Multi-Detection Microplate Reader with $\mathrm{Gen} 5^{\mathrm{TM}}$ software by BioTek Instruments. Peroxyl radicals were generated using 2,2'-azobis (2amidinopropane) dihydrochloride (AAPH). The solution serving as the fluorescence probe was fluorescein and rutin trihydrate served as a positive control. Trolox (6hydroxy-2, 5, 7, 8-tetramethylchroman-2-carboxylic acid), a vitamin $\mathrm{E}$ analogue was used as the standard for a reference point. Change in fluorescence intensity was used as a measure to detect the antioxidant capacity of the sample to act against free radicals. Five different concentrations of Trolox standards were prepared ranging from 6.25, 12.5, 25, 50 and $100 \mu \mathrm{M}$ and two concentrations (200 and $100 \mu \mathrm{M})$ of rutin control were prepared. Seabuckthorn extractions were prepared in a 1:1 1:2,1:4,1:8, and 1:16 dilutions of sample to potassium phosphate buffer. In a 96 micro-well plate, $20 \mu \mathrm{L}$ of each: buffer (blank), Trolox (standards), sample, and rutin (controls), with $120 \mu \mathrm{L}$ were loaded into their respective places in the micro-well plate. After 30 minutes of incubation at $37^{\circ} \mathrm{C}$, $60 \mu \mathrm{L}$ of AAPH peroxyl radical generator was added yielding a total well volume of 200 
$\mu \mathrm{L}$. The fluorometric microplate reader was used at an excitation wavelength of $485 \mathrm{~nm}$ and emission wavelength of $528 \mathrm{~nm}$. All samples were run in triplicate and ORAC values were expressed as $\mu \mathrm{mol}$ Trolox equivalents per $100 \mathrm{~g}$ of whole seabuckthorn berry ( $\mu \mathrm{mol}$ $\mathrm{TE} / \mathrm{g})$.

\subsection{6 $\mathrm{DPPH} \cdot$ scavenging activity assay}

A second method for antioxidant analysis was performed on seabuckthorn water extractable materials (CM and WEP) using the 2,2-diphenyl-1- picrylhydrazyl (DPPH) scavenging activity assay adapted from Li, Hydamaka, Lowry, and Beta (2009) (W. Li, Hydamaka, Lowry, \& Beta, 2009). The assay determined antioxidant activity by measuring the stability of the DPPH free radical. The radical carries unpaired electrons, which become paired when exposed to antioxidants. Once this reaction occurs a colour change can be observed from violet to yellow indicating that the free radical has formed its non-radical state. The spectrophotometer was used to follow the progress of the antioxidants ability to donate their electrons and was represented by a measurement. Over time, the absorbances will decreases as the non-radical form predominates.

A $60 \mu \mathrm{M}$ DPPH solution was prepared by dissolving DPPH powder in methanol to prepare a solution with $200 \mu \mathrm{L}$ of sample extract with $3.8 \mathrm{~mL}$ of DPPH• solution. Absorbance of the $\mathrm{DPPH} \bullet$ mixture was measured in triplicates using a $515 \mathrm{~nm}$ wavelength at timed intervals of $0,5,10,15,20,30,40,50,60$ minutes using the UVVisible SpectraMax Plus384. The blank was methanol, which was the solvent used to make the DPPH• solution. Scavenging activity was calculated using the following

equation representing $\% \mathrm{DPPH} \bullet:\left(1-\left[\frac{A_{\text {sample }}}{A_{\text {control } t=0}}\right]\right) \times 100$ 


\subsubsection{Statistical Analyses}

Statistical Analysis System SAS ( $9^{\text {th }}$ Version, SAS Institute Inc., Cary, NC) was used for statistical analysis. ANOVA was used to determine values with statistically significant differences $(\mathrm{P} \leq 0.05)$ between the eight treatments for each day. The eight treatments were analyzed using Duncan's Multiple Range test ( $\alpha$ level=0.05). Alphabetic letters were used to indicate values that were statistically different amongst the treatments. Letters that are different were considered statistically significant $(\mathrm{P} \leq 0.05)$ and letters that were the same were considered not statistically significant $(P>0.05)$. To investigate, the effect of days on the four different treatments as well as their interaction, two-way ANOVA (independent variables were treatment and days) was used where mean values were compared using Duncan's Multiple Range ( $\alpha$ level $=0.05$ ).

\subsection{Results and Discussion}

\subsubsection{Effect of whole fruit on microbial viability}

There were four yogurt treatments used as controls in comparison to the four yogurt treatments with seabuckthorn whole fruit. All yogurt treatments contained two starter cultures $S$. thermophilus and L. bulgaricus. Yogurts Y+1 (without fruit) and YS+1 (with seabuckthorn fruit) contained L. acidophilus (Probiotic 1), while treatment $\mathrm{Y}+2$ and YS +2 both contained $B$. lactis (Probiotic 2 ). The final treatment $\mathrm{Y}+1+2$ and $\mathrm{YS}+1+2$ contained both probiotic 1 and probiotic 2 . A growth range of range of 6 to $8 \mathrm{log}$ CFU/mL was recommended, before inoculation of the lactic acid bacteria and starter cultures (Vasiljevic \& Shah, 2008).

Microbial counts ranged from 7.8 to $8.5 \log \mathrm{CFU} / \mathrm{mL}$ after seven days of cold storage. All yogurt treatments containing seabuckthorn whole fruit had significantly 
higher counts of viable microorganisms compared to their respective control yogurts as seen in Figure 2-1. The nutritional value of seabuckthorn, which contains non-digestible oligosaccharides (NDO), sugars and various other nutrients can perhaps explain the increased numbers of viable microorganisms in yogurt treatments YS, YS+1, YS+2, and $Y S+1+2$, because the principal substrates for bacterial growth are dietary carbohydrates (Gibson \& Roberfroid, 1995). Non-digestible oligosaccharides (NDO) have demonstrated the capability to enhance the activity of health promoting bacteria found in the human digestive system and decrease the activity of health damaging bacteria (Gibson, et al., 1995).

Day 14 counts of viable microorganisms ranged from 7.2 to $8.2 \log$ CFU/mL (Figure 2-1). Treatments $Y S+1$ and $Y S+2$ contained significantly higher counts of viable microorganisms compared to the control yogurts $\mathrm{Y}+1$ and $\mathrm{Y}+2$ respectively (Figure 2-1). Seabuckthorn yogurt treatment YS+1, containing L. acidophilus, was $0.8 \log \mathrm{CFU} / \mathrm{mL}$ greater that its respective control and the highest among all yogurt treatments, which had never before been reported for seabuckthorn fruit in yogurt. Complex nutritional requirements are required for Lactobacilli and Bifidobacteria such as carbohydrates, amino acids, peptides, fatty esters, salts, nucleic acid derivatives, and vitamins (Charalampopoulos, Wang, Pandiella, \& Webb, 2002). Seabuckthorn contains insoluble components of dietary fiber (water soluble) and predominately two free sugars; glucose and fructose (Zeb, 2004a). Seabuckthorn also contains several amino acids, more specifically eight, which are required for the human body; free amino acids threonine, valine, methionine, leucine, lysine, trytophan, isoleucine, and phenylalanine (Zeb, 2004a). Additionally, it was previously reported that certain elements such as manganese 
and iron ( $\mathrm{Mn}$ and $\mathrm{Fe}$ ) are essential nutrients for lactic acid bacteria as they promote viability and growth (Agil \& Hosseinian, 2012). Seabuckthorn contains many essential nutrients including Mn, Fe, and high contents of calcium (Zeb, 2004a). Therefore, the micronutrients and dietary fiber present in the berry may have had a positive influence on the growth of the probiotic microorganisms in the yogurt.

Counts of viable microorganisms after 21 days of cold storage ranged from 7.6 to $8.24 \log$ CFU/mL. Yogurt treatments YS +1 and YS $+1+2$ showed higher counts of viable microorganisms $(\mathrm{P} \leq 0.05)$ compared to the controls $\mathrm{Y}+1$ and $\mathrm{Y}+1+2$ respectively (Figure $2-1$ ). The results revealed that yogurt treatment $\mathrm{YS}+1$ showed 21 consecutive days of significantly higher microbial counts $(\mathrm{P} \leq 0.05)$.

After 28 days of cold storage, counts of viable microorganism ranged from 6.9 to 8 $\log \mathrm{CFU} / \mathrm{mL}$ showing an overall decrease of viable microorganisms. All seabuckthorn yogurt treatments (YS, YS+1, YS+2, and YS+1+2) showed no statistical differences when compared to the control yogurts $(\mathrm{Y}, \mathrm{Y}+1, \mathrm{Y}+2$, and $\mathrm{Y}+1+2)(\mathrm{P}>0.05)$. The decline of bacterial viability at the end of the cold storage period could have resulted from nutrient depletion and accumulation of organic acids (Kailasapathy, et al., 2008). In addition, when comparing the effect of days on treatments, it was found that all control yogurt treatments had significantly lower microbial counts than the yogurts with seabuckthorn fruit throughout the 28 days of cold storage. Yogurt YS +1 containing $L$. acidophilus microorganisms had the highest counts. Maximum levels of microorganism counts were obtained on day 7 and 21 (Table 2-2). 


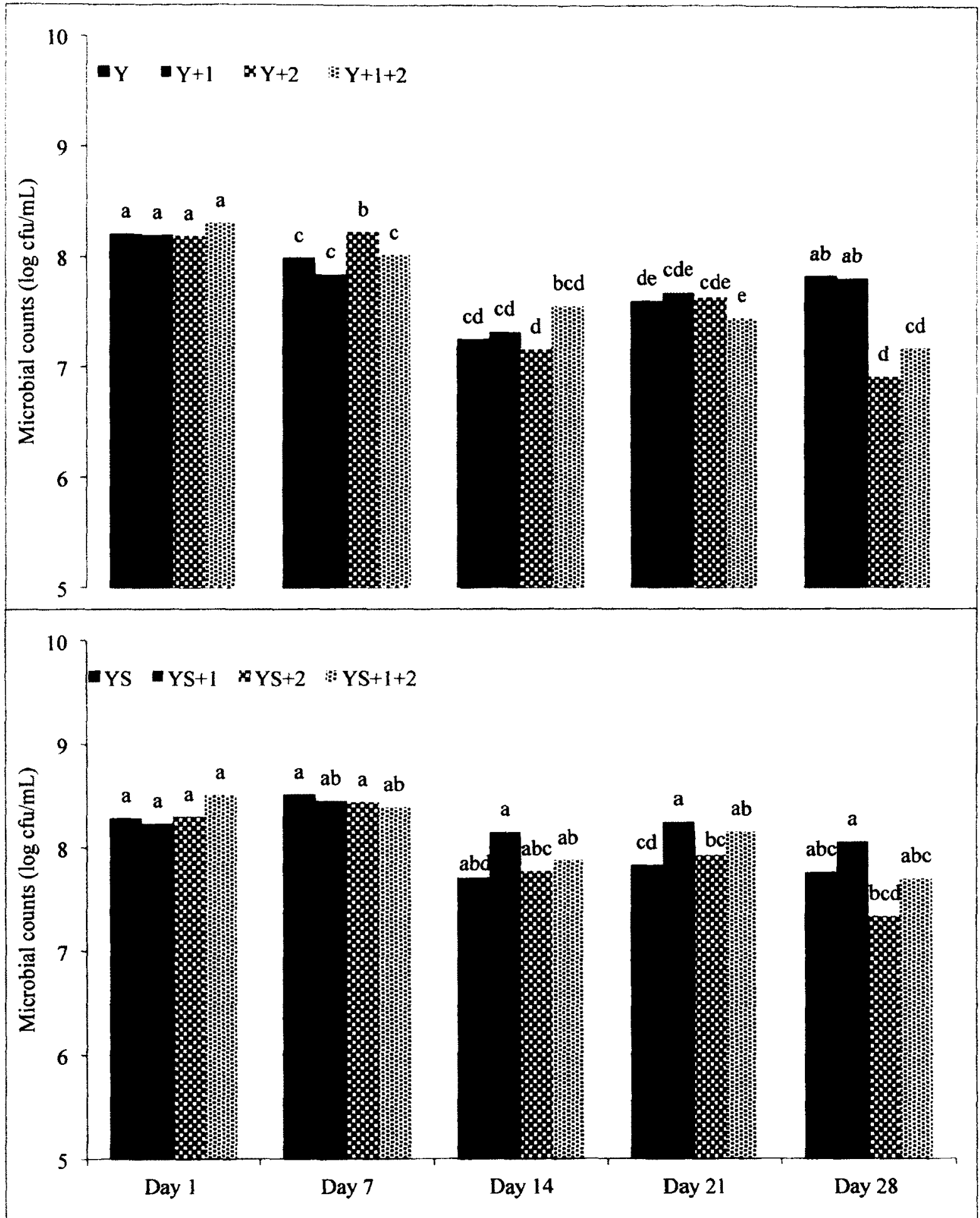

Figure 2- 1: Enumeration of viable lactic acid bacteria in yogurts without seabuckthorn (S) $(Y, Y+1, Y+2$, and $Y+1+2)$ and with $(Y S, Y S+1, Y S+2$, and $Y S+1+2)$ whole fruit within a day. Alphabetic superscripts that are different represent significantly different $(\mathrm{P} \leq \mathbf{0 . 0 5})$ values. Values represent average of three readings $(\mathrm{N}=3)$. 
Table 2- 2: Total microbial counts using two-way ANOVA showing the effect of days on all yogurt treatments $(\alpha=0.5)$.

\begin{tabular}{lcccc}
\hline Source & DF & Mean Square & F value & Pr $>$ F \\
\hline Storage day & 4 & 2.76 & 60.44 & $<.0001$ \\
Yogurt treatments & 7 & 0.72 & 15.74 & $<.0001$ \\
$\begin{array}{l}\text { Yogurt treatment* } \\
\text { Storage day }\end{array}$ & 28 & 0.15 & & \\
\hline
\end{tabular}

$\mathrm{R}^{2}=0.84$

\subsubsection{Effect of whole fruit on pH and Titratable Activity (TTA)}

Day 1 of cold storage showed that yogurts containing seabuckthorn whole fruit had lower $\mathrm{pH}$ levels in comparison to the corresponding controls without fruit $(\mathrm{P} \leq 0.05)$ (Table 2-3). Day 1 of cold storage also showed TTA in the range of 0.18 and $0.54 \mathrm{mg}$ lactic acid/g. The TTA was significantly higher $(\mathrm{P} \leq 0.05)$ in all seabuckthorn whole fruit yogurts when compared to the control (Table 2-4).

On day 7 , all four yogurt treatments containing seabuckthorn whole fruit (YS, YS+1, $\mathrm{YS}+2$, and $\mathrm{YS}+1+2)$ showed lower $\mathrm{pH}$ levels $(\mathrm{P} \leq 0.05)$ compared to those without fruit $(\mathrm{Y}, \mathrm{Y}+1, \mathrm{Y}+2$, and $\mathrm{Y}+1+2)$ indicating increased acid production in yogurts containing the fruit (Table 2-3). On day 7, TTA was not significantly different $(\mathrm{P}>0.05)$ in the seabuckthorn yogurts YS, YS +2 , and YS $+1+2$ when compared to their respective controls without fruit (Table 2-4). However, yogurt treatment containing probiotic $L$. acidophilus $(\mathrm{YS}+1)$ and seabuckthorn fruit, showed a significant difference $(\mathrm{P} \leq 0.05)$ with respect to its control $(\mathrm{Y}+1)($ Table 2-3). TTA was used to determine the amount of lactate content in the yogurts where increased lactate content would indicate increased microbial activity. However, other byproducts that would increase microbial activity may not be detectable with TTA. 
On day $14, \mathrm{pH}$ readings in the yogurts with seabuckthorn whole fruit (YS, YS +1 , $\mathrm{YS}+2$, and $\mathrm{YS}+1+2)$ were significantly lower $(\mathrm{P} \leq 0.05)$ than their respective controls (Table 2-3). On day 14, TTA for fruit yogurts with L. acidophilus (YS+1) was significantly higher $(\mathrm{P} \leq 0.05)$ when compared to its control $\mathrm{Y}+1$ (Table 2-4). This may indicate that $L$. acidophilus might be better adapted to breaking down lactose in the presence of seabuckthorn berries.

On day 21 , it was observed that the $\mathrm{pH}$ was significantly lower $(\mathbf{P} \leq 0.05)$ in all the yogurts with the whole fruit (YS, YS+1, YS+2, and YS+1+2) when compared to their controls $(\mathrm{Y}, \mathrm{Y}+1, \mathrm{Y}+2$, and $\mathrm{Y}+1+2)$ (Table 2-3). TTA was significantly higher $(\mathrm{P} \leq 0.05)$ for yogurt treatment $\mathrm{YS}+1$ in comparison to the control $\mathrm{Y}+1$, which coincides with the viable microbial counts found on day 21 .

After 28 days of cold storage, the $\mathrm{pH}$ readings in the yogurts with the fruit (YS, $\mathrm{YS}+1, \mathrm{YS}+2$, and $\mathrm{YS}+1+2)$ were all significantly lower $(\mathrm{P} \leq 0.05)$ then their respective controls (Table 2-3). In addition, all seabuckthorn yogurt treatments showed significantly higher levels of TTA $(\mathrm{P} \leq 0.05)$. Indicating that after 28 days of cold storage the fruit yogurts showed higher lactate content than the controls, which complimented the results found for viable microbial counts. 
Table 2- 3: pH during shelf life of yogurts without $(Y, Y+1, Y+2$, and $Y+1+2)$ and with S (YS, YS+1, YS+2, and YS+1+2). Alphabetic letters that are different represent significantly different $(\mathrm{P} \leq \mathbf{0 . 0 5})$ values within a day. Values represent average of three readings $(N=3)$.

\begin{tabular}{clllll}
\hline \multirow{2}{*}{ Treatment } & \multicolumn{5}{c}{$\mathbf{p H}$} \\
\cline { 2 - 6 } & $\mathrm{D} 1$ & $\mathrm{D} 7$ & $\mathrm{D} 14$ & $\mathrm{D} 21$ & $\mathrm{D} 28$ \\
$\mathrm{Y}$ & $5.96 \mathrm{a}$ & $5.83 \mathrm{a}$ & $5.63 \mathrm{a}$ & $5.75 \mathrm{a}$ & $5.11 \mathrm{a}$ \\
$\mathrm{Y}+1$ & $5.33 \mathrm{bc}$ & $5.12 \mathrm{c}$ & $5.0 \mathrm{~b}$ & $5.16 \mathrm{c}$ & $4.72 \mathrm{~b}$ \\
$\mathrm{Y}+2$ & $5.85 \mathrm{a}$ & $5.71 \mathrm{~b}$ & $5.58 \mathrm{a}$ & $5.64 \mathrm{~b}$ & $5.18 \mathrm{a}$ \\
$\mathrm{Y}+1+2$ & $5.5 \mathrm{~b}$ & $5.04 \mathrm{~d}$ & $4.94 \mathrm{c}$ & $5.1 \mathrm{~d}$ & $4.69 \mathrm{~b}$ \\
$\mathrm{YS}$ & $5.28 \mathrm{c}$ & $5.05 \mathrm{~d}$ & $4.97 \mathrm{bc}$ & $4.98 \mathrm{e}$ & $4.60 \mathrm{c}$ \\
$Y S+1$ & $4.97 \mathrm{~d}$ & $4.71 \mathrm{e}$ & $4.67 \mathrm{~d}$ & $4.78 \mathrm{~g}$ & $4.27 \mathrm{~d}$ \\
$Y S+2$ & $5.25 \mathrm{c}$ & $5.02 \mathrm{~d}$ & $4.96 \mathrm{bc}$ & $4.92 \mathrm{f}$ & $4.55 \mathrm{c}$ \\
$Y S+1+2$ & $4.91 \mathrm{~d}$ & $4.72 \mathrm{e}$ & $4.67 \mathrm{~d}$ & $4.8 \mathrm{~g}$ & $4.24 \mathrm{~d}$ \\
\hline
\end{tabular}

Table 2- 4: Total titratable acidity (TTA) of yogurts without seabuckthorn (S) (Y, $Y+1, Y+2$, and $Y+1+2$ ) and with (YS, YS+1, $Y S+2$, and $Y S+1+2)$ whole fruit. Alphabetic letters represent significantly different $(P \leq 0.05)$ values within a day. Values represent average of three readings $(N=3)$.

\begin{tabular}{|c|c|c|c|c|c|}
\hline \multirow[t]{2}{*}{ Treatments } & \multicolumn{5}{|c|}{$\begin{array}{l}\text { Titratable acidity } \\
\text { (\%lactic acid) }\end{array}$} \\
\hline & $\overline{\mathrm{D} 1}$ & D7 & D14 & $\mathrm{D} 21$ & $\bar{D} 28$ \\
\hline$Y$ & $0.18 \mathrm{~d}$ & $0.45 b$ & $0.54 \mathrm{ab}$ & $0.45 b c$ & $0.45 \mathrm{~cd}$ \\
\hline$Y+1$ & $0.36 \mathrm{c}$ & $0.45 b$ & $0.42 \mathrm{c}$ & $0.42 \mathrm{bc}$ & $0.43 \mathrm{c}$ \\
\hline $\mathrm{Y}+2$ & $0.36 \mathrm{c}$ & $0.45 b$ & $0.45 b c$ & $0.48 \mathrm{~b}$ & $0.39 \mathrm{~d}$ \\
\hline$Y+1+2$ & $0.45 b$ & $0.45 b$ & $0.42 \mathrm{c}$ & $0.45 b c$ & $0.45 \mathrm{~cd}$ \\
\hline YS & $0.45 b$ & $0.45 b$ & $0.45 b c$ & $0.36 \mathrm{c}$ & $0.63 b$ \\
\hline $\mathrm{YS}+1$ & $0.45 b$ & $0.54 \mathrm{a}$ & $0.6 \mathrm{a}$ & $0.63 a$ & $0.6 b$ \\
\hline $\mathrm{YS}+2$ & $0.45 b$ & $0.42 b$ & $0.45 b c$ & $0.48 b$ & $0.54 b c$ \\
\hline$Y S+1+2$ & $0.54 \mathrm{a}$ & $0.45 b$ & $0.36 \mathrm{c}$ & $0.51 b$ & $0.78 \mathrm{a}$ \\
\hline
\end{tabular}




\subsubsection{ORAC}

Antioxidant activity of CM and WEP was determined using a Trolox standard curve (Figure 2-2). Antioxidant activity was calculated using the equation from the standard curve to obtain the concentration from the extracts. It was observed that fluorescence decay increased as the net area under the curve (AUC) increased. As antioxidant activity represents the $\mathrm{AUC}$, the results show that as the delay in fluorescent time increased, so did the antioxidant activity of the extract (Agil, et al., 2012). A mean AUC was recorded for each concentration of CM of seabuckthorn and is represented in Figure 2-3. It was observed that higher concentrations of CM showed greater protection against fluorescence decay, which is caused by free radicals. This is represented by a larger mean AUC found under the curve. CM showed higher antioxidant activity $(\mathrm{P} \leq 0.05)$ compared to WEP with ORAC values of $138.95 \pm 0.99 \mu \mathrm{mol} \mathrm{TE} / 100 \mathrm{~g}$ of fruit and $29.22 \pm 3.08 \mu \mathrm{mol} \mathrm{TE} / 100 \mathrm{~g}$ of fruit respectively (Figure 2-4).

As expected CM showed a much higher antioxidant activity than the pure extract, which contained water soluble materials consisting of proteins, flavonoids, and polysaccharides. Seabuckthorn contains high levels of ascorbic acid; ranging from 360$2500 \mathrm{mg} / 100 \mathrm{~g}$ of berries compared to $35-56 \mathrm{mg} / 100 \mathrm{ml}$ of orange juice (Beveridge, et al., 1999), as well as flavonoids isorhamnetin or quercitin bound to carbohydrates such as glucose, fructose, and xylose (Bal, Meda, Naik, \& Satya, 2011). These compounds are most certainly responsible for the antioxidant activity exhibited in the crude extracts. Decreased antioxidant activity was observed in pure seabuckthorn extracts, because of the purification step of dialysis. Compounds that were greater than $3,500 \mathrm{Da}$, such as free phenolic compounds were eliminated from the extraction and the solution was left with 
polysaccharides. In addition, the enzymes $\alpha$-amylase and protease broke down proteins and carbohydrates that could have been bound to phenolic acids that are responsible for scavenging free radicals. Interestingly, polysaccharides in the purified solution showed some antioxidant activity, which may indicate that phenolic acids may be bound, such as gallic acid, a type of phenolic acid (Arimboor, Kumar, \& Arumughan, 2008).

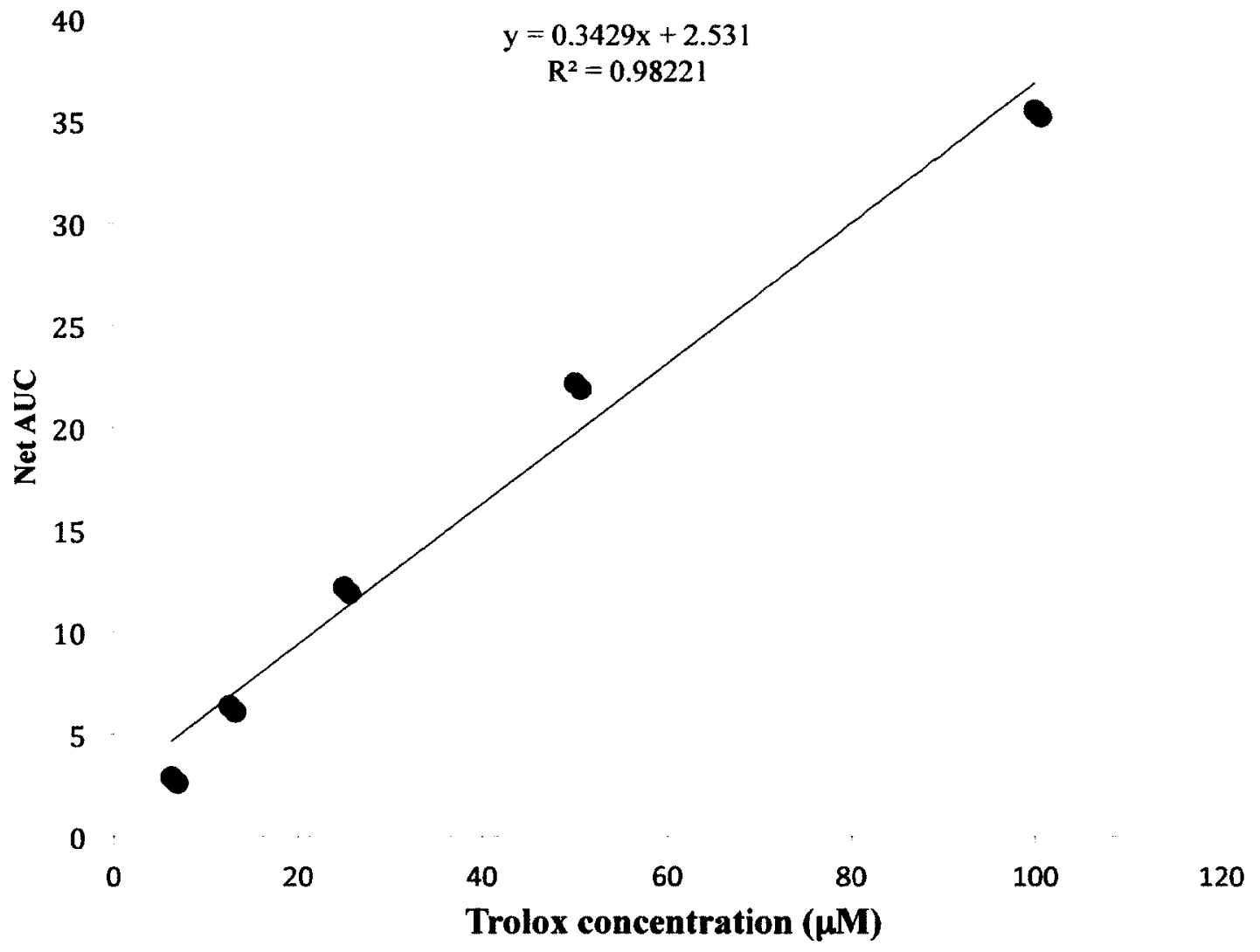

Figure 2- 2: Standard curve of concentration $(\mu \mathrm{M})$ versus antioxidant activity $(\mu \mathrm{mol})$ for Trolox standard. 


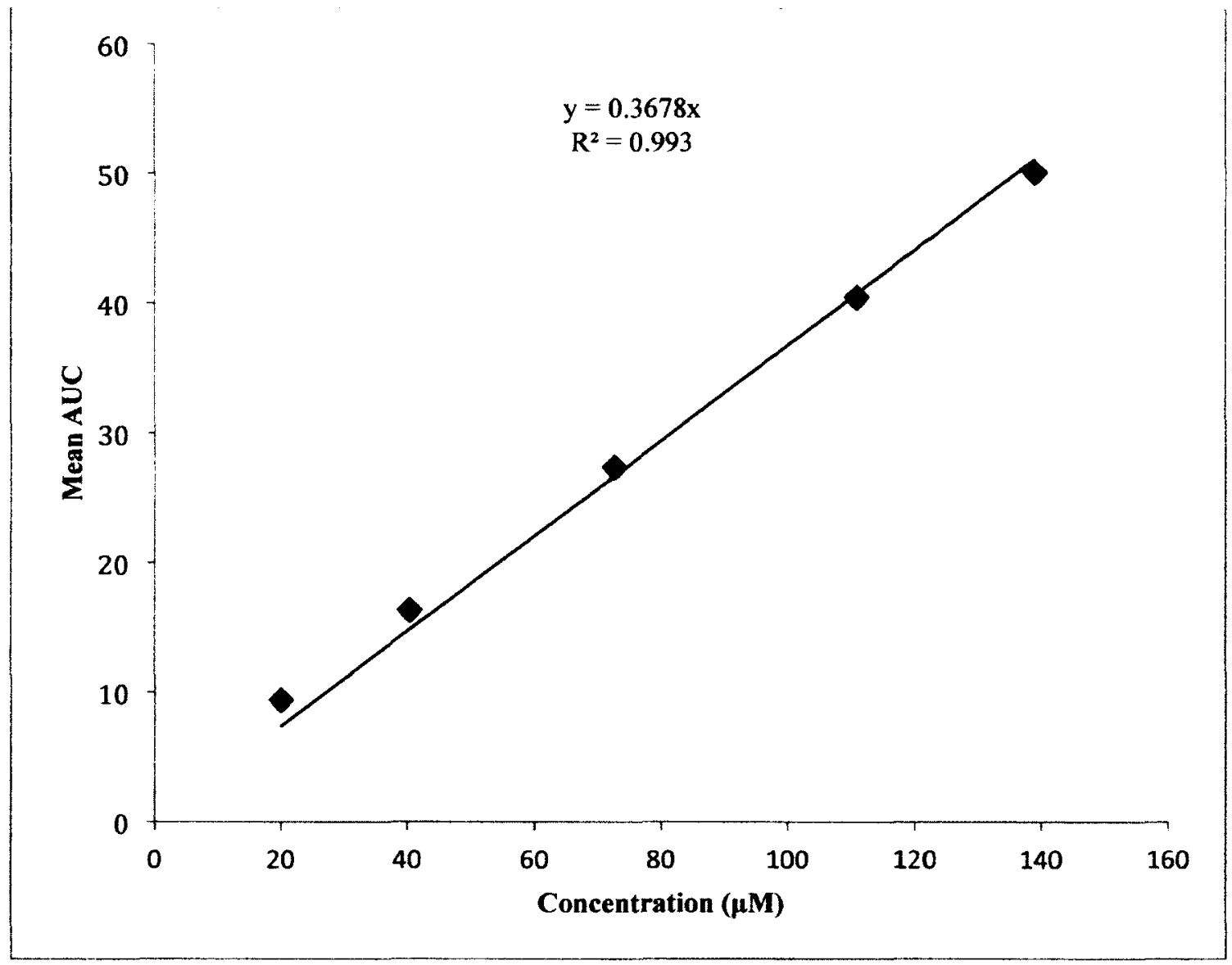

Figure 2- 3: Mean net area under the curve associated with various concentrations of crude water extractable (CM) materials from seabuckthorn. 


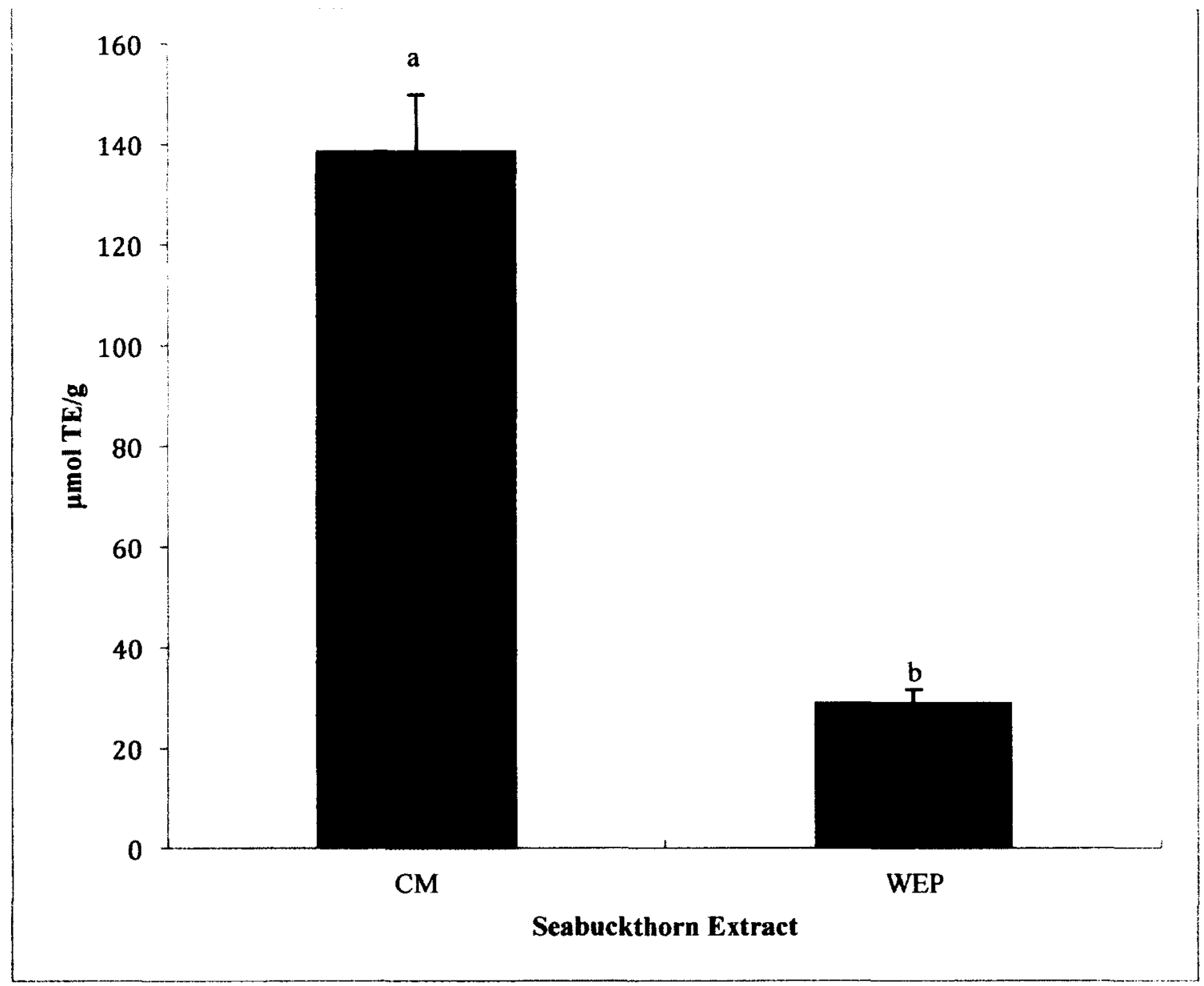

Figure 2- 4: ORAC values of water-extractable crude materials (CM) and polysaccharide materials (WEP) of seabuckthorn with a 1:1 dilution. Alphabetic superscripts represent values that are significantly different $(\mathbf{P} \leq \mathbf{0 . 0 5})$. Values represent average of three readings $(N=3)$. 


\subsubsection{DPPH}

DPPH scavenging activity assay was used as an additional method to confirm antioxidant trends of seabuckthorn extracts. DPPH is a widely used method to evaluate the free radical scavenging ability of various substrates (Lee, Hwang, Ha, Jeong, \& Kim, 2003). The kinetic curve in Figure 2-5 represents the scavenging activity of $\mathrm{CM}$ and WEP. After 20 minutes, seabuckthorn CM clearly showed higher antioxidant activity $(\mathrm{P} \leq 0.05)$ than WEP for the duration of 60 minute testing time. Confirming the results found from ORAC, CM was found to have higher antioxidant activity than WEP. After 60 minutes seabuckthorn CM showed $37 \%$ DPPH scavenging activity, while WEP showed $12 \%$ (Figure 2-5).

These results are comparable with the literature that found DPPH scavenging activity after 60 minutes was $29.97 \%$ for seabuckthorn without stone (W. Li, et al., 2009). The antioxidant activity of this berry may be attributed to the high content of flavonoids (mainly isorhamnetin, quercetin glycosides, and kaempferol), which can be found in the amount of 100-1000 mg/100 $\mathrm{g}$ fruit (Uruakpa, et al., 2012). 


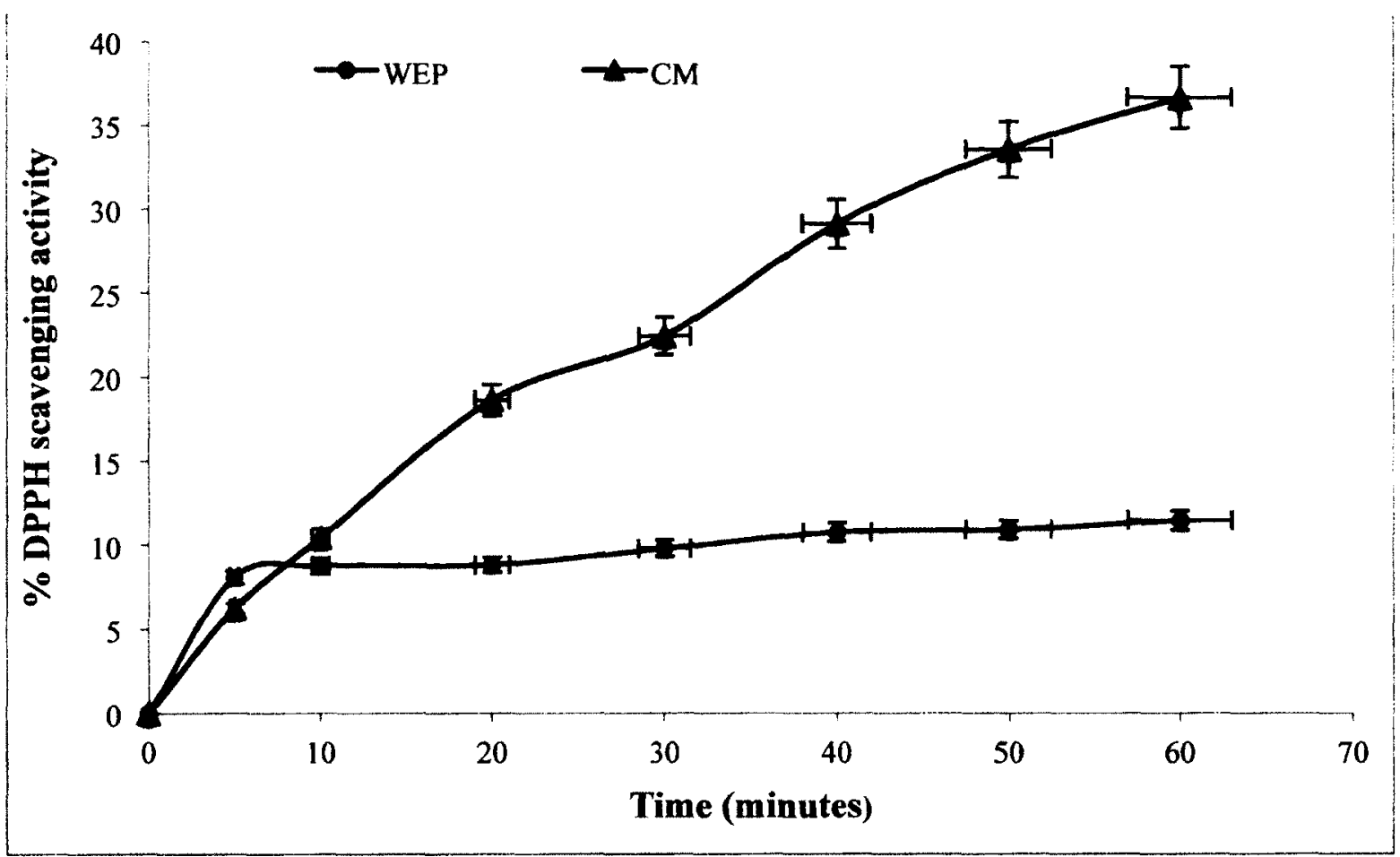

Figure 2- 5: DPPH free radical antioxidant scavenging activity of seabuckthorn water-extractable crude materials $(\mathrm{CM})$ and water-extractable polysaccharides (WEP). Values represent average of three readings $(\mathrm{N}=3)$.

\section{5. Conclusion}

After 21-days of storage period all yogurt treatments with seabuckthorn exhibited higher counts of viable microorganisms, which had not been previously reported in the literature. Seabuckthorn yogurts all exhibited decreased $\mathrm{pH}$ levels and increased TTA values after 21 days of cold storage. Additionally, CM from seabuckthorn showed significant antioxidant activity, which could be attributed to the phenolic acids found in the fruit and that WEP may contain phenolic groups attached to polysaccharides. This study is novel in the field, because seabuckthorn has never been studied in a yogurt medium. The results from this study are promising, because seabuckthorn can potentially be a valuable addition in fermented dairy products, due to the promotion of probiotic 
bacteria. In addition, the antioxidant activity of the fruit makes it a multifunctional fruit. Future studies would include animal models and human clinical trials to determine the reputable health-related properties of seabuckthorn and additionally its use in yogurt. 
Chapter 3- Potential of Water Extractable Materials from Seabuckthorn as a Prebiotic in Yogurt 


\subsection{Abstract}

The objectives of this study was to: i) define the optimum concentration of seabuckthorn water-extractable polysaccharide (SP) that can be incorporated in yogurt, ii) evaluate the effects of seabuckthorn whole fruit (S) and SP on different probiotic bacteria, $\mathrm{pH}$, and total titratable acidity (TTA) in yogurt during 28 days of cold storage. A concentration of $2 \%$ SP in yogurt was found to be the optimal amount that could be added to yogurt without causing synersis. Pasteurized whole milk (3.25\%) was divided into three different batches: whole crushed S (2\%), SP (2\%), and the control without fruit. The three batches were inoculated with yogurt starter cultures Streptococcus thermophilus and Lactobacillus bulgaricus and divided into four groups according to probiotic addition. Lactobacillus acidophilus (B-4495; USDA) and Bifidobacterium lactis (41405; USDA) were used as the probiotics and counts of viable microorganisms were measured on days $1,7,14,21$ and 28 of cold storage. After 21 days of cold storage, S and SP both maintained higher viable bacteria counts in both $L$. acidophilus and $B$. lactis, in comparison to the controls $(\mathrm{P} \leq 0.05)$. Confirming this data was the lower $\mathrm{pH}$ levels and higher TTA values of both S and SP samples. Interestingly, SP favoured an increase in L. acidophilus when grown with only starter cultures, while B. lactis showed more favourable growth $(\mathrm{P} \leq 0.05)$ in the presence of starter cultures and an additional probiotic after 4 weeks of cold storage. Results of this study suggest seabuckthorn may serve as a new prebiotic source for functional foods and nutraceutical applications.

\subsection{Introduction}

Seabuckthorn has high carotenoid content, which accounts for $300-870 \mathrm{mg} / 100 \mathrm{~g}$ pulp oil and $30-250 \mathrm{mg} / 100 \mathrm{~g}$ in the seed oil (Zeb, 2004b). Total contents of tocopherols 
and tocotrienols in the seed oil and whole berry oil is typically $0.1-0.3 \%$ (B. Yang \& Kallio, 2002), while total sterol content range in the area of $720 \mathrm{mg} / 100 \mathrm{~g}$ of pulp oil and $1090 \mathrm{mg} / 100 \mathrm{~g}$ of seed oil (Zeb, 2004b) making seabuckthorn a rich source for both aqueous and lipophilic antioxidants (Zeb, 2004b). The fruit is unique, because of the high content of unsaturated fatty acids that are found in the seed oil and the pulp oil $(87 \%$ and $67 \%$, respectively).

In the previous chapter, it was found that seabuckthorn had a positive effect on the growth of total bacteria (probiotic and starter cultures). However the question that still remains is which microorganisms in particular were impacted by seabuckthorn and to what degree. Thus the objectives of this study were: i) determine the optimum concentration of seabuckthorn water-extractable polysaccharide (SP) that can be incorporated in yogurt, ii) evaluate the effects of seabuckthorn whole fruit (S) and SP on different probiotic bacteria, $\mathrm{pH}$, and total titratable acidity (TTA) in yogurt during 28 days of cold storage. The findings of the following study would help to establish whether seabuckthorn has the potential to serve as a new prebiotic source for functional food and nutraceutical applications.

\subsection{Material and Methods}

Seabuckthorn berries were kindly supplied by Horticulture Research Center (Laval University, Quebec) and frozen upon arrival at $-20^{\circ} \mathrm{C}$.

\subsubsection{Seabuckthorn whole berries}

Seabuckthorn whole berries (S) were prepared by defrosting at $4{ }^{\circ} \mathrm{C}$ for twentyfour hours, prior to homogenization in a food processor. The homogenized berries were added to their respective sterile conical tubes $(50 \mathrm{~mL})$. 


\subsubsection{Preparation of seabuckthorn water-extractable polysaccharides}

Extraction of seabuckthorn water-extractable polysaccharides (SP) was executed by dissolving $5 \mathrm{~g}$ in $50 \mathrm{~mL}$ distilled water in a quartz tube belonging to CEM STAR System 2 microwave digestion system (CEM Corporation, Matthews, NC, USA). Extraction was set to $90^{\circ} \mathrm{C}$ for 30 minutes, where extract was cooled to room temperature $\left(23^{\circ} \mathrm{C}\right)$. The cooled mixture was then centrifuged at $4000 \mathrm{rpm}$ for 20 minutes at room temperature. Following initial crude extractions, $20 \mu \mathrm{l}$ of $\alpha$-amylase solution and $20 \mu \mathrm{l}$ proteases from Bacillus lichenformisis (Type XII-A) was added to eliminate proteins and starch molecules. The mixture was stirred overnight at $37^{\circ} \mathrm{C}$, followed by centrifuging at $4000 \mathrm{rpm}$ for 20 minutes at room temperature. The precipitate of the mixture was discarded and the supernatant solution was poured into $30 \mathrm{~mL}$ dialysis tubes that possessed a molecular weight restriction of $\leq 3,500$ (Spectra/Porß Dialysis Membrane wet in $0.1 \%$ sodium azide). The tubes were placed in double deionized water for 48 hours with water changes every 4 hours. Extract solution was then stored at $-20^{\circ} \mathrm{C}$ until further analysis.

\subsubsection{Prebiotic Addition}

\subsubsection{Seabuckthorn whole fruit}

It was determined that $2 \%(1 \mathrm{~g} / 50 \mathrm{~mL})$ of homogenized $\mathrm{S}$ was to be added to treatments, because it was the highest concentration that could be added without resulting in synersis. Extract was added to $50 \mathrm{~mL}$ pasteurized milk and incubated at $42^{\circ} \mathrm{C}$. 


\subsubsection{Seabuckthorn polysaccharides}

The maximum amount of SP that could be added to yogurt treatments without resulting in synersis was $1 \mathrm{~mL}$. Preliminary testing with additions of $1 \mathrm{~mL}, 2 \mathrm{~mL}, 3 \mathrm{~mL}$, and $4 \mathrm{~mL}$ was added to approximately $50 \mathrm{~mL}$ of pasteurized milk along with starter cultures to determine if yogurt formation would proceed (Figure 3-1).

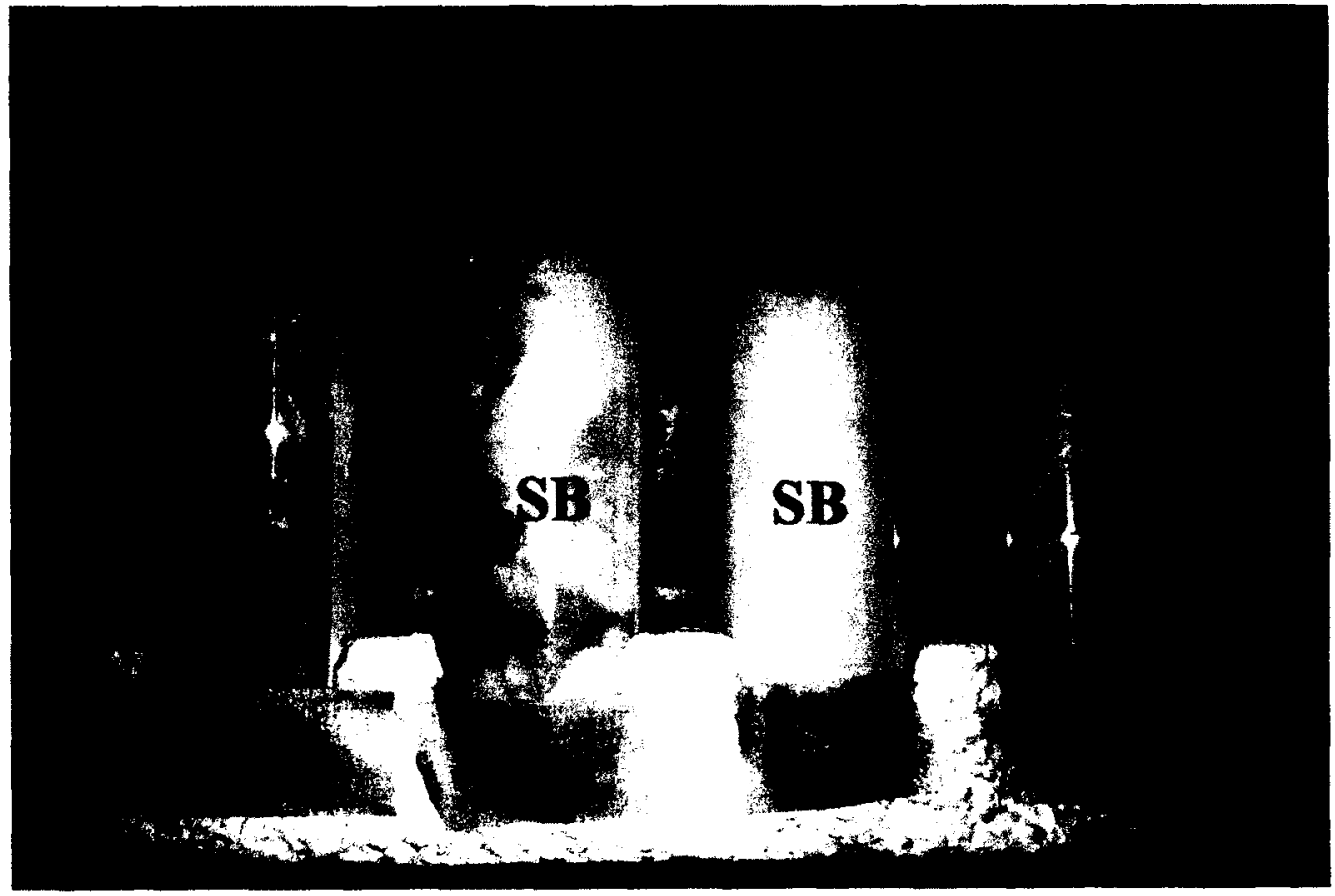

Figure 3- 1: Resultant yogurt products with varying concentrations of seabuckthorn polysaccharides.

\subsubsection{Microbial Analyses}

The analysis to monitor the effect of prebiotics on probiotic activity was performed, following the methods of Espirito Santo et al. (Espírito Santo, et al., 2010). 


\subsubsection{Propagation of Microbial Cultures}

Starter cultures used to prepare the yogurt were Lactobacillus delbrueckii subsp. bulgaricus (B-548; USDA) and Streptococcus salivarius subsp. thermophilus (14485; ATCC). Lyophilized probiotics used in the experimental were Lactobacillus acidophilus (B-4495; USDA) and Bifidobacterium lactis (41405; USDA). Each of the strains were grown in $10 \mathrm{~mL}$ sterile aliquots of MRS (Man Rogosa Sharpe) liquid media and incubated at $37^{\circ} \mathrm{C}$ for 48 hours. The activated cultures were used after three successive rinsing with sterilized distilled water for the preparation of the mother cultures to make yogurt. The cultures were diluted with sterilized milk $\left(121^{\circ} \mathrm{C}\right.$ for $15 \mathrm{~min}$. in an autoclave) to obtain a concentration of approximately $8 \log$ cell $/ \mathrm{mL}$. Once the dilutions were made, the treatments of yogurt were inoculated with $0.5 \mathrm{~mL}$ of each yogurt starter culture and $1.0 \mathrm{~mL}$ of required probiotic(s) as seen in Table 3-1.

\subsubsection{Milk Preparation}

Homogenized milk (3.25\%) was obtained from a local grocery store on the day of experimentation. Milk was first heated to $85^{\circ} \mathrm{C}$ for 15 minutes and then cooled to $42{ }^{\circ} \mathrm{C}$ in a water bath. Following cooling, $50 \mathrm{~mL}$ of whole milk was added to each of the thirtysix sterile conical tubes. Afterwards, tubes containing starter cultures of $0.5 \mathrm{~mL}$, probiotics of $1 \mathrm{~mL}$ and $\mathrm{S}$ or $\mathrm{SP}$ were vortexed to ensure distribution of all contents. Yogurts were all incubated at $42{ }^{\circ} \mathrm{C}$ until a pH of within the range of 6.2 and 4.9 was reached (Lundstedt \& Corbin Jr, 1983). 


\subsubsection{Experimental Design}

Twelve different yogurt treatments were prepared in triplicates; four treatments contained seabuckthorn whole berry (S), four treatments of seabuckthorn polysaccharides (SP) and four treatments that served as controls, which did not contain any fruit. The probiotics were added to the designated tubes as shown in Table 3-1. Initial pH levels were taken after inoculation and mixing using a Denver Instrument UB-5 Ultrabasic pH meter. Once fermented, the yogurts were stored at $4^{\circ} \mathrm{C}$.

Table 3- 1: Experimental design evaluating the effect of seabuckthorn whole fruit (S) and seabucthorn polysaccharide (SP) additon on probiotic viability in yogurt. Abbreviations: without seabuckthorn (-); with S or SP (+); S. thermophilus and $L$. bulgaricus (Y), Y+L. acidophilus (Probiotic 1) $(Y+1), Y+B$. lactis (Probiotic 2) $(Y+2), Y+$ Probiotic 1 and $2(Y+1+2)$.

\begin{tabular}{lcc}
\hline \multicolumn{1}{c}{ Microorganisms } & Fruit & $\begin{array}{c}\text { Sample } \\
\text { coding }\end{array}$ \\
\hline $\begin{array}{l}\text { Y: Streptococcus salivarius subsp.thermophilus }+ \\
\text { Lactobacillus delbrueckii subsp.bulgaricus }\end{array}$ & - & $\mathrm{Y}$ \\
Y + Lactobacillus acidophilus (Pro1) & & $\mathrm{Y}+1$ \\
Y + Bifidobacterium lactis (Pro2) & - & $\mathrm{Y}+2$ \\
Y + Pro1\&2 & - & $\mathrm{Y}+1+2$ \\
YS & - & $\mathrm{YS}$ \\
YS + Lactobacillus acidophilus (Pro1) & + & $\mathrm{YS}+1$ \\
YS + Bifidobacterium lactis (Pro2) & + & $\mathrm{YS}+2$ \\
YS + Pro 1 \& 2 & + & $\mathrm{YS}+1+2$ \\
YSP & + & $\mathrm{YSP}$ \\
YSP + Lactobacillus acidophilus (Pro1) & & $\mathrm{YSP}+1$ \\
YSP + Bifidobacterium lactis (Pro2) & + & YSP+2 \\
YSP + Pro 1 \& 2 & + & YSP+1+2 \\
\hline
\end{tabular}




\subsubsection{Microbiological Analyses}

Bacterial enumerations were performed on days 1, 7, 14, 21, and 28. Yogurt samples of $1 \mathrm{~mL}$ were diluted with $9 \mathrm{~mL}$ of sterile distilled water, which were serial diluted and then counted using the spread plate method on agar media in triplicates. For each treatment $S$. thermophilus colonies were enumerated on M17 agar under aerobic conditions for 24 hours at $37^{\circ} \mathrm{C}$ (Espírito Santo, et al., 2010) whereas L. bulgaricus was enumerated on MRS (pH 5.4) agar and grown under aerobic conditions for 72 hours at 42 ${ }^{\circ} \mathrm{C}$ (Goncalves, Freitas, Nero, \& Carvalho, 2009). Probiotic, L. acidophilus, was enumerated on T-MRS agar under aerobic conditions for 48 hours at $37^{\circ} \mathrm{C}(\mathrm{C} . \mathrm{G}$. Vinderola \& Reinheimer, 1999). T-MRS was made by replacing glucose, that is normally found in MRS media, with trehalose; a complex sugar, for selective growth of the microorganism (C. G. Vinderola, et al., 1999). B. lactis was enumerated on LP-MRS agar and incubated in anaerobic conditions using a BBL GasPak ${ }^{\mathrm{TM}}$ System (GasPak SystemOxoid, Basingstoke, Hampshire, England) for 72 hours at $42{ }^{\circ} \mathrm{C}$ (C. G. Vinderola, et al., 1999). LP-MRS media was made by substituting glucose with lithium chloride-sodium propionate, because it has been shown in previous studies to be selective for the growth of B. lactis (C. G. Vinderola, et al., 1999). Colonies were enumerated and translated to the log of colony forming units per microliter of sample using the following equation:

$$
\log \frac{\mathrm{CFU}}{\mathrm{mL}}=\frac{1000 \mu \mathrm{L} \times \mathrm{CFU} / \text { plate }}{10 \mu \mathrm{L}} \times \text { dilution factor }
$$

The units were expressed as $\log \mathrm{cfu} \mathrm{mL}^{-1}$ of fermented milk.

\subsubsection{Post-Acidification (pH) and Titratable Acidity (TTA)}

Post-acidification of the yogurt treatments was determined on days $1,7,14,21$, and 28 using a Denver Instruments UB-5 Ultrabasic pH meter. Results of the $\mathrm{pH}$ readings 
were expressed as the means of three replications. TTA was determined by titrating a mixture of $1 \mathrm{~mL}$ yogurt sample and $9 \mathrm{~mL}$ sterile distilled water (1:9) with $0.1 \mathrm{~N} \mathrm{NaOH}$ using a $0.1 \%$ phenolphetalein colour indicator, where results were expressed as the means of three replications.

\subsubsection{Statistical analyses}

Results were analyzed by Statistical Analysis System SAS $\left(9^{\text {th }}\right.$ Version, SAS Institute Inc., Cary, NC). ANOVA was used to determine values with statistically significant differences $(\mathrm{P} \leq 0.05)$ between the twelve treatments for each day. The mean values were compared using Duncan's Multiple Range test with $\alpha=\leq 0.05$. Alphabetic letters were used to indicate values that were statistically different amongst the treatments. Letters that are different were considered statistically significant $(\mathrm{P} \leq 0.05)$ and letters that were the same were considered not statistically significant $(\mathrm{P}>0.05)$. To investigate, the effect of days on the four different treatments as well as their interaction, two-way ANOVA (independent variables were treatment and days) was used where mean values were compared using Duncan's Multiple Range test with $\alpha=\leq 0.05$.

\section{4 Results and Discussion}

\subsection{1 pH and TTA}

On day $1, \mathrm{pH}$ varied from 6.1 to 6.56 amongst the treatments. The seabuckthorn whole fruit (S) and seabuckthorn polysaccharide (SP) yogurts did not show a significant difference in $\mathrm{pH}(\mathrm{P}>0.05)$ in relation to the corresponding controls without the extracts

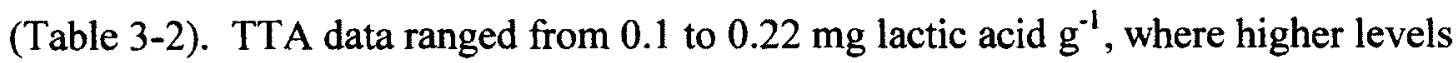
were observed on day 1 in S yogurts; YS, YS+1, and YS +2 and in all SP yogurts 
compared to the respective controls $(\mathrm{Y}, \mathrm{Y}+1, \mathrm{Y}+2, \mathrm{Y}+1+2)$ (Table 3-3). TTA data showed no significant differences between $\mathrm{S}$ and SP yogurts, except for $\mathrm{YS}+1+2$, containing both probiotics, which showed lower levels $(\mathrm{P} \leq 0.05)$ in relation to $\mathrm{YSP}+1+2$ in Table 3-3.

On day 7 of testing, $\mathrm{S}$ yogurts (YS, YS $+1, \mathrm{YS}+2$, and $\mathrm{YS}+1+2$ ) showed no difference $(\mathrm{P}>0.05)$ in $\mathrm{pH}$ compared to the respective controls $(\mathrm{Y}, \mathrm{Y}+1, \mathrm{Y}+2, \mathrm{Y}+1+2)$ without fruit (Table 3-2). The $\mathrm{pH}$ of SP yogurts: YSP, YSP+2, and YSP+1+2 were lower $(\mathrm{P} \leq 0.05)$ than those of the controls $(\mathrm{Y}, \mathrm{Y}+2$, and $\mathrm{Y}+1+2)$ with the exception of $\mathrm{YSP}+1$. TTA was significantly higher $(\mathrm{P} \leq 0.05)$ in the yogurts containing SP (YSP, YSP +1 , $\mathrm{YSP}+2$, and $\mathrm{YSP}+1+2$ ) when compared to the controls without extracts and the yogurts containing S (Table 3-3). From the $\mathrm{S}$ yogurts, only treatment $\mathrm{YS}+2$ containing $B$. lactis had higher $(\mathrm{P} \leq 0.05)$ TTA in comparison to the control yogurt $\mathrm{Y}+2$ (Table 3-3).

After 14 days of cold storage all S and SP yogurt treatments exhibited significantly lower $\mathrm{pH}(\mathrm{P} \leq 0.05)$ in comparison to the controls (Table 3-2). In addition, SP yogurts $\mathrm{YSP}+1, \mathrm{YSP}+2$, and $\mathrm{YSP}+1+2$ showed significantly lower $\mathrm{pH}$ than $\mathrm{S}$ yogurt treatments (YS+1, YS+2, and YS+1+2) (Table 3-2). Similarly, TTA data showed that all $\mathrm{S}(\mathrm{YS}, \mathrm{YS}+1, \mathrm{YS}+2$, and $\mathrm{YS}+1+2)$ and SP yogurt treatments (YSP, YSP+1, YSP+2, and $\mathrm{YSP}+1+2)$ showed higher levels of TTA $(\mathrm{P} \leq 0.05)$ in comparison to their respective controls (Table 3-3).

On day 21 of cold storage, $\mathrm{pH}$ ranged from 6.3 to 5.29 amongst the different treatments (Table 3-2). It was observed that all S and SP yogurt treatments had significantly lower $\mathrm{pH}(\mathrm{P} \leq 0.05)$ compared to their respective controls (Table 3-2). When 
comparing S yogurt treatments to those of SP there were no significant differences between treatments $(\mathrm{P}>0.05)$. In addition, only $\mathrm{S}$ yogurt treatments (YS, $\mathrm{YS}+1, \mathrm{YS}+2$, and $\mathrm{YS}+1+2)$ had higher levels $(\mathrm{P} \leq 0.05)$ of $\mathrm{TTA}$ in comparison to their respective controls $(\mathrm{Y}, \mathrm{Y}+1, \mathrm{Y}+2$, and $\mathrm{Y}+1+2)$, however SP treatments (YSP, YSP+1, $\mathrm{YSP}+2$, and $\mathrm{YSP}+1+2)$ showed no significant differences when compared to their controls $(\mathrm{P}>0.05)$ (Table 3-3).

After 28 days of cold storage all $\mathrm{S}(\mathrm{YS}, \mathrm{YS}+1, \mathrm{YS}+2$, and $\mathrm{YS}+1+2)$ and $\mathrm{SP}$ treatments (YSP, YSP+1, YSP+2, and YSP+1+2) exhibited significantly lower $\mathrm{pH}$ $(\mathrm{P} \leq 0.05)$ in comparison to the respective controls (Table 3-2). In addition, there were no significant differences $(\mathrm{P}>0.05)$ observed between treatments: $\mathrm{S}$ and $\mathrm{SP} p \mathrm{pH}$ readings (Table 3-2). All S treatments had higher TTA levels in comparison to the respective controls and to their equivalent SP treatments $(\mathrm{P} \leq 0.05)$ (Table 3-3). Also, SP treatments ( $\mathrm{YSP}, \mathrm{YSP}+1, \mathrm{YSP}+2$, and $\mathrm{YSP}+1+2)$ showed higher levels of TTA $(\mathrm{P} \leq 0.05)$ in comparison to the respective controls (YS, YS+1, YS+2, and YS+1+2) (Table 3-3).

Fermentation was allowed to reach a range between 6.2 and 4.9 following a U.S. patent for preparing cultured dairy products (Lundstedt, et al., 1983). In the literature a $\mathrm{pH}$ of approximately six was recommended as the most active form of the enzyme $\beta$ galactosidase ( $\beta$-gal), found in the bacteria S. thermophilus and L. bulgaricus, which is responsible for digesting lactose in yogurt (Martini, Kukielka, \& Savaiano, 1991). During the yogurt making process this enzyme helps break down the lactose in milk, which makes it easier for lactase-deficient people to consume yogurt.

After 28 days of cold storage all yogurts containing S and SP samples exhibited 
lower $\mathrm{pH}$ compared to the control (Table 3-2), which coincided with the TTA results (Table 3-3). By this time $\mathrm{S}$ and $\mathrm{SP}$ treatments showed a pH drop of $\sim 1.2$ and 1.5 respectively, while those of the controls only dropped $\sim 0.4$ units from day 1 readings. Suggesting that in the presence of seabuckthorn extracts, bacteria are potentially more active, thus producing more lactic acid and consequently decreasing $\mathrm{pH}$ (Table 3-2). Only $2 \%$ of seabuckthorn extracts were added, therefore the acidity of the whole fruit would have little effect on the $\mathrm{pH}$ of the yogurt.

The TTA test was used to identify and quantify the amount of lactic acid present in the yogurt samples. Lactic acid was targeted, because it is the most prevalent acid produced by probiotic bacteria, while other acids such as butyric and propionic acids are produced in lesser amounts (Agil, et al., 2012). It was observed that all yogurt treatments showed a general trend of increasing TTA levels (\% lactic acid) as seen in Table 3-3 indicating an increasing amount of bacteria activity, thus a result of growing number of bacteria (Agil, et al., 2012). After 28 days of cold storage, the TTA readings for both S and SP were significantly higher than the respective controls $(\mathrm{P} \leq 0.05)$. Suggesting, that in the presence of seabuckthorn samples, bacteria produce more lactic acid, which confirm the $\mathrm{pH}$ results. Other studies have reported similar findings of increased probiotic viability in yogurts with increased TTA levels and corresponding lower $\mathrm{pH}$ levels (Agil, et al., 2012; Espírito Santo, et al., 2010). 
Table 3- 2: $\mathrm{pH}$ values in yogurts without $(\mathrm{Y}, \mathrm{Y}+1, \mathrm{Y}+2$, and $\mathrm{Y}+1+2)$, with $(Y S, Y S+1$, $Y S+2$, and $Y S+1+2)$ seabuckthorn whole fruit, and seabuckthorn polysaccharides (YSP, YSP+1, YSP+2, and YSP+1+2). Means with different letters are significantly $(\mathrm{P} \leq \mathbf{0 . 0 5})$ different with means $(\mathrm{N}=3)$.

\begin{tabular}{clllll}
\hline Treatments & \multicolumn{5}{c}{$\mathbf{p H}$} \\
\cline { 2 - 6 } & $\mathbf{D 1}$ & $\mathbf{D}$ & $\mathbf{D 1 4}$ & $\mathbf{D 2 1}$ & $\mathbf{D 2 8}$ \\
$\mathrm{Y}$ & $6.56 \mathrm{a}$ & $6.47 \mathrm{a}$ & $6.4 \mathrm{a}$ & $6.3 \mathrm{a}$ & $6.04 \mathrm{a}$ \\
$\mathrm{Y}+1$ & $6.1 \mathrm{a}$ & $6.02 \mathrm{bcde}$ & $6.3 \mathrm{ab}$ & $5.9 \mathrm{~b}$ & $5.7 \mathrm{~b}$ \\
$\mathrm{Y}+2$ & $6.43 \mathrm{a}$ & $6.36 \mathrm{ab}$ & $6.16 \mathrm{~b}$ & $6.3 \mathrm{a}$ & $6.1 \mathrm{a}$ \\
& $6.50 \mathrm{a}$ & $6.47 \mathrm{a}$ & $6.23 \mathrm{~b}$ & $6.48 \mathrm{a}$ & $6.2 \mathrm{a}$ \\
$\mathrm{YS}$ & & & & & \\
$Y S+1$ & $6.35 \mathrm{a}$ & $6.11 \mathrm{abcd}$ & $5.73 \mathrm{de}$ & $5.43 \mathrm{c}$ & $5.13 \mathrm{c}$ \\
$\mathrm{YS}+2$ & $6.36 \mathrm{a}$ & $6.22 \mathrm{abc}$ & $5.86 \mathrm{~cd}$ & $5.36 \mathrm{c}$ & $5.11 \mathrm{c}$ \\
YS+1+2 & $6.3 \mathrm{a}$ & $6.10 \mathrm{abcd}$ & $5.73 \mathrm{de}$ & $5.29 \mathrm{c}$ & $5.01 \mathrm{c}$ \\
& & $6.28 \mathrm{abc}$ & $5.91 \mathrm{c}$ & $5.44 \mathrm{c}$ & $5.21 \mathrm{c}$ \\
YSP & $6.51 \mathrm{a}$ & $5.72 \mathrm{de}$ & $5.65 \mathrm{ef}$ & $5.41 \mathrm{c}$ & $5.16 \mathrm{c}$ \\
YSP+1 & $6.48 \mathrm{a}$ & $5.89 \mathrm{cde}$ & $5.62 \mathrm{ef}$ & $5.29 \mathrm{c}$ & $5.2 \mathrm{c}$ \\
YSP+2 & $6.24 \mathrm{a}$ & $5.69 \mathrm{e}$ & $5.56 \mathrm{f}$ & $5.33 \mathrm{c}$ & $5.16 \mathrm{c}$ \\
YSP+1+2 & $6.41 \mathrm{a}$ & $5.75 \mathrm{de}$ & $5.59 \mathrm{ef}$ & $5.3 \mathrm{c}$ & $5.1 \mathrm{c}$ \\
\hline
\end{tabular}


Table 3- 3: Total titratable acidity (TTA) in yogurts without $(Y, Y+1, Y+2$, and $Y+1+2$ ), with (YS, YS+1, YS+2, and YS+1+2) seabuckthorn whole fruit, and seabuckthorn polysaccharides (YSP, YSP+1, YSP+2, and YSP+1+2). Means with different letters are significantly $(P \leq 0.05)$ different with means $(N=3)$.

\begin{tabular}{clllll}
\hline \multirow{2}{*}{ Treatments } & \multicolumn{5}{c}{ Titratable Acidity (\% lactic acid) } \\
\cline { 2 - 6 } & $\mathbf{D 1}$ & $\mathbf{D} 7$ & $\mathbf{D 1 4}$ & $\mathbf{D 2 1}$ & $\mathbf{D 2 8}$ \\
$\mathrm{Y}$ & $0.1 \mathrm{~b}$ & $0.17 \mathrm{~d}$ & $0.21 \mathrm{c}$ & $0.38 \mathrm{bc}$ & $0.39 \mathrm{~g}$ \\
$\mathrm{Y}+1$ & $0.11 \mathrm{~b}$ & $0.17 \mathrm{~d}$ & $0.22 \mathrm{c}$ & $0.37 \mathrm{bcd}$ & $0.38 \mathrm{~g}$ \\
$\mathrm{Y}+1+2$ & $0.13 \mathrm{~b}$ & $0.17 \mathrm{~d}$ & $0.24 \mathrm{c}$ & $0.37 \mathrm{bc}$ & $0.39 \mathrm{~g}$ \\
& $0.1 \mathrm{~b}$ & $0.16 \mathrm{~d}$ & $0.23 \mathrm{c}$ & $0.36 \mathrm{bcd}$ & $0.42 \mathrm{~g}$ \\
$\mathrm{YS}$ & & & & & \\
YS+1 & $0.21 \mathrm{a}$ & $0.21 \mathrm{~cd}$ & $0.33 \mathrm{~b}$ & $0.71 \mathrm{a}$ & $0.74 \mathrm{~b}$ \\
$\mathrm{YS}+2$ & $0.2 \mathrm{a}$ & $0.22 \mathrm{~cd}$ & $0.35 \mathrm{~b}$ & $0.68 \mathrm{a}$ & $0.87 \mathrm{a}$ \\
YS+1+2 & $0.22 \mathrm{a}$ & $0.24 \mathrm{bc}$ & $0.35 \mathrm{~b}$ & $0.65 \mathrm{a}$ & $0.71 \mathrm{bc}$ \\
& & $0.21 \mathrm{~cd}$ & $0.31 \mathrm{~b}$ & $0.63 \mathrm{a}$ & $0.69 \mathrm{~cd}$ \\
YSP & $0.18 \mathrm{a}$ & $0.26 \mathrm{bc}$ & $0.33 \mathrm{~b}$ & $0.4 \mathrm{~cd}$ & $0.57 \mathrm{de}$ \\
YSP+1 & $0.2 \mathrm{a}$ & $0.35 \mathrm{a}$ & $0.42 \mathrm{a}$ & $0.32 \mathrm{~d}$ & $0.53 \mathrm{ef}$ \\
YSP+2 & $0.2 \mathrm{a}$ & $0.3 \mathrm{ab}$ & $0.38 \mathrm{ab}$ & $0.36 \mathrm{bcd}$ & $0.53 \mathrm{ef}$ \\
YSP+1+2 & $0.21 \mathrm{a}$ & $0.33 \mathrm{a}$ & $0.35 \mathrm{~b}$ & $0.44 \mathrm{~b}$ & $0.51 \mathrm{f}$ \\
\hline
\end{tabular}

\subsubsection{Viable Microbial Enumeration}

\subsubsection{Starter Culture Enumerations- $S$. thermophilus}

Day 1 of cold storage, for viable counts of S. thermophilus, ranged from 7.18 to $8.16 \log$ cfu $\mathrm{mL}^{-1}$ amongst all the treatments. There were no significant differences $(\mathrm{P}>0.05)$ observed between SP yogurts YSP and S yogurts YS in comparison to their respective controls (Y), nor were there differences seen between S yogurts YS and SP yogurts YSP (Figure 3-2). Yogurts containing S and L. acidophilus (YS+1) showed significantly higher counts of $S$. thermophilus $(\mathrm{P} \leq 0.05)$ than its respective controls $(\mathrm{Y}+1)$ while there was no difference $(\mathrm{P}>0.05)$ in comparison to SP yogurts $(\mathrm{YSP}+1)$ (Figure 3- 
2). There were no significant differences in $S$. thermophilus counts $(\mathrm{P}>0.05)$ found between treatments $\mathrm{Y}+2, \mathrm{YS}+2$, and $\mathrm{YSP}+2$ containing B. lactis (Figure 3-2). Treatments containing both probiotics (YS $+1+2$ and $\mathrm{YSP}+1+2$ ) showed significantly higher counts of $S$. thermophilus $(\mathrm{P} \leq 0.05)$ compared to the respective control $(\mathrm{Y}+1+2)$. Additionally, there was no difference found between treatment YS $+1+2$ and $Y S P+1+2$ $(\mathrm{P}>0.05)$ (Figure 3-2).

On day 7 of cold storage, counts of S. thermophilus ranged from 7.49 to $8.73 \mathrm{log}$ cfu $\mathrm{mL}^{-1}$ amongst all the treatments. Counts in YSP were significantly higher $(\mathrm{P} \leq 0.05)$ than the control $(\mathrm{Y})$ and fruit yogurts (YS) (Fig 3-2). Yogurt treatment $\mathrm{Y}+1, \mathrm{YS}+1$, and YSP+1 showed no significant differences. SP treatment YSP+2 was observed to have higher counts than the control $\mathrm{Y}+2$, while $\mathrm{S}$ treatment $\mathrm{YS}+2$ showed no significant difference compared to the control $(\mathrm{Y}+2)$ and $\mathrm{SP}(\mathrm{YSP}+2)(\mathrm{P}>0.05)$. In the fourth treatment YSP $+1+2$ showed significantly higher $S$. thermophilus counts than the respective control $(\mathrm{Y}+1+2)$ (Figure 3-2).

After 14 days of cold storage $\mathrm{S}$ yogurt treatments $\mathrm{YS}, \mathrm{YS}+2$, and $\mathrm{YS}+1+2$ and $\mathrm{SP}$ yogurt treatments YSP, YSP $+1, \mathrm{YSP}+2$, and YSP+1+2 exhibited higher $S$. thermophilus counts $(\mathrm{P} \leq 0.05)$ than the respective controls $(\mathrm{Y}, \mathrm{Y}+1, \mathrm{Y}+2$, and $\mathrm{Y}+1+2)$ with the exceptions of YS+1 (Figure 3-2).

On day 21 all S treatments (YS, $Y+1, Y S+2$, and $Y S+1+2$ ) and SP treatments (YSP, YSP+1, YSP+2, and YSP+1+2) showed significantly higher counts of $S$. thermophilus $(\mathrm{P} \leq 0.05)$ with respect to the controls $(\mathrm{Y}, \mathrm{Y}+1, \mathrm{Y}+2$, and $\mathrm{Y}+1+2)$ (Figure 32). Additionally, there was no statistical difference between the $S$ yogurt treatments and 
SP treatments $(\mathrm{P}>0.05)$ (Figure 3-2).

After 28 days of cold storage S yogurt treatments YS and YS+1 and SP treatments YSP and YSP+1 showed no significant differences in $S$. thermophilus counts when compared to each other $(\mathrm{P}>0.05)$ and to the respective controls $(\mathrm{Y}$ and $\mathrm{Y}+1)$ (Figure 3-2). Treatment YS+2 and YSP+2 had significantly higher S. thermophilus counts $(\mathrm{P} \leq 0.05)$ than the respective controls $\mathrm{Y}+2$. There was no difference $(\mathrm{P}>0.05)$ between $\mathrm{S}$ and $\mathrm{SP}$ yogurt of this treatment. Finally, treatment $\mathrm{YS}+1+2$ and $\mathrm{YSP}+1+2$ showed significantly higher counts $(P \leq 0.05)$ than the controls $Y+1+2$. S yogurts of this treatment had the highest counts of $S$. thermophilus $(\mathrm{P} \leq 0.05)$ (Figure 3-2). Further analysis looking at the effect of days on treatments revealed that all control yogurt treatments were significantly lower than both the yogurts with seabuckthorn fruit and polysaccharide addition throughout the 28 days of cold storage (Table 3-4).

For 21 consecutive days of cold storage all S and SP yogurt treatments showed higher counts $(\mathrm{P} \leq 0.05)$ of viable $S$. thermophilus as seen in Figure 3-2. However, by day 28 only a few treatments of S and SP (YS $+2, Y S+1+2$ and YSP $+2, Y S P+1+2)$ were higher than the controls $(\mathrm{P} \leq 0.05)$. The third and fourth treatment both contained $\mathrm{B}$. lactis bacteria, which could suggest a possible correlation of increased S. thermophilus levels with increased B. lactis counts. In a previous study, with acai pulp yogurts, the counts of S. thermophilus showed a moderate positive correlation with B. lactis counts (Espírito Santo, et al., 2010).

On average, the survival rate of $S$. thermophilus was better compared to those of L. bulgaricus and that of the probiotic organisms, which match with observations found in the literature (Dave \& Shah, 1997). Traditional function of yogurt cultures such as $L$. 
bulgaricus and $S$. thermophilus is to ferment lactose to produce lactic acid in order to increase lactic acid content, consequently decreasing yogurt $\mathrm{pH}$ and forming yogurt. However, in the last ten years yogurt starter cultures have been identified to meet the current concept of probiotics for its beneficial effect on lactose digestion in vivo (Adolfsson, Meydani, \& Russell, 2004). These yogurt cultures are even suspected to induce other health benefits such as reduction in severity and duration of acute diarrhea or prevention of allergic disorders (Adolfsson, et al., 2004). Therefore, seabuckthorn whole fruit and polysaccharide addition may have the added benefit of increasing the growth of starter cultures, which may further benefit the host. 

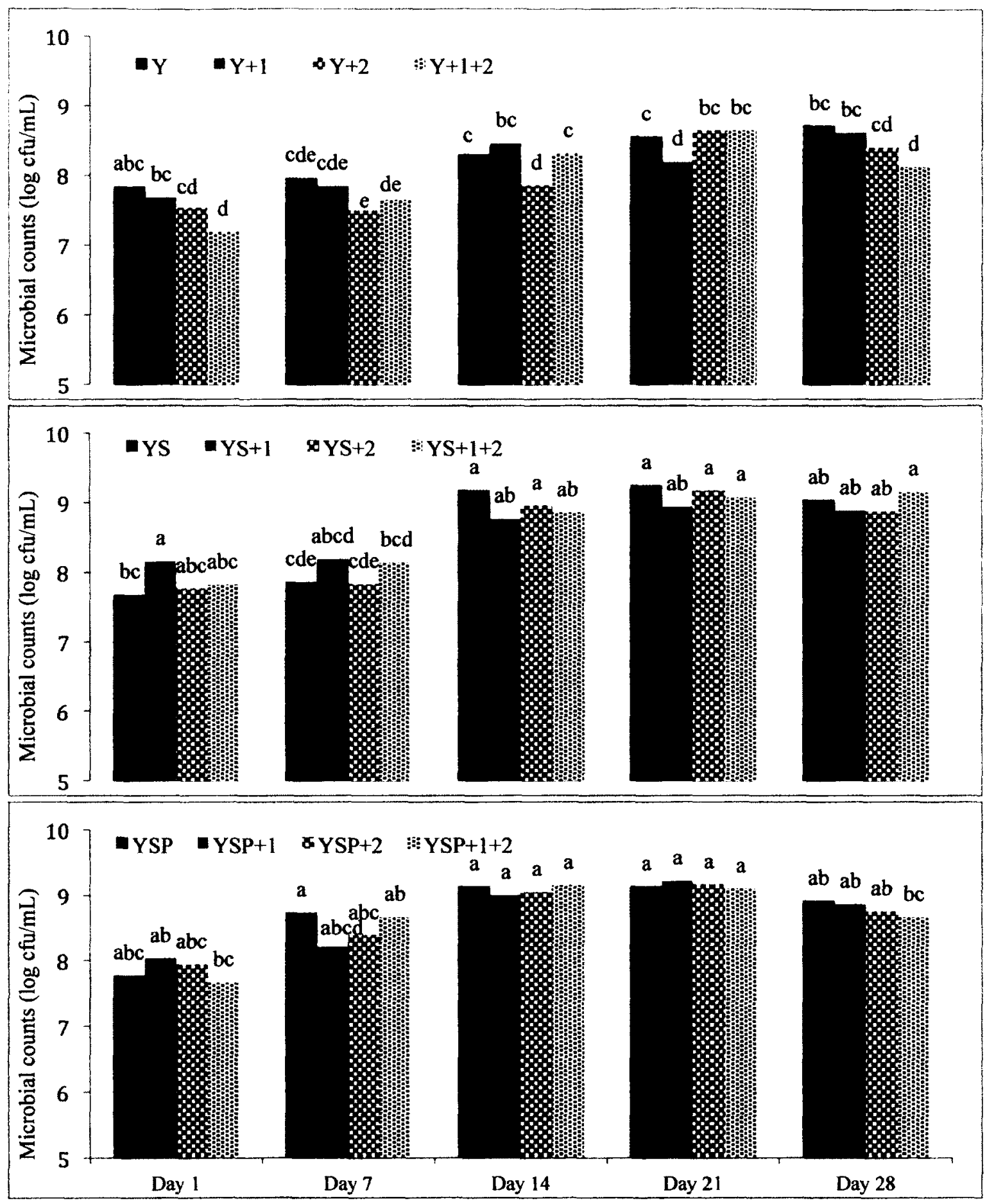

Figure 3- 2: $S$. thermophilus counts in yogurt with S, SP, and without seabuckthorn samples on day $1,7,14,21$, and 28 respectively. Abbreviations are: yogurts with no probiotics (Y, YS, YSP), with L. acidophilus (Y+1, YS+1, YSP+1), with B. lactis $(Y+2, Y S+2, Y S P+2)$ and with both probiotics $(Y+1+2, Y S+1+2, Y S P+1+2)$. Means with different letters are significantly $(P \leq 0.05)$ different with means $(N=3)$. 
Table 3- 4: Two-way ANOVA analysis showing the effect of days on $S$. thermophilus counts in yogurt treatments.

\begin{tabular}{|l|c|c|c|c|}
\hline Source & DF & Mean Square & F value & Pr $>$ F \\
\hline Storage day & 4 & 9.23 & 156.97 & $<.0001$ \\
\hline Yogurt treatments & 11 & 1.15 & 19.48 & $<.0001$ \\
\hline $\begin{array}{l}\text { Yogurt treatment* } \\
\text { Storage day }\end{array}$ & 44 & 0.15 & 2.54 & $<.0001$ \\
\hline
\end{tabular}

$\mathrm{R}^{2}=0.89$

\subsubsection{Starter Culture Enumerations- $L$. bulgaricus}

L. bulgaricus counts ranged from 5.33 to $7.82 \log \mathrm{cfu} \mathrm{mL}^{-1}$ after one day of cold storage (Figure 3-3). Control yogurt treatments $(Y, Y+1, Y+2$, and $Y+1+2)$ all showed significantly lower $L$. bulgaricus counts $(\mathrm{P} \leq 0.05)$ compared to yogurts with $\mathrm{S}$ and $\mathrm{SP}$ in Figure 3-3.

On day $7, L$. bulgaricus counts in all $\mathrm{S}$ yogurt treatments were not significantly different $(\mathrm{P}>0.05)$ from their respective controls. Only, SP yogurt treatments YSP and $\mathrm{YSP}+1$, had higher counts of microorganisms $(\mathrm{P} \leq 0.05)$ in comparison to the controls $(\mathrm{Y}$ and $\mathrm{Y}+1$ ) (Figure 3-3)

After 14 days of cold storage, L. bulgaricus exhibited counts from 8.04 to $9.2 \mathrm{log}$ cfu $\mathrm{mL}^{-1}$, showing an overall increase in all yogurt treatments. No difference $(P>0.05)$ was observed between SP yogurt treatments YSP, YSP+1, YSP+2, and YSP $+1+2$ and the respective controls. Only, S treatment YS without probiotics showed significantly higher growth of $L$. bulgaricus $(\mathrm{P} \leq 0.05)$ in comparison to the control Y. In addition YS yogurt treatment had the highest $(P \leq 0.05)$ counts, with an increase of over $1 \log c f u \mathrm{~mL}^{-1}$, on day 14 in Figure 3-3. Analysis looking at the effect of days on treatments revealed that the highest microbial counts of $L$. bulgaricus were found on day 14 of cold storage (Table 
On day 21 of cold storage all S yogurt treatments (YS, YS $+1, Y S+2$, and $Y S+1+2)$ exhibited significantly higher growth of $L$. bulgaricus $(\mathrm{P} \leq 0.05)$ in comparison to the control yogurts $(\mathrm{Y}, \mathrm{Y}+1, \mathrm{Y}+2$, and $\mathrm{Y}+1+2)$ by more than $1 \log \mathrm{cfu} \mathrm{mL}^{-1}$, which had not been previously recorded in the literature. While, only SP yogurt treatment YSP+1, containing probiotic $L$. acidophilus, (2SP) showed higher counts $(\mathrm{P} \leq 0.05)$ in comparison to the control $(\mathrm{Y}+1)$. Interestingly, $\mathrm{SP}$ addition in the third treatment $\mathrm{YSP}+2$ resulted in significantly lower $L$. bulgaricus counts $(\mathrm{P} \leq 0.05)$ with respect to the control (Fig. 3).

After 28 days of cold storage seabuckthorn whole fruit addition no longer showed any effect on the growth of $L$. bulgaricus $(\mathrm{P}>0.05)$ in Figure 3-3. Interestingly, almost all SP yogurt treatments showed a lower growth $(\mathrm{P} \leq 0.05)$ in comparison to the controls. Suggesting that after 28 days of cold storage seabuckthorn polysaccharide addition may have a negative impact on starter culture L. bulgaricus.

At the end of the cold storage period, counts of viable $L$. bulgaricus microorganisms seemed to be negatively impacted $(\mathrm{P} \leq 0.05)$ by the presence of $\mathrm{SP}$, with the exception of $Y S P+1+2$, which showed no difference $(P>0.05)$ compared to the control in Figure 3-3. This observation may be explained by the fact that counts of $L$. bulgaricus increase initially followed by a sharp decline during the latter stages of a storage period (Dave, et al., 1997). In the present study, counts were initially low followed by maximum numbers at day 14 and slightly decreasing by day 28 (Figure 3-3). However, SP yogurts showed more decreasing counts that closely matched those of day 
1. This may be explained by $L$. bulgaricus requirement for simple sugars, such as sucrose and lactose for growth (C.G. Vinderola, Costa, Regenhardt, \& Reinheimer, 2002). Seabuckthorn polysaccharide extract contains more complex sugars, which may not have been easily digested by the starter culture. In addition, the presence of probiotics and $S$. thermophilus starter cultures in the various treatments and depletion of nutrients would be expected by the end of the cold storage period. Furthermore, in Figure 3-4 growth of all probiotics with the presence of S and SP flourished and in some cases grew more with SP presence. Therefore, increased microbial activity of the probiotics and lack of simple sugars in the SP extract may have negatively affected the viability of L. bulgaricus. Therefore, the addition of SP may indirectly aid probiotic viability by antagonizing the growth of $L$. bulgaricus. If this is indeed the case it would be an added benefit to SP addition as it has been recommended that $L$. bulgaricus be replaced or removed to improve survival of probiotic organisms, due to its production of hydrogen peroxide, which may affect probiotics (Vasiljevic, et al., 2008). 

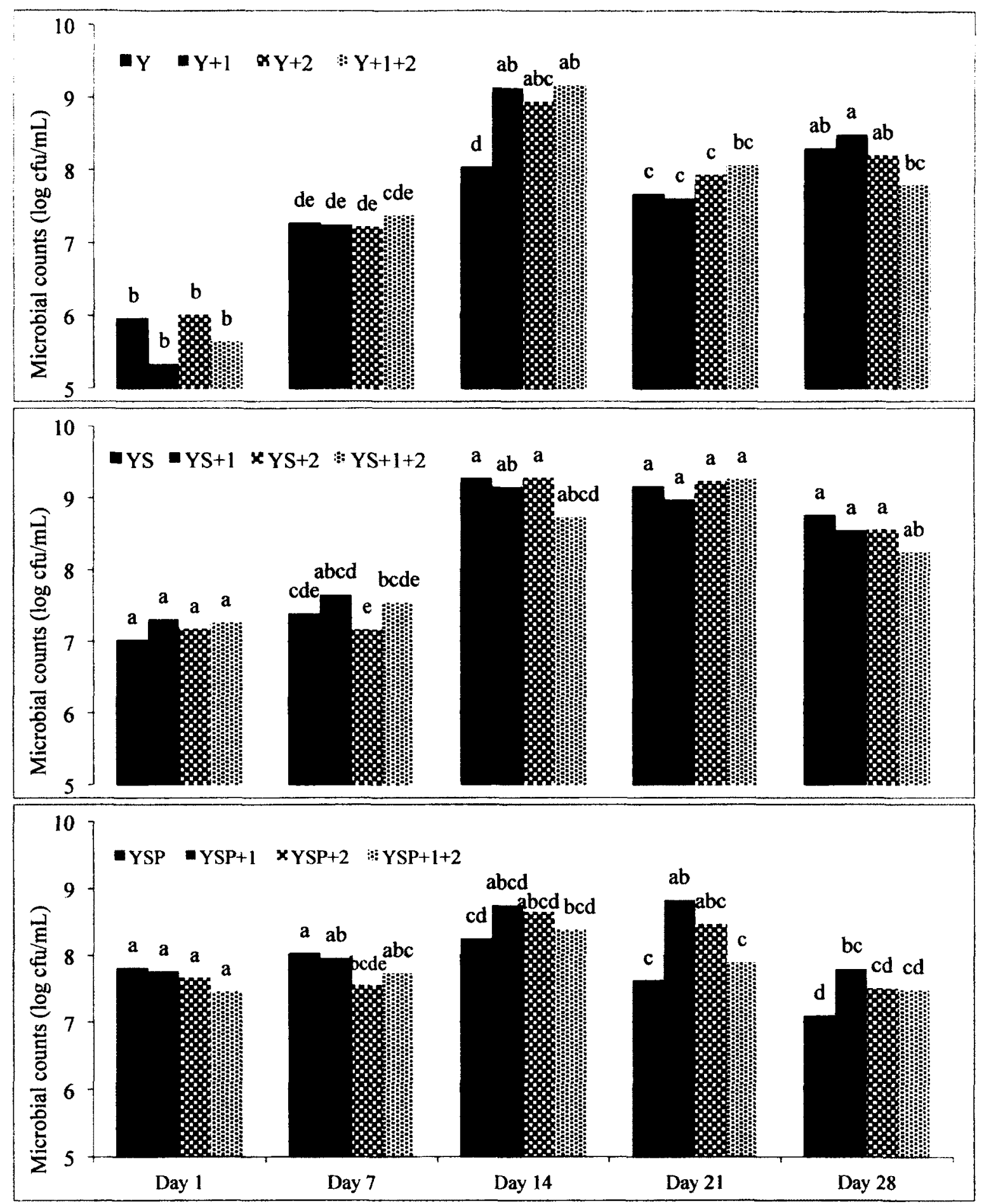

Figure 3- 3: Enumeration of $L$. bulgaricus in yogurt with seabuckthorn fruit (S), seabuckthorn polysaccharide (SP), and without extracts during shelf-life $(1,7,14$, 21 , and 28 respectively). Abbreviations are: yogurts with no probiotics (Y, YS, YSP), with $L$. acidophilus (Y+1, YS+1, YSP+1), with $B$. lactis $(Y+2, Y S+2, Y S P+2)$ and with both probiotics $(Y+1+2, Y S+1+2, Y S P+1+2)$. Means with different letters are significantly $(\mathrm{P}<0.05)$ different with means $(\mathrm{N}=3)$. 
Table 3- 5: Two-way ANOVA analysis showing the effect of days on $L$. bulgaricus counts in yogurt treatments.

\begin{tabular}{|l|c|c|c|c|}
\hline Source & DF & Mean Square & F value & Pr $>$ F \\
\hline Storage day & 4 & 20.95 & 127.38 & $<.0001$ \\
\hline Yogurt treatments & 11 & 1.59 & 9.69 & $<.0001$ \\
\hline $\begin{array}{l}\text { Yogurt treatment* } \\
\text { Storage day }\end{array}$ & 44 & 0.92 & 5.56 & $<.0001$ \\
\hline
\end{tabular}

$\mathrm{R}^{2}=0.88$

\subsubsection{Probiotic Enumerations}

Probiotic counts for control, S, and SP yogurt treatments are shown in Figure 34A and 4B over 28 days of cold storage. Probiotic L. acidophilus was present in the second treatment $(\mathrm{Y}+1, \mathrm{YS}+1$, and $\mathrm{YSP}+1)$ and $\mathrm{B}$. lactis in the third $(\mathrm{Y}+2, \mathrm{YS}+2$, and YSP+2). A fourth treatment contained both probiotics L. acidophilus and B. lactis $(\mathrm{Y}+1+2, \mathrm{YS}+1+2$, and $\mathrm{YSP}+1+2)$ to observe if there were any synergistic affects between the probiotics.

On day 1 , the presence of $\mathrm{S}$ and $\mathrm{SP}$ resulted in more growth $(\mathrm{P} \leq 0.05)$ of $\mathrm{L}$. acidophilus in yogurts $\mathrm{YS}+1$ and $\mathrm{YSP}+1$ as well as in treatment $\mathrm{YS}+1+2$ and $\mathrm{YSP}+1+2$ as seen in Figure 3-4A. There was no significant difference $(\mathrm{P}>0.05)$ of viable $\mathrm{L}$. acidophilus counts between treatments two and four. For the second probiotic, after 1 day of cold storage, the presence of SP increased $(P \leq 0.05)$ the growth of $B$. lactis in treatment third and fourth treatment (YSP+2 and YSP+2 respectively) in comparison to the controls $\mathrm{Y}+2$ and $\mathrm{Y}+1+2$ as seen in Figure 3-4B. While, only $\mathrm{S}$ treatment $\mathrm{YS}+1+2$ showed higher counts $(\mathrm{P} \leq 0.05)$ of $\mathrm{B}$. lactis. In addition, it was observed that there was no significant difference $(\mathrm{P}>0.05)$ between the third and fourth treatment in regards to $\mathrm{B}$. lactis viability (Figure 3-4B). 
On day 7 , the presence of $\mathrm{S}$ and $\mathrm{SP}$ revealed significantly higher $(\mathrm{P} \leq 0.05)$ growth of L. acidophilus in yogurts $\mathrm{YS}+1$ and $\mathrm{YSP}+1$ as well as in the fourth treatment $\mathrm{YS}+1+2$ and YSP $+1+2$ containing both probiotics (Figure 3-4A). In addition, L. acidophilus counts were significantly higher $(\mathrm{P} \leq 0.05)$ in yogurts $\mathrm{YSP}+1+2$ when compared to treatment YSP+1. On day 7 counts of $B$. lactis were significantly higher $(P \leq 0.05)$ in $S$ and SP in the third treatment $\mathrm{YS}+2$ and $\mathrm{YSP}+2$ as well as in treatment $\mathrm{YS}+1+2$ and $\mathrm{YSP}+1+2$ in comparison to the controls $\mathrm{Y}+2$ and $\mathrm{Y}+1+2$ (Figure $3-4 \mathrm{~B}$ ). In addition, there seemed to be no significant difference $(\mathrm{P}>0.05)$ in the number of viable $\mathrm{B}$. lactis counts in the treatment with one probiotic compared to the treatment with two probiotics (Figure 3-4B).

On day 14, the counts of L. acidophilus in the second treatment were significantly higher $(\mathrm{P} \leq 0.05)$ in yogurts $\mathrm{YS}+1$ and $\mathrm{YSP}+1$ as well as in the fourth treatment $\mathrm{YS}+1+2$ and $\mathrm{YSP}+1+2$ containing both probiotics in comparison to the respective controls $\mathrm{Y}+1$ and $\mathrm{Y}+1+2$ as seen in Figure 3-4A. In addition, SP treatment yogurts $\mathrm{YSP}+1$ and $Y S P+1+2$ contained the highest amount $(\mathrm{P} \leq 0.05)$ of viable L. acidophilus: 9.1 log cfu $\mathrm{mL}^{-1}$ in $\mathrm{YSP}+1$ and $9.0 \log \mathrm{cfu} \mathrm{mL} \mathrm{m}^{-1}$ in $\mathrm{YSP}+1+2$ (Figure 3-4A). There was no difference $(\mathrm{P}>0.05)$ in L. acidophilus counts between yogurts from the second and fourth treatments. After 14 days of cold storage, counts of B. lactis in S treatments YS+2; $\mathrm{YS}+1+2$ and SP treatments $\mathrm{YSP}+2$; YSP $+1+2$ were significantly higher $(\mathrm{P} \leq 0.05)$ in comparison to the controls $\mathrm{Y}+2$ and $\mathrm{Y}+1+2$ (Fig 3-4B). No significant difference $(\mathrm{P}>0.05)$ was observed in the number of viable $\mathrm{B}$. lactis between the third and fourth treatments (Fig 3-4B).

After 21 days of cold storage, the presence of S and SP maintained a positive 
influence on the growth of L. acidophilus. Yogurts of the second treatment YS+1 and $\mathrm{YSP}+1+2$ as well as yogurts of treatment four $\mathrm{YS}+1+2$ and $\mathrm{YSP}+1+2$ showed significantly higher growth of L. acidophilus $(\mathrm{P} \leq 0.05)$ in comparison to controls $\mathrm{Y}+1$ and $\mathrm{Y}+1+2$ (Figure 3-4A). For the third consecutive week, L. acidophilus counts were the highest $(\mathrm{P} \leq 0.05)$ in the second treatment and fourth treatments. On day $21, \mathrm{~S}$ yogurts $\mathrm{YS}+2$; $\mathrm{YS}+1+2$ and $\mathrm{SP}$ yogurts $\mathrm{YSP}+2 ; \mathrm{YSP}+1+2$ had higher $(\mathrm{P} \leq 0.05)$ growth of $\mathrm{B}$. lactis in comparison to the respective controls $(\mathrm{Y}+2$ and $\mathrm{Y}+1+2)$ (Figure 3-4B). Interestingly, the yogurts containing $\mathrm{SP}(\mathrm{YSP}+2$ and $\mathrm{YSP}+1+2)$ contained the highest amount $(\mathrm{P} \leq 0.05)$ of viable B. lactis: $8.9 \log \mathrm{cfu} \mathrm{mL}^{-1}$ in the third treatment and $9.2 \log$ cfu $\mathrm{mL}^{-1}$ in the fourth treatment, which paralleled results observed of L. acidophilus (Figure 3-4A and 3-4B).

On day 28, only SP yogurts from the second treatment (YSP+1) exhibited higher counts $(\mathrm{P} \leq 0.05)$ of L. acidophilus in comparison to the control $\mathrm{Y}+1$ (Figure 3-4A). There was no marked difference in the number of viable L. acidophilus $(\mathrm{P}>0.05)$ in the yogurts of the fourth treatment as seen in Figure 3-4A. Interestingly, L. acidophilus counts of yogurts $\mathrm{YSP}+1$ were significantly higher $(\mathrm{P} \leq 0.05)$ in comparison to all the yogurts in the second and fourth treatment. After 28 days of cold storage, no differences $(\mathrm{P}>0.05)$ in $\mathrm{B}$. lactis counts between yogurts of the third treatment $(\mathrm{Y}+2, \mathrm{YS}+2$, and $\mathrm{YSP}+2)$ were observed. However, yogurts YSP $+1+2$, in the fourth treatment, showed significantly higher $(\mathrm{P} \leq 0.05)$ counts of $\mathrm{B}$. lactis (Figure 3-4B).

After 28 days of cold storage, the enumeration of L. acidophilus, in the second treatment was the highest $(\mathrm{P} \leq 0.05)$ in yogurts containing $\mathrm{SP}\left(8.9 \log \mathrm{cfu} \mathrm{mL} \mathrm{m}^{-1}\right)$ (Figure 34A). From days 7 and 28, the yogurts containing SP, in the second treatment, showed 
higher counts of $\mathrm{L}$. acidophilus than the yogurts supplemented with $\mathrm{S}(\mathrm{P} \leq 0.05)$. Between day 1 and $21, S$ yogurts in the second treatment, also exhibited a positive effect on the enumeration of L. acidophilus. The last enumeration on day 28 pointed to a lack of influence $(\mathrm{P}>0.05)$ of $\mathrm{S}$ upon L. acidophilus viability in the second treatment. In the fourth treatment the enumeration of L. acidophilus was higher $(\mathrm{P} \leq 0.05)$ in both $\mathrm{S}$ and $\mathrm{SP}$ yogurts for 21 consecutive days of cold storage. However, on the $28^{\text {th }}$ day of cold storage $\mathrm{S}$ and SP yogurts seemed to have no effect $(\mathrm{P}>0.05)$ on the growth of L. acidophilus in the fourth treatment. Based on two-way ANOVA analysis it was found that all control yogurt treatments containing $L$. acidophilus were significantly lower than both the yogurts with seabuckthorn fruit and polysaccharide addition throughout the 28 days of cold storage. Yogurts containing the polysaccharide extract exhibited the highest counts of L. acidophilus microorganisms in treatments $\mathrm{YSP}+1$ and $\mathrm{YSP}+1+2$. Microbial counts reached maximum levels on day twenty-one and twenty eight of cold storage (Table 3-6).

Both the S and SP extracts had a positive effect on the growth of both probiotics, because both have substrates such as oligosaccharides, which stimulate the growth of probiotic bacteria. Non-digestible oligosaccharides (NDOs) are low molecular weight carbohydrates that are intermediate in nature between simple sugars and water extractable materials (Mussatto \& Mancilha, 2007). Oligosaccharides are water-soluble and are fermented by various strains of bifidobacteria and lactobacilli, because they serve as a food source. Bacteria utilize the oligosaccharides by fermentation, resulting in shortchain fatty acids, therefore serving as an energy source (Agil, et al., 2012). Seabuckthorn whole fruit have a mixture of hydrophobic materials from the fruit and seeds, while the polysaccharide sample contained a more potent amount of the NDOs, due to the 
extraction methods. Therefore, SP may have had a stronger effect on $L$. acidophilus then the whole fruit, because of the higher level of polysaccharide substrates selectively stimulating microbial growth (Agil, et al., 2012). A larger food supply of oligosaccharides would explain the increased counts of L. acidophilus, because Lactobacilli prefer carbohydrate rich environments (Vasiljevic, et al., 2008).

However, on day 28, L. acidophilus counts in SP treatment YSP+1+2 was $8.4 \log$ cfu $\mathrm{mL}^{-1}$ and showed no difference compared to the control. Indicating that the presence of a second probiotic may have an effect on viable L. acidophilus amounts due to an accumulation of cellular waste and nutrient depletion after 28 days of storage (Vasiljevic, et al., 2008).

The enumeration of $B$. lactis showed a slightly different growth pattern from that of L. acidophilus. After 21 days of cold storage, the enumeration of B. lactis, in the third treatment was higher $(\mathrm{P} \leq 0.05)$ amongst $\mathrm{S}$ and $\mathrm{SP}$ yogurts, but highest $(\mathrm{P} \leq 0.05)(8.8 \mathrm{log}$ cfu mL $\mathrm{mL}^{-1}$ ) in SP yogurts (Figure 3-4B). On day 28, in treatment three, both S and SP no longer showed an influence $(\mathrm{P}>0.05)$ upon $B$. lactis viability. In addition, the fourth treatment containing both B. lactis and L. acidophilus, after 21 days of cold storage, were higher in $\mathrm{S}$ and $\mathrm{SP}$ yogurts $(\mathrm{P} \leq 0.05)$ compared to the controls, but highest $(\mathrm{P} \leq 0.05)$ in $\mathrm{SP}$ yogurts. After 28 consecutive days of cold storage only the yogurts containing SP had the highest $(\mathrm{P} \leq 0.05)$ counts of viable B. $\operatorname{lactis}\left(8.8 \log \mathrm{cfu} \mathrm{mL}^{-1}\right)$, because of the presence of concentrated polysaccharides. Based on two-way ANOVA analysis it was found that all control yogurt treatments containing B. lactis $(\mathrm{Y}+2$ and $\mathrm{Y}+1+2)$ were significantly lower than both the yogurts with seabuckthorn fruit and polysaccharide addition throughout the 28 days of cold storage. Yogurts containing the polysaccharide extract exhibited the 
highest counts of $B$. lactis microorganisms in treatments $\mathrm{YSP}+2$ and $\mathrm{YSP}+1+2$. Microbial counts reached maximum levels throughout fourteen and twenty eight days of cold storage (Table 3-7).

Yogurts containing SP were observed to have a more significant influence on probiotics throughout the $28^{\text {th }}$ day of cold storage than the whole fruit, which had not been previously recorded in the literature.

Seabuckthorn contains oligosaccharides and essential nutrients that promote viability and growth of microbes. In particular, Bifidobacteria utilizes amino acids such as valine, glycine, and histidine to support its growth (Vasiljevic, et al., 2008). Seabuckthorn contains high quantities of these elements: valine, glycine, and histidine, with levels of $21.8 \mathrm{mg} / 100 \mathrm{~g}, 16.7 \mathrm{mg} / 100 \mathrm{~g}$, and $13.7 \mathrm{mg} / 100 \mathrm{~g}$ respectively (Beveridge, et al., 1999). Probiotic organisms have weak proteolytic activity, therefore they require these free amino acids to increase their numbers (Vasiljevic, et al., 2008). In addition, the pH levels of the yogurt can also explain the successful growth of B. lactis. During experimentation all yogurts possessed a pH higher than 5.0 (Table 3-2). This would explain why B. lactis had higher counts $\left(8.7 \log\right.$ cfu $\left.\mathrm{mL}^{-1}\right)$ than L. acidophilus $(8.5 \log$ cfu $\mathrm{mL}^{-1}$ ) in the fourth treatment. L. acidophilus has a high cytoplasmic buffering capacity of $\mathrm{pH} 3.72-7.74$, depending on the strain, but has greater viability when $\mathrm{pH}$ is between 4.1 and 4.5 (Espírito Santo, et al., 2010). Bifidobacterium species, growth is significantly retarded with a $\mathrm{pH}$ below 5.0 suggesting that the range of $\mathrm{pH}$ in the yogurt contributed the viability of this specifies, while in the presence of L. acidophilus. 

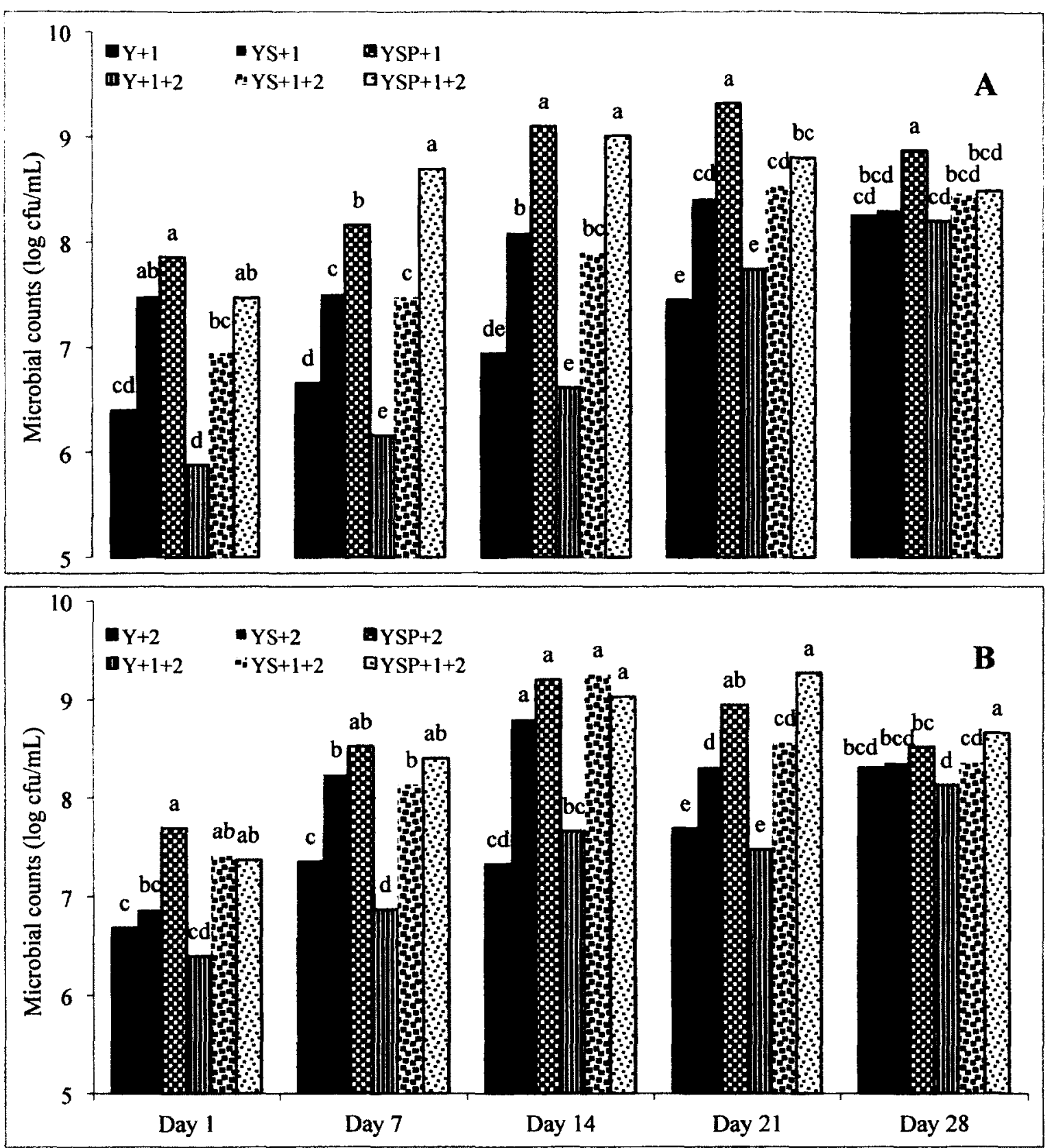

Figure 3- 4: A) Enumeration of $L$. acidophilus in yogurts with seabuckthorn fruit (S), seabuckthorn polysaccharide (SP), and without extract during shelf-life (1, 7,

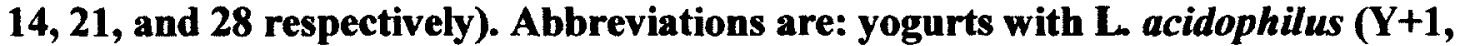
YS+1, YSP+1) and enumerations of L. acidophilus in the presence of B. lactis $(Y+1+2, Y S+1+2, Y S P+1+2), B)$ enumeration of $B$. lactis in yogurts with $S, S P$, and without extract during shelf-life $(1,7,14,21$, and 28 respectively). Abbreviations are: yogurts with $B$. lactis $(Y+2, Y S+2, Y S P+2)$ and enumerations of $B$. lactis in the presence of $L$. acidophilus $(Y+1+2, Y S+1+2, Y S P+1+2)$. Means with different letters are significantly $(P \leq 0.05)$ different with means $(N=3)$ within a day. 
Table 3- 6: Two-way ANOVA showing the effect of days on yogurt treatments containing $L$. acidophilus.

\begin{tabular}{|l|c|c|c|c|}
\hline Source & DF & Mean Square & F value & Pr $>$ F \\
\hline Storage day & 4 & 6.77 & 89.85 & $<.0001$ \\
\hline Yogurt treatments & 5 & 7.38 & 97.96 & $<.0001$ \\
\hline $\begin{array}{l}\text { Yogurt treatment* } \\
\text { Storage day }\end{array}$ & 20 & 0.42 & 5.59 & $<.0001$ \\
\hline
\end{tabular}

$\mathrm{R}^{2}=0.94$

Table 3- 7: Two-way ANOVA showing the effect of days on yogurt treatments containing B. lactis.

\begin{tabular}{|l|c|c|c|c|}
\hline Source & DF & Mean Square & F value & Pr $>$ F \\
\hline Storage day & 4 & 2.76 & 60.44 & $<.0001$ \\
\hline Yogurt treatments & 7 & 0.72 & 15.74 & $<.0001$ \\
\hline $\begin{array}{l}\text { Yogurt treatment* } \\
\text { Storage day }\end{array}$ & $\mathbf{2 8}$ & 0.15 & 3.22 & $<.0001$ \\
\hline
\end{tabular}

$\mathrm{R}^{2}=0.84$ 


\section{5 Conclusion}

It can be concluded that seabuckthorn shows potential as a source of prebiotics in dairy products, because it may increase the viability of probiotics in yogurt. Canada has traditionally used seabuckthorn plants for the purposes of soil preservation and wind protection for crops. However, this fruit is a source of great nutrition that has not yet been exploited in the food market. The nutritional value of this fruit has been previously researched, however its use as a prebiotic is novel and has the potential to contribute to the Canadian food and health market. 
Chapter 4- E-nose as a Novel Technique to "sniff-out" out Lactic Acid Bacteria in Seabuckthorn-yogurt 


\subsection{Abstract}

Electronic noses (E-noses) have been used to analyze complex odorous headspace of a variety of food and drink. However, milk and yogurt products have presented a challenge due to the complex mixture of organic volatiles and heterogeneous nature of the matrix (Ampuero, et al., 2003). The objective of this study was, to determine if e-nose could interpret between different flavours of yogurt. With the application of principal component analysis (PCA) seabuckthorn, raspberry, and plain yogurts revealed distinct trajectories after twenty-four hours of cold storage.

\subsection{Introduction}

E-nose technology has been used in commercial and research applications in food industry. Applications of e-nose have looked at grading odour according to the type of food and freshness/quality of foodstuff (Gardner, et al., 2000). However, the number of studies dedicated to dairy products is still limited, due to the complexity of the matrices (Ampuero, et al., 2003). Headspace of milk and yogurt presents a complex mixture of organic volatiles such as acetone, hexanal, 2-butanone, toluene, limonene, heptanal, styrene, and chloroform at substantially different levels (Ampuero, et al., 2003). Adding to the complexity of the matrix is the high percentage of relative humidity and the heterogeneous composition of the yogurt (Ampuero, et al., 2003).

The combination of sensory characteristics and health benefits associated with yogurt has made this product popular among consumers (Ampuero, et al., 2003). Flavoured yogurts were created by adding fruit and later on prebiotics to improve nutritional properties, thus evolving the benefits of yogurt. E-nose is a novel device that can potentially detect and classify odours of probiotics, which are part of the gut 
microflora, thus playing a role in human health (Ampuero, et al., 2003). The objective of this study was to observe if e-nose could distinguish between different flavours of yogurt, while future studies would consist of distinguishing yogurts containing probiotics and building libraries of classification models.

\subsection{Materials and Methods}

\subsubsection{Fruit preparation}

Seabuckthorn berries were obtained from Horticulture Research Center (Laval University, Quebec) and raspberry samples were obtained from Dentz Orchards in Ottawa, Canada. Seabuckthorn (SB) and raspberry (R) were blended using a juice processor and stored in Ziploc bags in the freezer at $-20^{\circ} \mathrm{C}$ prior to analysis.

\subsubsection{Yogurt making}

Three different yogurt treatments were prepared containing seabuckthorn $(2 \mathrm{~g})$, raspberry ( $3 \mathrm{~g})$, and a third plain yogurt without fruit.

Each test tube contained $50 \mathrm{~mL}$ of pasteurized milk and $0.5 \mathrm{~mL}$ of each starter culture (Streptococcus thermophiles and Lactobacillus bulgaricus). Yogurts with abbreviations can be seen in Table 4-1. Following inoculation, yogurts were incubated at $42{ }^{\circ} \mathrm{C}$ until formed, once formed the tubes were stored at $4{ }^{\circ} \mathrm{C}$.

\subsubsection{Sample Preparation}

E-nose responses were measured for samples (Y, YSB, and YR) after 24 hours of cold storage, because yogurt texture is most consistent in the early period of storage versus the end of the shelf life period. Three separate vials for each yogurt sample were prepared (labeled Y1, Y2, Y3 (yogurt with no fruit); YSB1, YSB2, YSB3 (yogurt with 
seabuckthorn); YR1, YR2, YR3 (yogurt with raspberry). A sample of $1 \mathrm{~mL}$ was

transferred, by pipette from the original containers. The twelve $10 \mathrm{~mL}$ vials were then capped and loaded into a temperature-controlled sample tray where they were maintained at $4{ }^{\circ} \mathrm{C}$ during the measurement period prior to processing.

Table 4- 1: Experimental design: plain yogurt (Y), seabuckthorn (SB), and Raspberry (R). Abbreviations: without fruit (-); fruit ( + ); all yogurts contained starter cultures $S$. thermophilus + L. bulgaricus $(Y)$.

\begin{tabular}{lcc}
\hline \multicolumn{1}{c}{ Microorganisms } & Fruit & $\begin{array}{c}\text { Sample } \\
\text { coding }\end{array}$ \\
\hline $\begin{array}{l}\text { Y: Streptococcus salivarius ssp. thermophilus } \\
+ \text { Lactobacillus delbrueckii ssp. bulgaricus }\end{array}$ & - & Y \\
YSB & + & YSB \\
& & \\
YR & + & YR \\
\hline
\end{tabular}

\subsubsection{E-nose}

Parameters for analysis was adapted from a study of e-nose detection of spoilage among dairy products (Green, Chan, \& Goubran, 2011).

AlphaMOS FOX 3000 e-nose is used commercially to collect odour responses as it contains twelve metal oxide sensors (MOS) for the purpose of detecting odour patterns (AlphaMOS FOX, AlphaMOS, Toulouse, France). $1 \mathrm{~mL}$ of yogurt sample, was pipetted into $10 \mathrm{mLvials}$ and heated to $35^{\circ} \mathrm{C}$ where it was then agitated for $60 \mathrm{~s}$ using the AlphaMOS HS100 robotic auto-sampler (Green, et al., 2011). Agitation is initiated in 
order to mix the sample for the purpose of releasing volatile organic compounds (VOCs) into the vial's headspace. There is a $2 \mathrm{~mL}$ headspace, containing VOCs that is extracted with a syringe and met with a flow rate of $150 \mathrm{~mL} / \mathrm{s}$. A mass-flow controller directly controlled by the software regulates the flow rate, over the sensors (Dewettinck, Van Hege, \& Verstraete, 2001). Once, the VOCs are in the sensor chamber the MOS respond by swelling or contracting by varying amounts. This changes their electrical conductivity over the duration of the gas sampling cycle in a manner that is slightly different from sensor to sensor. Sensor responses are then recorded every $0.5 \mathrm{~s}$ for $120 \mathrm{~s}$, producing 12 separate response curves of conductivity versus time using Alphasoft Version 12 software (Green, et al., 2011).

\subsubsection{Dimension Reduction}

Principal component analysis is a multivariate statistical tool of Alphasoft Version 12 software and was used to analyze the food samples. PCA searches for axes along which the samples are scattered and is the first analysis performed. PCA is a dimensionality reduction method that uses linear transformations, in order to project the original feature vectors into a reduced feature space (Green, et al., 2011). Transformed features are assigned coefficients, which are called principal components that assess the highest variability of the original feature data-eliminating correlations between feature vector components (Green, et al., 2011). Discriminating between samples is based on the discrimination index (measures the effectiveness of discriminating between given samples) and the dispersion and grouping of the samples on the figure. This form of analysis has been used to compare different competitors or brands of samples from each other. 


\subsection{Results and Discussion}

PCA was used to analyze the three different types of yogurt after 24 hours of cold storage. Figure 4-1 is a bar-graph representation of the MOS response of samples $\mathrm{Y}, \mathrm{SB}$, and $\mathrm{R}$ to show the responses of the twelve sensors on a given sample. This technique is useful, because the cross-reactivity of the different semi-conductive sensors will generate "fingerprints" for a specific sample (Ampuero, et al., 2003). Each sensor has a thin layer $(50 \mathrm{~mm})$ of a metal oxide film that is consigned on a ceramic film, which allows them to display a good sensitivity towards a very broad range of chemical compounds (Dewettinck, et al., 2001). Therefore, samples with similar aromas will typically show similar sensor response patterns, while different samples will show differences in their patterns (Ampuero, et al., 2003). An overview of some of the FOX 3000 sensors and the chemical compounds they are sensitive to can be seen in Table 4-2. The e-nose machine used in the present study consisted of $\mathrm{T}, \mathrm{P}$ and $\mathrm{L}$ sensors. 
Table 4- 2: FOX 3000 sensors in the electronic nose representing chemical compounds that they are sensitive to adapted from (Dewettinck, et al., 2001).

\begin{tabular}{|l|l|}
\hline Sensor & Chemical Compounds Detected \\
\hline P30/1 & Polar compounds \\
\hline P10/1 & Hydrocarbons \\
\hline P10/2 & $\begin{array}{l}\text { Methane, propane and aliphatic nonpolar } \\
\text { molecules }\end{array}$ \\
\hline P40/1 & $\begin{array}{l}\text { Chlorinated and fluorinated compounds of } \\
\text { P40/2 Aldehydes }\end{array}$ \\
\hline P40/2 & Aldehydes \\
\hline PA3 & Hydrogen bounds, smoke detection \\
\hline P70/0 & $\begin{array}{l}\text { Food aromas, alcohol and aromatic } \\
\text { compounds }\end{array}$ \\
\hline T50/3 & $\begin{array}{l}\text { Ammonia derivatives and amine containing } \\
\text { compounds }\end{array}$ \\
\hline PA2 & $\begin{array}{l}\text { Low concentrations of hydrogen, H2S and } \\
\text { ammonia }\end{array}$ \\
\hline T50/1 & S-containing compounds \\
\hline T40/1 & Chlorinated and fluorinated compounds \\
\hline T70/2 & Alcohol vapors and aromatic compounds \\
\hline
\end{tabular}


$\gamma$

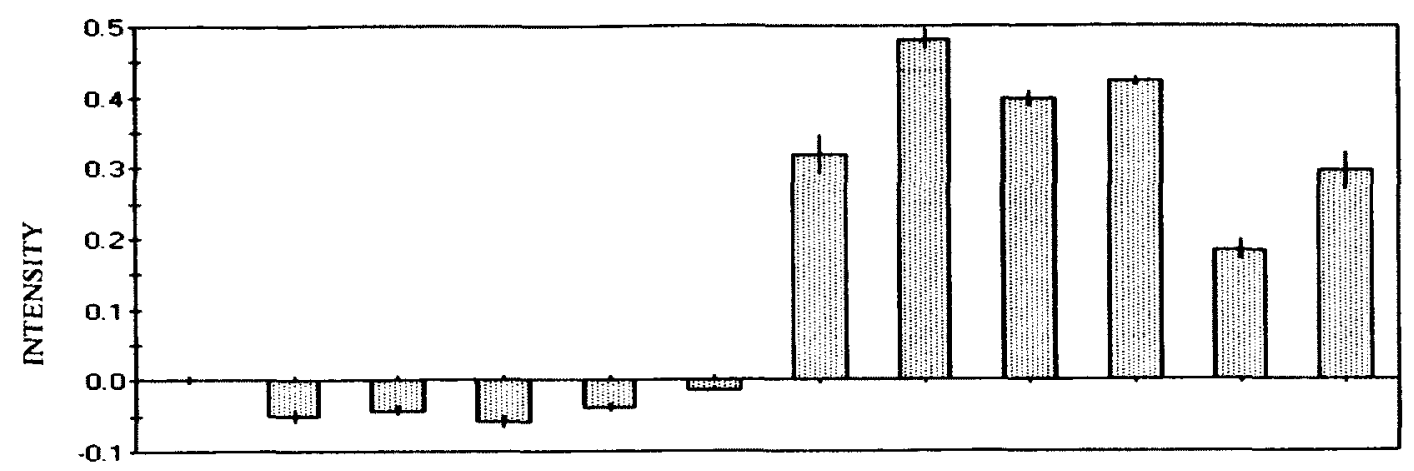

SB

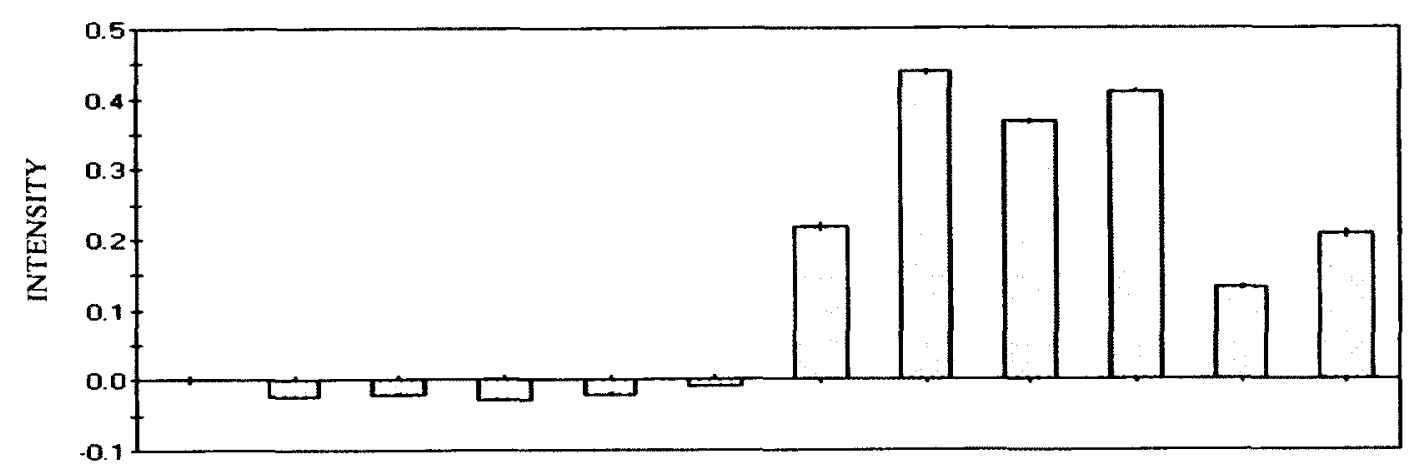

F

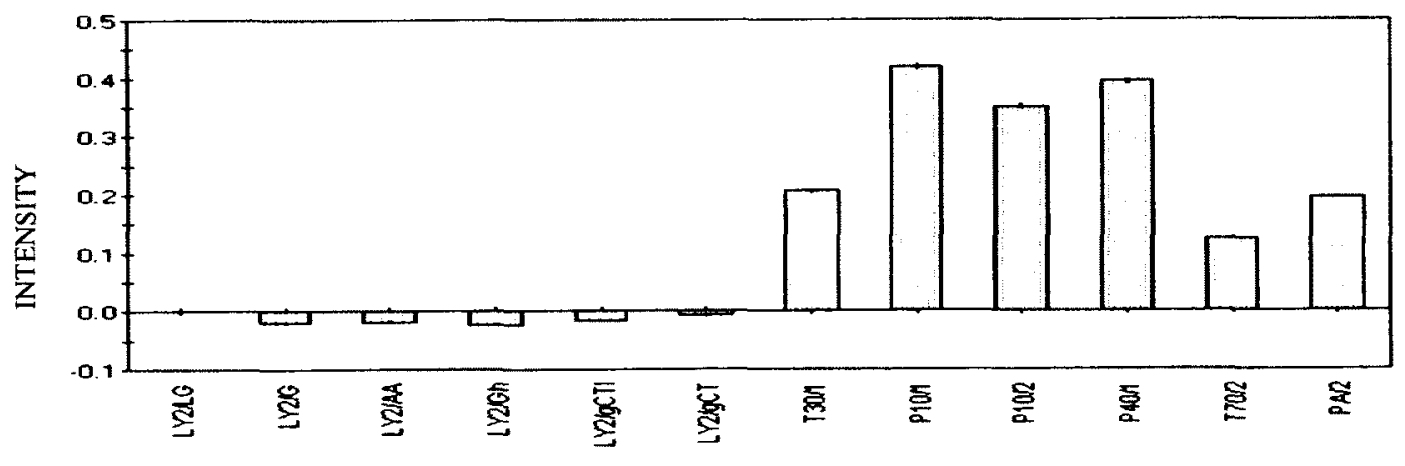

SENSORS

Figure 4- 1: Bar-graph representation of raw e-nose sensor responses for yogurt samples $Y, S B$, and $R$. The twelve sensors are represented on the $x$-axis and the intensity of each sensor is represented on the $y$-axis. 
Figure 4-2 illustrates how the three yogurt samples odours are represented in the PCA space. In addition, Figure 4-2 demonstrates the ability of the e-nose system to distinguish between the different flavours of yogurt. From the PCA plot it was observed that groups $\mathrm{Y}, \mathrm{SB}$, and $\mathrm{R}$ were located in distinct regions suggesting that the method used by Green, Chan, and Goubran (2011) can be applicable to differentiating flavours in a yogurt matrix.

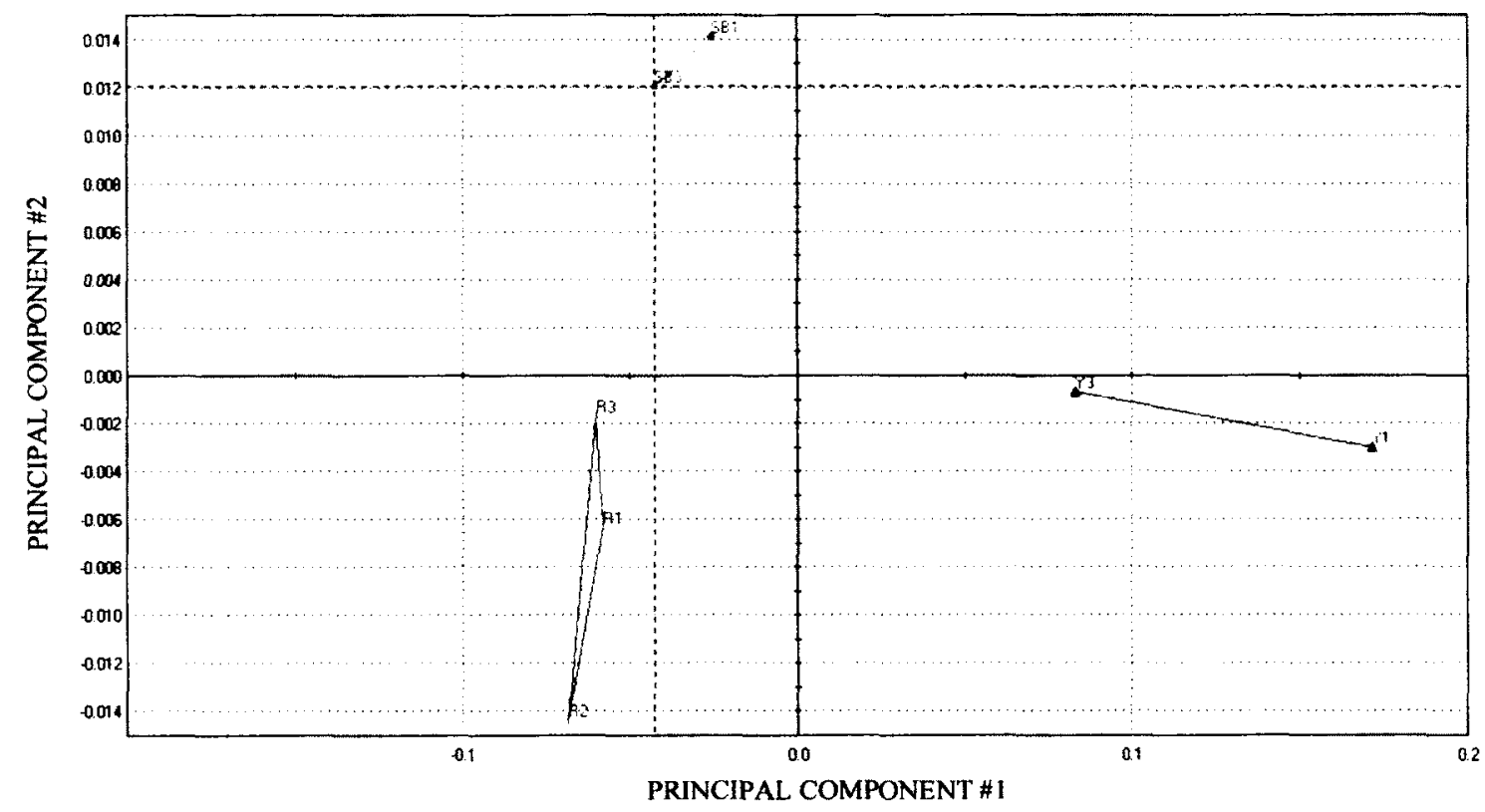

Figure 4- 2: PCA representation of e-nose responses of samples that were grouped into plain yogurt (Y), seabuckthorn yogurt (SB), and raspberry yogurt $(R)$ categories. Discrimination index percentage represents variability within a group; dispersed groups will reduce the discrimination index.

Finally, a discrimination index bar graph was translated from the PCA figure to show the distance between yogurt groups, which is a convenient way to assess the similarities between two groups of samples (Figure 4-3). The distance between Y and SB yogurt had a value of $0.16 \% \mathrm{DI}$, a distance of $0.19 \% \mathrm{DI}$ was observed for $\mathrm{Y}$ and $\mathrm{R}$ 
yogurts, and the distance between SB and R had the smallest value of $0.03 \%$ DI. The discrimination index percentage represents the distance between the centers of gravity of one group to another in which case greater values of represents greater differences between the groups. From the values it can be determined that plain yogurt is most different from raspberry yogurts indicating that their aroma pattern, containing volatile compounds, differ from each other. Seabuckthorn and raspberry yogurts were observed to have the most similar aroma patterns, as their discrimination distance was lower than the previous comparisons. SB and R were still considered distinct on the PCA figure, however they both seem to share similar organic compounds. This observation is not surprising, because both raspberry and seabuckthorn contain phenolic compounds such as gallic acid, quercetin, kaempferol, and other phenolic compounds, which would be detected by the e-nose sensors.

DISTANCES

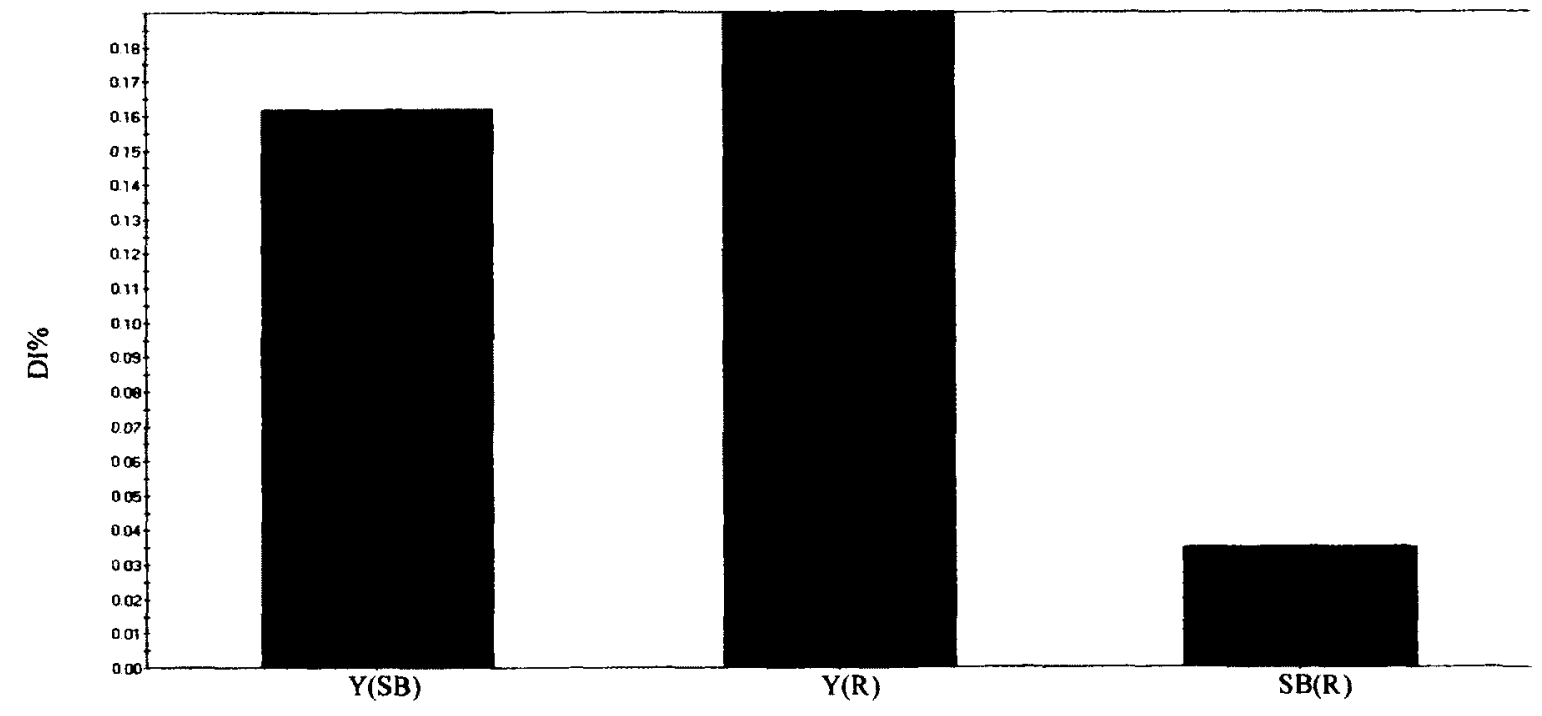

Figure 4- 3: Discrimination index percentage (DI\%) representing the distance between two groups at a time. Abbreviations: plain yogurt (Y), seabuckthorn yogurt $(\mathrm{SB})$, and raspberry yogurt $(\mathrm{R})$. 


\subsection{Conclusions}

The results of this study indicate that flavours of various yogurts may be distinguishable using e-nose. Detecting flavoured yogurts was a preliminary step, to which future studies would look at using e-nose to decipher aroma patterns of various yogurts. Further future studies would use e-nose to characterize "healthy" aromas of health benefits associated with different yogurts, such as ones fortified with prebiotics. 
Chapter 5- Conclusion 


\subsection{Thesis Conclusions}

Seabuckthorn was chosen for this study, because of the many nutritional benefits that has been linked with the fruit. Seabuckthorn had not been previously analyzed as a prebiotic in yogurt mediums, therefore first experiments looked at the effect on total count of bacteria. It was found that seabuckthorn yogurts increased growth of total count of bacteria in yogurt and had decreased $\mathrm{pH}$ levels and increased TTA values after 21 days of cold storage-indicative of increased microbial activity. However, it could not be determined, which microorganisms were effected. Additionally, antioxidant activity of the fruit and WEP was found to be comparable with values found in the literature making it a possible multifunctional fruit.

The second part of the study was to determine, which microorganisms were being effected in yogurt and if S or SP had a greater effect on microbial activity. It was found that after 21 days of cold storage, both S and SP maintained higher viable bacteria counts in both L. acidophilus and B. lactis, in comparison to the controls $(\mathrm{P} \leq 0.05)$. Interestingly, SP favoured an increase in L. acidophilus when grown with only starter cultures, while B. lactis showed more favourable growth $(\mathrm{P} \leq 0.05)$ in the presence of starter cultures and an additional probiotic after 4 weeks of cold storage. Suggesting that seabuckthorn may serve as a new prebiotic source for functional foods and nutraceutical applications.

Finally, the study with e-nose sought to determine if future studies could be analyzed using this novel technique with yogurt. The results of this study indicate that flavours of various yogurts may be distinguishable using e-nose and future studies may be developed to help determine a fingerprint for healthy foods. 


\section{References}

Adolfsson, O., Meydani, S. N., \& Russell, R. M. (2004). Yogurt and gut function. The American Journal of Clinical Nutrition, 80, 245-256.

Agil, R., \& Hosseinian, F. (2012). Dual functionality of triticale as a novel dietary source of prebiotics with antioxidant activity in fermented dairy products. Plant Foods for Human Nutrition, 67, 88-93.

Ampuero, S., \& Bosset, J. O. (2003). The electronic nose applied to dairy products: a review. Sensors and Actuators B: Chemical, 94, 1-12.

Arimboor, R., Kumar, K. S., \& Arumughan, C. (2008). Simultaneous estimation of phenolic acids in sea buckthorn (Hippophae rhamnoides) using RP-HPLC with DAD. Journal of Pharmaceutical and Biomedical Analysis, 47, 31-38.

Bal, L. M., Meda, V., Naik, S. N., \& Satya, S. (2011). Sea buckthorn berries: A potential source of valuable nutrients for nutraceuticals and cosmoceuticals. Food Research International, 44, 1718-1727.

Balasundram, N., Sundram, K., \& Samman, S. (2006). Phenolic compounds in plants and agri-industrial by-products: Antioxidant activity, occurrence, and potential uses. Food Chemistry, 99, 191-203.

Beshkova, D. M., Simova, E. D., Frengova, G. I., Simov, Z. I., \& Dimitrov, Z. P. (2003). Production of volatile aroma compounds by kefir starter cultures. International Dairy Journal, 13, 529-535.

Beveridge, T., Li, T. S., Oomah, B. D., \& Smith, A. (1999). Sea buckthorn products: manufacture and composition. Journal of Agriculture and Food Chemistry, 47, $3480-3488$. 
Burns, A. J., \& Rowland, I. R. (2000). Anti-carcinogenicity of probiotics and prebiotics. Current Issues in Intestinal Microbiology, 1, 13-24.

Cencic, A., \& Chingwaru, W. (2010). The role of functional foods, nutraceuticals, and food supplements in intestinal health. Nutrients, 2, 611-625.

Charalampopoulos, D., Wang, R., Pandiella, S. S., \& Webb, C. (2002). Application of cereals and cereal components in functional foods: a review. International Journal of Food Microbiology, 79, 131-141.

Dave, R. I., \& Shah, N. P. (1997). Viability of yoghurt and probiotic bacteria in yoghurts made from commercial starter cultures. International Dairy Journal, 7, 31-41.

Dewettinck, T., Van Hege, K., \& Verstraete, W. (2001). The electronic nose as a rapid sensor for volatile compounds in treated domestic wastewater. Water Research, $35,2475-2483$.

Espírito Santo, A. P. d., Silva, R. C., Soares, F. A. S. M., Anjos, D., Gioielli, L. A., \& Oliveira, M. N. (2010). Açai pulp addition improves fatty acid profile and probiotic viability in yoghurt. International Dairy Journal, 20, 415-422.

Gardner, J. W., Shin, H. W., \& Hines, E. L. (2000). An electronic nose system to diagnose illness. Sensors and Actuators B: Chemical, 70, 19-24.

Gibson, G. R., Probert, H. M., Loo, J. V., Rastall, R. A., \& Roberfroid, M. B. (2004). Dietary modulation of the human colonic microbiota: updating the concept of prebiotics. Nutrition Research Reviews, 17, 259-275.

Gibson, G. R., \& Roberfroid, M. B. (1995). Dietary modulation of the human colonic microbiota: introducing the concept of prebiotics. The Journal of nutrition, 125, $1401-1412$ 
Gliwa, J., Gunenc, A., Ames, N., Willmore, W. G., \& Hosseinian, F. S. (2011). Antioxidant activity of alkylresorcinols from rye bran and their protective effects on cell viability of PC-12 AC cells. Journal of Agriculture and Food Chemistry, $59,11473-11482$.

Goncalves, M. M., Freitas, R., Nero, L. A., \& Carvalho, A. F. (2009). Enumeration of starter cultures during yogurt production using Petrifilm AC plates associated with acidified MRS and M17 broths. Journal of Dairy Research, 76, 229-233.

Green, G. C., Chan, A. D., \& Goubran, R. A. (2011). Tracking food spoilage in the smart home using odour monitoring. In M. M. a. A. P. (MeMeA) (Ed.), IEEE International Workshop on (pp. 284-287). Bari.

Huang, D., Ou, B., Hampsch-Woodill, M., Flanagan, J. A., \& Prior, R. L. (2002). Highthroughput assay of oxygen radical absorbance capacity (ORAC) using a multichannel liquid handling system coupled with a microplate fluorescence reader in 96-well format. Journal of Agricultural and Food Chemistry, 50, 44374444.

Kailasapathy, K., \& Chin, J. (2000). Survival and therapeutic potential of probiotic organisms with reference to Lactobacillus acidophilus and Bifidobacterium spp. Immunology and cell biology, 78, 80-88.

Kailasapathy, K., Harmstorf, I., \& Phillips, M. (2008). Survival of Lactobacillus acidophilus and Bifidobacterium animalis ssp. lactis in stirred fruit yogurts. LWT - Food Science and Technology, 41, 1317-1322.

Khurana, H. K., \& Kanawjia, S. K. (2007). Recent trends in development of fermented milks. Current Nutrition \& Food Science, 3, 91-108. 
Koca, I., \& Karadeniz, B. (2009). Antioxidant properties of blackberry and blueberry fruits grown in the Black Sea Region of Turkey. Scientia Horticulturae, 121, 447450.

Kumar, R., Kumar, G. P., Chaurasia, O., \& Singh, S. B. (2011). Phytochemical and pharmacological profile of seabuckthorn oil: a review. Research Journal of Medicinal Plant, 5, 491-499.

Lee, S. E., Hwang, H. J., Ha, J. S., Jeong, H. S., \& Kim, J. H. (2003). Screening of medicinal plant extracts for antioxidant activity. Life Sciences, 73, 167-179.

Li, T. S., \& Schroeder, W. R. (1996). Sea buckthorn (Hippophae rhamnoides L.): a multipurpose plant. Hort Technology, 6, 370-380.

Li, W., Hydamaka, A. W., Lowry, L., \& Beta, T. (2009). Comparison of antioxidant capacity and phenolic compounds of berries, chokecherry and seabuckthorn. Central European Journal of Biology, 4, 499-50.

Lourens-Hattingh, A., \& Viljoen, B. C. (2001). Yogurt as probiotic carrier food. International Dairy Journal, 11, 1-17.

Lundstedt, E., \& Corbin Jr, E. A. (1983). U. S. Patent No. 4, 416, 905. Washington, DC:, U.S. Patent and Trademark Office.

Martini, M. C., Kukielka, D., \& Savaiano, D. A. (1991). Lactose digestion from yogurt: influence of a meal and additional lactose. The American Journal of Clinical Nutrition, 53, 1253-1258.

Mussatto, S. I., \& Mancilha, I. M. (2007). Non-digestible oligosaccharides: a review. Carbohydrate Polymers, 68, 587-597. 
Negi, P. S., Chauhan, A. S., Sadia, G. A., Rohinishree, Y. S., \& Ramteke, R. S. (2005). Antioxidant and antibacterial activities of various seabuckthorn (Hippophae rhamnoides L.) seed extracts. Food Chemistry, 92, 119-124.

Ranadheera, R. D. C. S., Baines, S. K., \& Adams, M. C. (2010). Importance of food in probiotic efficacy. Food Research International, 43, 1-7.

Roberfroid, M. B. (2007). Inulin-type fructans: functional food ingredients. Journal of Nutrition, 137, 2493S-2502S.

Saxelin, M., Tynkkynen, S., Mattila-Sandholm, T., \& de Vos, W. M. (2005). Probiotic and other functional microbes: from markets to mechanisms. Current Opinion in Biotechnology, 16, 204-211.

Scholz-Ahrens, K. E., Ade, P., Marten, B., Weber, P., Timm, W., Acil, Y., et al. (2007). Prebiotics, probiotics, and synbiotics affect mineral absorption, bone mineral content, and bone structure. Journal of Nutrition, 137, 838S-846S.

Sies, H., \& Stahl, W. (1995). Vitamins E and C, beta-carotene, and other carotenoids as antioxidants. The American Journal of Clinical Nutrition, 62, 1315S-1321S.

Tuohy, K. M., Probert, H. M., Smejkal, C. W., \& Gibson, G. R. (2003). Using probiotics and prebiotics to improve gut health. Drug Discovery Today, 8, 692-700.

Upadhyay, N. K., Kumar, M. S., \& Gupta, A. (2010). Antioxidant, cytoprotective and antibacterial effects of Sea buckthorn (Hippophae rhamnoides L.) leaves. Food and Chemical Toxicology, 48, 3443-3448.

Uruakpa, F. O., \& Utioh, A. (2012). Seabuckthorn (Hippophae rhamnoides L.) and its products: A powerhouse of phytochemicals. In F. O. Uruakpa (Ed.), Bioactive 
Molecules in Plant Foods, VI. (pp. 163-189). New York: Nova Science Publishers, Inc.

Varshneya, C., Kant, V., \& Mehta, M. (2012). Total phenolic contents and free radical scavenging activities of different extracts of seabuckthorn (Hippophae rhamnoides) pomace without seeds. International Journal of Food Sciences and Nutrition, 63, 153-159.

Vasiljevic, T., \& Shah, N. P. (2008). Probiotics-from Metchnikoff to bioactives. International Dairy Journal, 18, 714-728.

Vinderola, C. G., Costa, G. A., Regenhardt, S., \& Reinheimer, J. A. (2002). Influence of compounds associated with fermented dairy products on the growth of lactic acid starter and probiotic bacteria. International Dairy Journal, 12, 579-589.

Vinderola, C. G., \& Reinheimer, J. A. (1999). Culture media for the enumeration of Bifidobacterium bifidum and Lactobacillus acidophilus in the presence of yoghurt bacteria. International Dairy Journal 9, 497-505.

Yang, B., \& Kallio, H. (2002). Composition and physiological effects of sea buckthorn (Hippophaë) lipids. Trends in Food Science \& Technology, 13, 160-167.

Yang, Z. H., Miyahara, H., \& Hatanaka, A. (2011). Chronic administration of palmitoleic acid reduces insulin resistance and hepatic lipid accumulation in KK-Ay Mice with genetic type 2 diabetes. Lipids in Health and Disease, 10, 1-10.

Zeb, A. (2004a). Chemical and Nutritional Constituents of Sea Buckthorn Juice. Pakistan Journal of Nutrition 3, 99-106.

Zeb, A. (2004b). Important therapeutic uses of sea buckthorn (Hippophae): a review. Journal of Biological Sciences, 4, 687-693. 
Zheng, X., Long, W., Liu, G., Zhang, X., \& Yang, X. (2012). Effect of seabuckthorn (Hippophae rhamnoides ssp. sinensis) leaf extract on the swimming endurance and exhaustive exercise-induced oxidative stress of rats. Journal of the Science of Food and Agriculture, 92, 736-742. 